\title{
Animal Models of transcranial Direct Current Stimulation: Methods and Mechanisms
}

\author{
Mark P. Jackson, Asif Rahman, Belen Lafon, Gregory Kronberg, Doris Ling, Lucas C. \\ Parra, Marom Bikson
}

Department of Biomedical Engineering, The City College of The City University of New York, NY, USA

\author{
Corresponding author: \\ Marom Bikson \\ Department of Biomedical Engineering, The City College of The City University of New York. ST-403B, \\ 160 Convent Ave 10031, New York, NY, USA \\ Tel: +1-212-650-6791 \\ Email: bikson@ccny.cuny.edu
}

Keywords: transcranial direct current stimulation, noninvasive brain stimulation, galvanotropy, oscillations, long term potentiation, synaptic plasticity, animal models

\begin{abstract}
$\underline{\text { Abstract }}$
The objective of this review is to summarize the contribution of animal research using direct current stimulation (DCS) to our understanding of the physiological effects of transcranial direct current stimulation (tDCS). We comprehensively address experimental methodology in animal studies, broadly classified as: 1) transcranial stimulation; 2) direct cortical stimulation in vivo and 3) in vitro models. In each case advantages and disadvantages for translational research are discussed including dose translation and the overarching "quasi-uniform" assumption, which underpins translational relevance in all animal models of tDCS. Terminology such as anode, cathode, inward current, outward current, current density, electric field, and uniform are defined. Though we put key animal experiments spanning decades in perspective, our goal is not simply an exhaustive cataloging of relevant animal studies, but rather to put them in context of ongoing efforts to improve tDCS. Cellular targets, including excitatory neuronal somas, dendrites, axons, interneurons, glial cells, and endothelial cells are considered. We emphasize neurons are always depolarized and hyperpolarized such that effects of DCS on neuronal excitability can only be evaluated within subcellular regions of the neuron. Findings from animal studies on the effects of DCS on plasticity (LTP/LTD) and network oscillations are reviewed extensively. Any endogenous phenomena dependent on membrane potential changes are, in theory, susceptible to modulation by DCS. The relevance of morphological changes (galvanotropy) to tDCS is also considered, as we suggest microscopic migration of axon terminals or dendritic spines may be relevant during tDCS. A majority of clinical studies using tDCS employ a simplistic dose strategy where excitability is singularly increased or decreased under the anode and cathode, respectively. We discuss how this strategy, itself based on classic animal studies, cannot account for the complexity of normal and pathological brain function, and how recent studies have already indicated more sophisticated approaches are necessary. One tDCS theory regarding "functional targeting" suggests the specificity of tDCS effects are possible by modulating ongoing function (plasticity). Use of animal models of disease are summarized including pain, movement disorders, stroke, and epilepsy.
\end{abstract}




\section{Meaningful Animal Studies of tDCS}

This review is an update, with permission, of a previously published work (Bikson et al. , 2012).

The basic motivation for tDCS research using animals is similar to other translational medical research efforts: to allow rapid and risk free screening of stimulation protocols in research and clinical settings, and to address the mechanisms of tDCS with the ultimate goal of informing clinical efficacy and safety of tDCS. To have a meaningful relevance for clinical tDCS, animal studies must be designed with consideration for: 1) correctly emulating the delivery of DCS into the brain; and 2) measuring responses which can be used to draw clinically relevant inferences. Before reviewing the main insights drawn from animal studies, we outline the basis for translational animal research on tDCS, as well as their limitations.

What is the role of translational animal models of tDCS within the broader context of tDCS science and clinical application? Like any model, using DCS on animals is intended to reproduce some relevant features for human applications with the goal of: 1) retrospectively providing a mechanistic explanation for findings in human; and 2) prospectively informing rational effort to optimize tDCS. In these senses the need for animal model is evident given the current state of understanding of tDCS, including highly limited understanding on how to customize tDCS for any given applications. The parameter space in designing tDCS is large, spanning dose selection (electrode montage, current intensity, duration), potential use of biomarkers to titrate and customize dose, subject selection, and pairing of tDCS with adjust interventions such as cognitive training or rehabilitation. It is impractical to test this parameter space comprehensively in human. Therefore, animal models are intended to guide human research by informing how improved protocols are discovered.

In addition to an exhaustive iterative search of published papers (forward and backward citations, prior review), candidate papers were identified through a PubMed search including key words: in vivo, in vitro, animal model, tDCS, direct current, polarizing current, rodent, rat, cat, ferret, rabbit.

\subsection{Stimulators, Nomenclature, and Electrode Techniques.}

To ensure reproducibility and precision during tDCS, clinical and animal studies should always use current controlled stimulation. The electrode-solution interface represents an unknown and changing impedance in series with the brain tissue, but it is well established that current control guarantees consistent stimulation of tissue through this interface (Merrill et al. , 2005). The electric field in the brain tracks the applied current and can be simply scaled to match clinical electric field values. Using voltage control during DCS may result in a variable electric field, which is not direct current (DC). If voltage control is used, the electric field generated in the tissue should be monitored during the entire course of stimulation, but this will reveal the spatio-temporal characteristics of the generated electric field are not reliably DC. However, simply using current control does not negate the importance of considering: 1) electrode size and position which determines the brain current flow pattern; and 2) electrode material and use of any buffer which determine electrochemical changes. Moreover, the two can be interrelated, as electrode degradation will make a portion of the electrode inactive, causing current redistribution, while increasing electrode size (in particular electrode contact area) reduces electrochemical burden. We caution: as more diverse research groups apply increasingly sophisticated techniques for analyzing DCS effects and understanding mechanisms of tDCS, the application of current itself is often conducted in an ad hoc manner with minimal understanding of translational design. At a minimum, the "dose" of stimulation needs to be reported in a manner that allows reproduction consistent with clinical rules of dose reporting and control (Peterchev et al. , 2012). Clarification of terms used to indicate the intensity and polarity of DCS is useful. tDCS/DCS intensity is defined as the current intensity (in $\mathrm{mA}$ ) of the steady-state current injected into the anode 
(opposite to cathode). If multiple electrodes are used, the current intensity is the sum of the current at all anodes (opposite of the sum at all cathodes). Stimulation duration in seconds or minutes indicates the time the current is at the desired stimulation level, excluding the ramp-up and ramp-down periods, which for studies using minutes of stimulation are typically 10-30 seconds. The dose of tDCS is defined by the electrode montage (electrode size, position), and a single tDCS/DCS session is defined by one intensity and one duration. All other metrics are derivative in the sense that they are determined by dose, and in some cases by dose and tissue properties. tDCS/DCS is current controlled, meaning the voltage is varied to maintain a fixed current (Domingo et al. , 1990). Some of the variation occurs at the electrode interface so the voltage at the surface of the body and brain cannot be controlled, but current control guarantees a known quantity of current reached the body regardless of electrode condition. In addition, the fraction of applied current reaching the brain will depend heavily on individual anatomy (Datta et al. , 2012, Edwards et al. , 2013) or the presence of preexisting injury (Datta et al. , 2011, Dmochowski et al., 2013), and the current reaching the brain could theoretically change over time if tissue impedances substantially change in response to stimulation.

Electrode current density, as used in the literature, indicates the average current density at the electrode calculated by taking the applied current through a given electrode and dividing by electrode area, which should not be confused with distributed brain current densities. Also, average current density is not necessarily indicative of peak current density at the electrode, which may be concentrated in areas (Kronberg et al. , 2012), or in the brain, which depends on many other factors (Miranda et al. , 2009). Stimulation charge (in $\mathrm{mC}$ ) is determined by multiplying the current intensity by the stimulation duration. Stimulation charge density is charge divided by the electrode area, again an average metric. Stimulation energy (in joules) is the product of charge and voltage, while stimulation power (in $\mathrm{mW}$ ) is the product of joules and duration. For any tDCS session, the above metrics are a single number, or a single number per electrode, and is determined only by dose.

In brain electrical stimulation anode and cathode terminology should always be used consistently for indicating the electrode where positive current is entering the body (anode) and the electrode where positive current is exiting the body (cathode) (Merrill et al. , 2005). For tDCS/DCS using two electrodes, there is one anode and one cathode, with the anode at a positive voltage relative to the cathode. In clinical and animal studies, anodal stimulation or cathodal stimulation indicates a cortical region of interest was nearer the anode or the cathode, respectively. It is important to recognize stimulation always includes an anode and cathode. In classic animal literature the terms surface positive and surface negative correspond to an anode or cathode, respectively, placed on the surface of the cortex, with the other electrode often placed on the neck or body. Considering the cortical surface, the current is described as either tangential or radial, and unless otherwise stated, it is implied the current and electric fields are normal/radial to the cortical surface rather than tangential/parallel. Inward current and outward current are typically expected under the anode and cathode respectively, although cortical anatomy may produce deviations. For electric field, the direction also needs to be specified. In our Finite Element Method (FEM) studies we adopt the convention of an inward current will produce a positive electric field measured from outside pointed in, while an outward current will produce a negative electric field (Datta et al. , 2008). Current density will be in the same direction (and polarity) as electric field. In tissue/brain slices, the terms anode and cathode remain unambiguous in regards to the electrodes, but the electric field reference direction is arbitrary and needs to be defined. In our studies where uniform DCS is applied to cortical slices, we conventionally define the electric field as positive when the anode is on the pia side of the slice and the cathode on the midbrain side, while a negative electric field indicates the cathode on the pia side (Radman et al. , 2009). Thus a positive electric field indicates a stimulation polarity associated with clinical anodal tDCS, while negative electric field indicates a polarity associated with cathodal tDCS. Typically, in hippocampal slice studies using long parallel wires, a positive electric field indicates the anode on the 
alveus side of CA1 (Gluckman et al., 1996, Ghai et al. , 2000, Bikson et al. , 2004, Ranieri et al. , 2012). However, given "positive" and "negative" electric fields are arbitrary terms, it is important to verify convention in each study. Finally, the term polarizing (polarizing current) is found in classic animal literature and some modern tDCS studies, and appears to refer to the use of prolonged, not pulsed, DCS applied using macro electrodes (as opposed to microelectrodes), with the polarization related to the electrodes, brain, and/or neurons. While all electrical stimulation operates by producing a membrane polarization, polarizing is used in the above context to emphasize a presumed mechanism of action specific to DCS based on a sustained change in membrane potential.

\subsection{Classification of Animal Studies}

The scope of this review includes animal studies testing the neurophysiological, behavioral, and molecular response of the brain to DCS (Figure 1; Table 1) with a focus on macro electrodes delivering sustained (seconds to minutes) rather than pulsed (millisecond or less) waveforms. tDCS animal studies can be broadly classified by method of stimulation (namely where the electrodes are placed) as: 1) transcranial stimulation in animals; 2) intracranial stimulation in vivo including with one electrode on the cortex; and 3) stimulation of tissue in vitro, including brain slices.

1) Modern animal studies on tDCS typically use transcranial stimulation with a skull screw which functions as the electrode, or skull mounted cup filled with electrolyte, and an electrode (Liebetanz et al. , 2006b, Cambiaghi et al. , 2010, Yoon et al. , 2012, Bolzoni et al. , 2013a). Advantages of transcranial stimulation include preventing electrochemical products from the electrodes from reaching the brain, which would confound any results. If the screw penetrates completely through the skull, stimulation is no longer in the transcranial category. Some studies have applied electrodes to the intact scalp of rodents and cats have also been used in some studies (Bolzoni et al. , 2013b). In rodent models, a return electrode on the body mounted in a jacket is typically used for unipolar stimulation, which is broadly analogous to a human tDCS extracephalic electrode. In a study on anesthetized rabbits, four silver ball electrodes formed a single virtual electrode to stimulate the target brain region (Marquez-Ruiz et al. , 2012). Alternatively, two cranial electrodes produce bipolar stimulation (Ozen et al. , 2010). Since the cranium is not penetrated, the effects of DCS are quantified through behavioral tests, noninvasive recording (electroencephalogram, EEG), noninvasive electrical interrogation (e.g. transcranial magnetic stimulation, TMS; transcranial electrical stimulation, TES), or histology after sacrifice. In some older studies, tDCS was applied in larger animals such as monkeys (Toleikis et al. , 1974), but results should be interpreted with caution. When the skull is penetrated for recording electrode placement, current flow is distorted (Datta et al. , 2010) and recording between electrodes without control for cortical folding can lead to variations in current direction through cortical gyrations and produce inconsistent effects. Replacement of removed skull with insulating filler (e.g. dental cement) may correct shunting through the skull cavity (Marquez-Ruiz et al. , 2012).

2) Classic studies of DCS on animals typically used an electrode directly on the cortical surface (Creutzfeldt et al. , 1962, Bindman et al. , 1964), where the electrode was covered in cotton wick (Redfearn et al. , 1964) to buffer electrochemical changes. When an electrode is placed inside the cranium then it is possible interference from electrochemical changes will diffuse into the brain and confound any results directly related to tDCS. While electrochemical byproducts from electrodes can be polarity specific (Merrill et al. , 2005) and produce reversible changes, direct electrochemical diffused from the electrode surface to the brain is not considered relevant for tDCS. Steps to reduce interference from electrochemical byproducts include using suitable electrode (e.g. $\mathrm{Ag} / \mathrm{AgCl}$ ) and wrapping the electrode in cotton to shield chemical changes (Redfearn et al. , 1964). Passage of prolonged DC through a poorly selected electrode material (e.g. steel) produces significant electrochemical changes near the metal, and results from such 
studies must be considered with caution. For this reason, data from studies using an electrode on the brain are not used here to inform tDCS safety - indeed passage of DC through invasive electrodes are well known to produce electrochemical lesions (Bolzoni et al. , 2013b). For cortical electrodes, it is generally assumed current through the nearby cortex will be unidirectional (inward for anode, outward for cathode; see conventions below). However, the presence of CSF in convoluted gyri, especially in larger animals, will distort current flow patterns and can invert current direction locally (Creutzfeldt et al. , 1962). The absence of intermediary skull will also produce current concentrations substantially different from either stimulation across the skull (tDCS) or in a dish (in vitro DCS). Despite these concerns, the rationale for invasive stimulation in classic animal studies may simply be that the cranium must be exposed to facilitate insertion of recording electrodes, and a majority of these studies were interested in the general DC effects on brain function and not necessarily clinical transcranial DCS.

3) The use of brain slices to study weak DCS effects dates to work by John G.R. Jefferys in 1981 (Jefferys, 1981, Nitsche et al. , 2000, Ardolino et al. , 2005), with experimental techniques used to the present day established by the research groups of Bruce Gluckman and Steven Schiff (Gluckman et al. , 1996) and subsequently adapted by Dominique Durand as well as our group (Durand et al. , 2001). The rationale for using a brain slice from rodents and/or ferrets is the ability to probe specific brain regions in detail using a range of electrophysiological, pharmacological, molecular, and imaging techniques. In isolated tissue, the direction of current flow can also be precisely controlled. Lopez-Quintero described has techniques for stimulating cultured monolayers (Lopez-Quintero et al. , 2010). In a seminal series of papers, Chan and Nicholson used isolated turtle cerebellum to study DCS modulations of spiking patterns (Chan et al., 1986, Chan et al. , 1988). For in vitro DCS studies, electrodes are placed in the bath at some distance from the tissue to shield electrochemical changes. As emphasized below, DCS delivers electrical current, not chemicals to the brain.

\section{[FIGURE 1]}

\section{3. tDCS Effects Are Secondary to Membrane Polarization, Alternative Transduction Hypothesis}

In the context of the Alternative Transduction Hypothesis, transduction refers to the brains' primary sensory mechanism for recognizing an applied electric current (e.g. a cellular process that is a function of DCS), and all other consequences of stimulation are secondary to transduction. A central theme in this review is the physiological effects of tDCS can be understood using animal models by characterizing the membrane polarization induced during stimulation. Both the time a neuron's membrane is polarized and the sensitivity of a membrane compartment to polarization is paramount to quantify tDCS effects (Section 2.3). The central emphasis of membrane polarization can be rationalized either by working forward or working backward. Working forward, changes via weak DCS begin with cell membrane polarization; specifically, the compartment of the cell exposed to an electrical current produced by DCS will result in a sustained membrane polarization. Understanding which cells (i.e. neurons, interneurons, glia, endothelial cells, etc.) are polarized, and more specifically which compartments within these cells (soma, dendrite, axon) is thus a central to characterizing DCS effects as well as any other form of brain stimulation. The consequences of membrane polarization are multifaceted and complex, spanning from changes to blood-brain barrier function, action potential (AP) threshold and timing, network coherence, synaptic plasticity, and morphological and molecular changes. These diverse consequences are addressed throughout this review. However, the effects of DCS begin with polarization of cell membranes. Working backwards, we expect the cognitive, behavioral, and clinical results from tDCS are reflected by alterations to neuronal function even when other cells types are implicated. Therefore, regardless of how DCS influences the nervous system, neuronal membrane polarization remains a fundamental consequence. 
Early studies referred to tDCS/DCS as a "polarizing current", implying transduction by membrane polarization. While all types of electrical stimulations (TMS, DBS, etc.) polarize the cell membrane, tDCS has the inherent feature of being a sustained polarization, and therefore does not recover or reverse polarity as a consequence of stimulation waveform change. The peculiar time dependence of tDCS/DCS to changes in plasticity have resulted in the need for sustained polarization, meaning the time dependence on plasticity changes from tDCS may be unique to DCS.

Several additional theories of tDCS plasticity, such as NMDA modulation, are evidently secondary to neuronal membrane polarization (Section 3.1,3.2), and polarization of non-neuronal targets, such as glial cells and endothelial cells, would still reflect a primary polarization transduction mechanism (Section 5.2, 5.3). Some theories, such as axonal guidance, are also presumably linked to processes which are sensitive (secondary) to membrane polarization (Section 3.5).

A range of alternate transduction mechanisms have been explored to explain how ionic concentration changes are directly generated by DCS (e.g. iontophoresis of charged molecules/ions), but to our knowledge no quantitative analysis, much less experimental evidence, exists for tDCS. Speculation about a direct electrochemical change in the brain should not be confused with: 1) established electrochemical reactions which occur at the electrode interface, which would not reach the brain using scalp electrodes because they cannot diffuse from the electrode to the brain (Merrill et al. , 2005, Minhas et al. , 2010); or 2) possible indirect chemical and molecular changes secondary to neuronal activation (Stagg et al. , 2011). Prolonged DC application, especially in combination with ongoing activity, can change ionic (chemical) concentrations intracellularly or extracellularly, though these changes cannot violate electro neutrally. For example, enhancement of synaptic activity or NMDA-dependent LTP by DCS (see section 3.4) would be expected to change a neurons' intracellular $\mathrm{Ca}^{2+}$ concentration, but electro neutrality will be maintained through concentration changes of other positive or negative ions within that neuron. We warn against unsubstantiated theories suggesting a violation of electro neutrality during DCS. Rather, as explained in detail throughout the remainder of this review, our mechanistic considerations typically start with the wellestablished principle of membrane polarization induced by extracellular DC, and all other changes occur secondarily to membrane polarization.

Consideration should be given to tDCS dosage prior to characterizing physiological mechanisms. For example, some mechanisms of transduction, such as joule heating of the brain and electroporation (Section 1.5), are plausible for other forms of high intensity brain stimulation but may not be realistic at tDCS intensities. Conversely, the basic mechanisms for how DCS influences nervous tissue is important for meaningful dose consideration as they underpin the use of brain electric field as a translational scaling metric, including through the quasi-uniform assumption.

\section{4. tDCS dose in Human and Animals, and the Quasi-Uniform Assumption}

The Quasi-Uniform assumption for animal research on noninvasive electrical stimulation underpins translational efforts, but has only been formalized and made explicit recently (Bikson et al. , 2013). The clinical dose of tDCS has been defined by stimulation parameters that are externally controlled by the operator (Bikson et al. , 2008, Peterchev et al. , 2012), namely electrode montage (shape, location, etc.) and the specifics of the DC waveform (duration, intensity in mA applied, ramp, etc.). However, it would be fundamentally misguided to simply replicate clinical dose parameters in animal studies. tDCS produces a complex spatial pattern of current flow across the brain, which results in a dose specific electric field (current density) which varies significantly across brain regions. This brain electric field distribution represents and determines the electrical actions of tDCS. The brain electric field is not a simple function of any dose parameter. For example, the current density at the electrodes (total current/area) does not map 
simply to the peak electric field in the brain (Miranda et al. , 2007). Fortunately, there are well established methods to predict the electric field generated in the brain using computational models (Miranda et al. , 2006, Datta et al. , 2009a). Though methodological approaches vary across groups, those modeling studies using realistic anatomy have converged in their estimates of peak electrical fields generated during tDCS to between $0.2-0.5 \mathrm{~V} / \mathrm{m}\left(0.05-0.14 \mathrm{~A} / \mathrm{m}^{2}\right.$ current density) for a $1 \mathrm{~mA}$ intensity (Miranda et al. , 2006, Datta et al. , 2009a, Sadleir et al. , 2010). The electric field scales linearly with current intensity such that $2 \mathrm{~mA}$ would produce a range of $0.4-1 \mathrm{~V} / \mathrm{m}\left(0.1-0.28 \mathrm{~A} / \mathrm{m}^{2}\right.$ current density). These peaks represent specific regions of concentrated electric field, and weaker electric fields are generated across much of the brain using conventional tDCS montages. In addition, due to subject specific idiosyncratic cortical folding, the electric field is clustered (Datta et al. , 2009a), with many local maxima (Figure 2). There is thus no single uniform electric field generated in the brain during tDCS but rather a range of electric field magnitudes varying across the brain. Therefore, the question is: given this complexity of electric field distribution across brain structures, what can and should be mimicked in animal models? It is important to emphasize that simply mimicking tDCS clinical dose in animal models, or adjusting dose guidelines by an arbitrary rule of thumb (e.g., by head volume), may not be prudent.

We emphasize it would be misguided to replicate dose parameters used in humans during animal studies and expect results to be directly translatable to humans. This would be analogous to providing a rodent a human dose of a drug. While high DC dosage can be useful to produce large effects, only under the assumption of a linear or even monotonic dose response relationship can mechanisms be scaled to a tDCS relevant dose.

One solution is to consider only the brain region of interest, and then to replicate the selected electric field in the animal model. It is impractical to replicate the electric field induced in each brain region during tDCS within all corresponding brain regions in an animal model. By doing so, one implicitly adopts the assumption that electric fields are nearly uniform ("quasi-uniform assumption") on the length scale of interest (Bikson et al. , 2013). This approach is supported by evidence suggesting electric fields generated during tDCS are largely uniform across any specific cortical column (neuronal dendritic tree) of interest (Figure 2, "Quasi-uniform Electric Field) - hence one can speak of a single electric field in reference to a region of interest.

However, considering the peak of the electric field either across the whole brain or in a sub region as the basis for the electric field amplitude may be misleading. First, the electric fields' amplitude can change by orders of magnitudes in different brain regions and even across local gyri (Datta et al. , 2009a, Rahman et al. , 2013). The average and/or median value of the electric field can be up to 10 times smaller than the field peak depending on local geometry and conductivity properties. Second, it is necessary to consider how the coupling constant might vary across species. For example, given an applied electric field, the resulting polarization of a rat cortical pyramidal neuron is the same as a human cortical pyramidal neuron, between neuronal polarization and electric field applied can vary across species (Section 2.3). While the average electric field can be smaller than the peak value, the polarization of neurons in humans could be higher, assuming a higher coupling constant in humans (Section 2.3). This species dependent discrepancy can translate to the polarization of human neurons being substantially higher than predicted by animal models.

Generally, experimental design falls into one of three categories: 1) Transcranial stimulation in animal; 2) invasive stimulation of animals with intracranial electrodes; or 3) Stimulation of tissue/brain slices with bath electrodes. For each category, the quasi-uniform assumption is applied in regards to the human brain region being considered and then to the targeted region of the animal brain or across isolated tissue. 
1. In the first case of transcranial stimulation of animal, the same modeling approaches which predict electric fields during clinical tDCS can be used to model and guide stimulation design (Gasca et al. , 2010, Bernabei et al. , 2014, Lee et al. , 2015). As is the case in clinical tDCS, in DC transcranial stimulation in animals it is important to consider how the position of the return/reference electrode influences current flow even under the active electrode (Bikson et al. , 2010, Brunoni et al. , 2011). As anatomically precise animal models are under development, concentric sphere models scaled to size can be used to determine the electric field intensity generated in the animal brain (Marquez-Ruiz et al. , 2012). A free web based tool to simulate brain stimulation, BONSAI, is available at: http://neuralengr.com/bonsai/. In the absence of specific modeling of current flow in animals, and in cases where the electrode is placed directly on the skull, one can, to a first approximation, assume a maximum potential brain current density equal to the average electrode current density (Bikson et al. , 2009). However, it is important to recognize the direction (inward or outward) of the electric fields generated across the brain, including in deep brain structures (particularly in higher animals with increasing convoluted cortex) may also vary, as it does in human tDCS. The electric field in a region of interest may also be measured with invasive electrodes (Ozen et al. , 2010), recognizing it is not uniform throughout the animal brain, and the insertion and presence of electrodes may itself distort current flow.

2. In the second case, for animal studies with an electrode placed on the brain surface, one might again assume the (quasi-uniform) current density in the brain directly under the electrodes equals the average current density at the electrode. As with scalp electrodes in tDCS, when a sponge of cotton wrapper is used, its contact areas should be used in calculations. But depending on the electrode design, current density may be orders of magnitude higher at electrode edges (Miranda et al., 2006, Minhas et al. , 2011, Kronberg et al. , 2012). This is an issue which is aggravated for small electrodes where electric field near a monopolar source can be very high leading to further complications (Bindman et al. , 1964) (see discussion in Section 1.1). As with transcranial stimulation, current spread throughout the brain, affecting both cortical and subcortical structures, should be assumed when using return electrodes located away from the head (Islam et al. , 1995a).

3. In the third approach, including in vitro brain slice studies, the task is simplified by using long parallel wires or plates placed in a bath across the entire tissue. With proper care, this method generates a uniform electric field across the entire tissue and can be readily calibrated to match tDCS levels (Gluckman et al. , 1996, Francis et al. , 2003, Bikson et al. , 2004). The uniformity of the electric field across brain slices has been verified (Bikson et al. , 2004), though exceptions have been reported (Kabakov et al. , 2012). The presence of conductive fluid around the brain slices may dull any laminar inhomogeneity effects to resistivity. Typically, the placement of the electrodes in the bath, away from the tissue of interest, protects the tissue from electrochemical products. The simplicity and versatility of this technique makes control of DC parameters in slice straightforward and allows detailed analysis of brain function not possible with other techniques.

\section{[FIGURE 2]}

\subsection{Dose Translation and Meaningful Animal Studies}

One of the most fundamental sources of ambiguity when interpreting and designing meaningful animal tDCS experiments relates to dose. Many proposals for tDCS mechanisms based on animal studies fail to consider the much higher DCS intensities and/or durations used in some animal experiments. On the other hand, recognizing tDCS may produce weak effects, high DCS intensities are often intentionally to more reliably detect changes during animal studies. Assumptions are made about the ability to linearly correlate effects of specific DCS mechanisms based on a linear dose response. Often these studies present important 
mechanisms for "amplification" (Section 2.4) by which weak DCS may still have significant effects. Indeed, the search for amplification be it at the cellular, synapse, or network level, is an essential feature of many modern animal DCS studies. Regardless, a cautious, rational approach to reading responses to DCS doses should be taken.

Throughout this review, we emphasize caution when exploiting conclusions from animal studies using DC at current intensities that far exceed electric field magnitudes compared to those generated during clinical tDCS - which is the overwhelming majority of them. While these experiments are valuable for suggesting tDCS mechanisms, just as with drugs, increasing the dose beyond clinical levels by orders of magnitude can induce physiological changes not clinically relevant. For example, some animal studies have shown DC application can control the orientation of neuronal processes and their growth direction (Alexander et al. , 2006, Li et al. , 2008) (Section 3.5), but both the duration and intensity of electric fields were often orders of magnitude greater than tDCS. Additionally, mechanisms such as electroporation and joule heating can be produced by some forms of electrical stimulation, but the waveforms required to produce these effects are not relevant to tDCS (Bikson et al. , 2009, Datta et al. , 2009b, Liebetanz et al. , 2009). Thus, some mechanisms which require waveforms incompatible with tDCS, and their associated animal studies, are not considered further here.

Though important to our understanding of tDCS mechanisms, classic animal work on DCS used invasive electrodes at higher current densities than are used during tDCS on the scalp (most of these studies did not intend to mimic tDCS). Recent animal studies have often used tDCS at current densities higher on the skull than is used in human tDCS at the electrodes (Fregni et al. , 2007, Brunoni et al. , 2011). Motivated in part by magnify

ing effects and not necessarily only by tDCS, many recent in vitro studies, including those done by our group, have used electric fields higher than those generated clinically (Andreasen et al. , 1996, Bikson et al. , 2004). Because of the complex nonlinearity of nervous system function, one cannot automatically assume a monotonic (e.g. more field $=$ more response) relationship between intensity and outcome. However, in vitro studies that explore field strength-response curves do indicate a surprisingly linear response curve over low intensities (Bikson et al. , 2004, Reato et al. , 2010), and the membrane coupling constant certainly appears to be linear with electric field strength (Section 2.3). In vitro studies that have explicitly explored the lower electric field limit of sensitivity to fields (Section 4) (Francis et al. , 2003, Jefferys et al. , 2003, Reato et al. , 2010) report statistically significant responses at $<0.2 \mathrm{~V} / \mathrm{m}$, which is within human tDCS ranges.

High DC intensities can produce opposite effects than are expected at tDCS relevant intensities. As discussed later, DC electric fields can increase excitability and evoked responses (e.g. synaptic efficacy) in a polarity specific manner. But if the DC intensity is increased significantly, neuronal excitability may increase to a point where the neuron generates high frequency discharges, and the responsiveness of a very active neuron to a stimulus may then decrease because it will often be in a refractory state. This phenomenon has been shown in brain slices (Bikson et al. , 2004) and may explain in vivo results using high DC current intensities (Purpura et al. , 1965a). The nonlinearity and state dependence of DCS dose response may be pertinent to the understanding of mechanisms and rational optimization of tDCS techniques.

Throughout this review we emphasize the dose used in any given animal study can be orders of magnitude greater than the dose generated in the brain during tDCS. We attempt to be explicit when making an assumption about linear dose responses to DCS findings going from high to low intensity to predict effect sizes for tDCS. We emphasize the issues surrounding dose response remain some of the most overlooked yet most important aspects when translating from animal DCS to human tDCS. Dose translation is 
inherently linked with mechanism, affecting experimental design, and which stimulation features (e.g. electric field) are considered relevant for scaling, and how insights from animal models shape clinical practice, including dose optimization.

\subsection{Dose Response and Safety}

Issues with dose-response curve assumptions are particularly acute in the context of safety, as any attempt to develop safety standards requires assumptions be made about dose response and the variability within a response.

One agnostic approach (Section 7.1) to the dose-response curve is to use the lowest documented current intensity that produces a measurable, destructive brain tissue response in an animal model at any stimulation duration. This approach has limitations and makes assumptions, as the precision of current increments tested and the number of animals used will limit validation of a single lowest damage threshold. Alternatively, the entire data set may consolidate to a single curve to determine a minimum damage threshold. Though the quality of the correlation between current intensity and damage may support this approach, assumptions about the type of dose-response curve for damage (i.e. a linear dose-response, homeostatic dose-responses) will profoundly affect the resulting exploration within the "safe" tDCS range. In the absence of a mechanistic explanation for damage supporting a particular dose-response, we limit our discussion on damage thresholds (Section 7.1) to current intensity and avoid conjectural summary metrics such as charge or charge density. Because the animal trials cited in Section 7.1 used stimulation durations equal to or greater than clinical tDCS, limits based simply on current intensity can be considered conservative in regards to summary metrics influenced by time.

Another issue surrounding tDCS dose-responses for safety is the time at which an animal is sacrificed after stimulation. Experimental studies have limited time points for measuring damage, as the collection of tissue for analysis requires terminal procedures. We assume damage was irreversible when present but cannot exclude delayed damage responses, which, if applicable, would result in a more sensitive safety threshold for tDCS. Without an established mechanism for damage, we limit ourselves here to reported data.

The relative sensitivity of animal versus human tissue to tDCS injury is unclear. While developing safety guidelines are sometimes arbitrary, our review summarizes rodent studies focusing on brain injury (Section 7.1). It is prudent not to approach injury thresholds observed in rodents when developing human safety guidelines given electrode montage and inter individual differences (Figure 2), and scaling consolidated animal tDCS safety data to humans using computational models indicate conventional tDCS protocols are orders of magnitude below the threshold for damage (Section 7.1).

\subsection{Methods for Recording Responses}

Consideration for the method used to record responses when designing animal translational studies is imperative. Animal disease models can be used to validate responses, characterize physiological mechanisms, and optimize stimulation protocols for clinical treatment using tDCS (Sunderam et al. , 2010, Yoon et al. , 2012). To evaluate and quantify tDCS responses in humans, researchers have used neurophysiological recording methods such as spontaneous EEG (Marshall et al. , 2004, Marshall et al. , 2006) and transcranial magnetic stimulation-motor evoked responses (TMS-MEP) (Nitsche et al. , 2000). These generic clinical measures of "excitability" are roughly analogous to spontaneous firing rate, oscillations, and evoked responses in an animal, though evoked responses or oscillations of a given frequency may not have the same origin in animals and humans. 
Animal research in tDCS has only started to access the breadth of behavior and disease models available today. As summarized by Brunoni (2015): "Although pre-clinical studies, including experiments with animals, are critical in developing novel human therapies, translational research also has several challenging aspects, as animal and human studies can differ in characteristics of disease (i.e., 'human disease' vs. 'experimental animal model'), definition of outcomes (especially for neurological research that often rely heavily on behavioral outcomes...”(Brunoni et al. , 2011).

Having outlined potential drawbacks for translational tDCS studies, the need and value of well-designed animal research remains evident. Contributions of animal studies to our current understanding of tDCS and their importance as tDCS becomes more sophisticated are discussed in the next sections.

\subsection{Relation to Clinical Neurophysiologic Metrics}

The primary clinical neurophysiology metric used to establish the acute and lasting tDCS effects in humans is the TMS-MEP, and the establishment of modern tDCS can be traced to the discovery that tDCS can modulate TMS-MEP in a polarity (anode, cathode) and montage specific manner (Nitsche et al. , 2000). While animal studies of DCS are not typically intended to reproduce clinical neurophysiology findings per se, there are noteworthy analogies. A common metric used in animal trials is synaptic responses evoked by micro electrical stimulation (e.g. field excitatory post-synaptic potentials, fEPSPs), and indeed studies of how DCS affects evoked synaptic potentials in tissues has served as the basis for the characterization of cellular mechanisms (Bikson et al. , 2004, Kabakov et al. , 2012, Marquez-Ruiz et al. , 2012, Rahman et al. , 2013).

Both TMS in humans and microelectrode stimulation in animals use suprathreshold stimulation of afferent pathways to assess how DCS modulates the processing of that input by cortical neurons. Despite evident differences in the nature of evoked responses, lessons can be learned from similarities and differences in observed response. Similarities include the pathways and dose specific modulation of excitability (Bikson et al. , 2004, Kabakov et al. , 2012, Marquez-Ruiz et al. , 2012, Rahman et al. , 2013). For example, in brain slice the micro stimulation allows assessment of how modulation varies depending on the specific fiber volley activated (e.g. thalamo-cortical as opposed to cortical-cortical connections). Modulation of response evoked from tDCS by invasive micro stimulation electrodes to applied transcranial stimulation can be tested in animals (Bolzoni et al. , 2013b). In humans, there is less fine isolation of pathways with TMS, but emerging data suggest there is pathway dependence in humans as well (Brzyski et al. , 1989, Hamada et al. , 2014), which may account for some of the variability observed.

In addition to event related potentials (ERPs) from electrical probes (TMS, micro stimulation), ERPs produced by environmental cues (e.g. light) can also be seen in both humans and animals. These measures are biomarkers of DCS neuromodulation. Another direct neurophysiological marker found in animal DCS studies that correlates with human tDCS is network oscillations. EEG can be used to monitor and assess tDCS effects on ongoing brain oscillations, while field recording in animals can be used to study the role of DCS on oscillation models. Despite differences in the etiology of oscillations between human and animal models (even when the frequency appears matched), mechanistic findings from animal studies on how DCS affects oscillations in an activity dependent manner (Reato et al. , 2010, Reato et al., 2015) may help elucidate encouraging but complex effects of tDCS on oscillations in humans.

\subsection{Stimulation Artifact in Recording}

DCS has no frequency, and the first approach to remove stimulus artifact produced by DCS when recordings is to use a high pass filter. While high pass filtering is possible in situations where the DC component of the recording is not important, such as with unit recording or field recordings, high pass filtering is not possible when the DC component of the signal is important, as is the case with intracellular recording. Moreover, no DC source is ideal and stimulation artifact may include high frequency 
components that should be measured and considered when interpreting results. In this sense, noise levels should be considered when the stimulator is powered on and off. Additionally, aspects of the stimulation recording itself such as drift in electrode conditions and field uniformity (change in isopotential, see below) may result in artifact even under DCS.

When recording extracellular electrophysiological signals such as unit or field potentials (fEPSPs, population spikes, fiber volleys, etc.), the small output signals need to be amplified (e.g. 100x). The application of DCS can produce large artifacts during recording that can saturate the amplifier when the signal is amplified, which can happen prior to the high pass filtering stage, making interpretation of recording difficult. Using a second extracellular electrode placed in the bath rather than the tissue where the DCS artifact is comparable to that of the electrophysiological recording location (both electrodes are at an isopotential point relative to the DCS (Ghai et al. , 2000) can help distinguish noise from cellular physiology. Recording the electrophysiological signal relative to the bath's isopotential location allows for subtraction of the artifact at the early hardware stage as well as amplification without saturation, with the remaining artifact removed by later stage high pass filtering.

Analog to digital converters with increased dynamic range may reduce the need for DC artifact subtraction along with consideration of recording and isopotential electrode positions. Another possibility is to utilize recording hardware that allows for AC coupling, where the voltage offset induced by DCS will be filtered, leaving the electrophysiological signal within the dynamic range of recording. When the field turns on and off, there will be a period of time when the signal can't be acquired, which will depend on the time constant of the AC coupled equipment.

When the recording cannot be high pass filtered because the DC component of the signal is relevant, special care must be taken to prevent DCS artifact from corrupting the recording. An intracellular electrode, for example, can become sensitive to the stimulation artifact and provide misleading information on cell polarization under DCS (e.g. coupling constant). In this case, a solution is to place an extracellular recording electrode adjacent to the intracellular electrode. By subtracting the intracellular electrode signal from the extracellular electrode signal, a true transmembrane potential is obtained, since we assume the artifact is identical in the intracellular and extracellular electrode by virtue of proximity.

A similar approach is used by placing the isopotential electrode in the tissue. In this way both the artifact and any extracellular physiological signal is subtracted, which is consistent with the goal of transmembrane potential recording. To check the reliability of this technique, break the intracellular recording by either mechanical or electrical means after the intracellular recording is complete, such that the intracellular electrode is now also outside the membrane but in the same position. If the DCS is now repeated, ideally no difference between the intracellular electrode and extracellular reference would be detected, confirming the correction was effective. However, if a difference were detected, this difference would have corrupted the prior transmembrane potential measurement and should be accounted for in signal post-processing. All intracellular recordings are transmembrane but the potential is typically zeroed before the cell is impaled such that the potential directly outside the cell is taken as zero. This assumes the potential outside the cell is stable during the experiment which is not the case in DCS. The above approach has proven effective for current clamp recording under diverse conditions (Bikson et al., 2004, Radman et al. , 2009).

Under voltage clamp conditions the matter is further complicated since the amplifier will detect the artifact and provide a compensatory current. Technical caution should be applied if attempting voltage-clamp during DCS. Techniques such as optical imaging with voltage sensitive dyes would be insensitive to stimulation artifacts (Bikson et al. , 2004). Some measurements, such as AP timing changes and coherence may also be insensitive to DCS artifact (Radman et al. , 2007b, Reato et al. , 2010). 


\section{The Somatic Doctrine and Need for Amplification}

Since seminal clinical neurophysiology in 2000 (Nitsche et al. , 2000, Ardolino et al. , 2005, Fregni et al. , 2005, Fregni et al. , 2007), there has been exponential growth in the exploration of tDCS for clinical and cognitive/neuroscience research. Broad adaptation has been encouraged by the apparent simplicity of the technique, and the perception that tDCS protocols can be designed for any application simply by placing an electrode over the targeted brain region. In the next sections, starting with consideration of acute effects at the level of a single neuron, we: 1) define the "somatic doctrine"; 2) describe the somatic doctrine's origin in classic animal studies; 3 ) outline modern efforts to quantify somatic polarization using brain slices; and 4) describe possible amplification mechanisms of tDCS.

\subsection{Neuronal Polarization}

DCS leads to current flow across the brain (Datta et al. , 2009a), resulting in cell membrane polarization when the current crosses the membrane. Current into a membrane compartment results in local membrane hyperpolarization, and current out of a membrane compartment results in local membrane depolarization (Andreasen et al. , 1996, Bikson et al. , 2004). A purely depolarizing or purely hyperpolarizing weak DCS does not exist, which is a concept commonly overlooked in clinical literature. The physics of electrical stimulation dictate that a single neuron receiving extracellular DCS will have some compartments that are depolarized and some compartments that are hyperpolarized (Chan et al., 1988, Bikson et al. , 2004). The direction the compartments are polarized depends on the neuronal morphology relative to the DC electric field. For example, for a typical cortical pyramidal cell with a large apical dendrite pointed toward the cortical surface, a surface anode generating a cortical inward current flow will result in somatic and basal dendrite depolarization but apical dendrite hyperpolarization (Radman et al. , 2009). For this same neuron, a surface cathode generating cortical outward current flow will result in somatic and basal dendrite hyperpolarization but apical dendrite depolarization.

The relative importance of the somatic compartment in eliciting AP's, and thereby determining cortical output, suggest somatic polarization plays a critical role in determining cortical excitability (the basis for the somatic doctrine). However, whether a neuron fires is not only determined by the soma, but by the integration of activity in all neuronal compartments (dendrites, axon, presynaptic terminal, axon hillock, etc.). DC electric fields can modulate the function of these compartments, increasing the complexity of a pure somatic doctrine (Rahman et al. , 2013). tDCS protocols based on the somatic doctrine simply assume somatic polarization determines all relevant functional/clinical outcomes. This consensus of a generic excitation/inhibition by anodal/cathodal stimulation combined with the concept of brain (dis) function as a sliding scale of excitability underpins a majority of clinical tDCS study design.

\subsection{Modulation of Excitability, Polarity Specific Effects}

The application of DCS (often as short pulses) to the neuromuscular system dates to the origin of batteries, but a historical review of DCS is well beyond the scope of this review (Guleyupoglu et al. , 2013). However, some highlights may help provide context to the origin of the somatic doctrine. In 1870 Fritsch and Hitzig may have been the first to show applying a positive current to the cortex had stimulating effects while a negative current had inhibitory effects, a finding that itself contributed to early understanding of the cortex as electrically excitable (Carlson and Devinsky , 2009). Terzuolo and Bullock and Creutzfeldt helped establish ongoing discharge frequency is enhanced by surface positive current and decreased by surface negative currents (Terzuolo et al. , 1956, Creutzfeldt et al. , 1962). The debate over the role of endogenous electric fields is reflected in these early works in which Creutzfeldt suggested they are epiphenomena while Terzuolo and Bullock suggested a physiological role, and indeed modern work with 
weak transcranial stimulation has provided the strongest clinical evidence for a physiological role, (Frohlich et al. , 2010, Reato et al. , 2010, Ali et al. , 2013, Reato et al. , 2015).

The concept that the threshold for electric field sensitivity would be "lower for modulation of the frequency of an already active neuron than for excitation of a silent one" was thus established, with early observations of changes in discharge rate with fields as low as $0.8 \mathrm{~V} / \mathrm{m}$ (Terzuolo et al. , 1956). The electric fields induced by tDCS are considered far too weak to trigger AP's in quiescent neurons (compare $>100 \mathrm{~V} / \mathrm{m}$ induced by TMS to $<1 \mathrm{~V} / \mathrm{m}$ by tDCS in humans). It is not surprising that early animal studies on lower intensity DCS addressed modulation of ongoing normal or pathological neuronal firing rate, as well as evoked responses. In the early 1960's, animal studies by Bindman and colleagues (Bindman et al. , 1962, Bindman et al. , 1964) confirmed polarity specific changes in discharge rate and further showed excitability changes both cumulative with time and present after stimulation (Section 3). This group went on to explore long duration stimulation as early psychiatric treatment. It was also recognized that the direction of discharge rate changes was consistent with presumed somatic polarization and dependent on the orientation of the apical dendrites. Furthermore, animal studies in the 50's and 60's examining control of epileptic discharges (Purpura et al. , 1966), evoked responses (Creutzfeldt et al. , 1962, Bindman et al. , 1964, Purpura et al. , 1965a), lasting effects and related molecular changes (Section 3.4) (Gartside, 1968b), also reinforced the concept that the direction of somatic polarization determined the overall effect on excitability/functional outcomes.

\subsection{Quantifying Polarization with Coupling Constants}

In this section we introduce the concept of the "coupling constant", one of the most basic quantitative tools for characterizing the effects of DCS. A specific and predictive understanding of tDCS requires a quantitative model, beginning with quantification of somatic and dendritic polarization during tDCS. In the 1980's, Chan (Chan et al. , 1986, Chan et al. , 1988) used neurophysiological recordings from turtle cerebellum to model and quantify membrane polarization under near static electric fields (very low frequency sinusoid currents). These monumental studies identified the basic morphological determinants for neuron sensitivity to applied DCS. Using the rat brain slice, we extended this work to hippocampal neurons and then to the cortex with the approach of quantifying cell specific polarization by weak DCS using a single number, which we called the coupling constant (also referred to as the 'coupling strength' or 'polarization length').

To quantify cell specific polarization, we assumed the membrane polarization at any given compartment, including the soma, produced by DCS is linear with electric field intensity along the primary neural axis (or for long compartments, see Section 3.5) for weak, subthreshold electric fields (stimulation intensities too weak to significantly activate voltage gated membrane channels). For uniform electric fields, the membrane potential can thus be expressed as: $\mathrm{V}_{\mathrm{tm}}=\mathrm{G}^{*} \mathrm{E}$ where $\mathrm{V}_{\mathrm{tm}}$ is the polarization of the neural compartment (in Volts), $\mathrm{G}$ is the coupling constant (in $\mathrm{V}$ per $\mathrm{V} / \mathrm{m}$, or simply: $\mathrm{m}$ ) and $\mathrm{E}$ is the electric field (in $\mathrm{V} / \mathrm{m}$ ) along the primary somatodendritic axis. For rat hippocampal and cortical neurons, the somatic coupling constant was in the range of 0.1-0.3 mm (Bikson et al. , 2004, Deans et al. , 2007, Radman et al. , 2009). Similarly, in ferret cortical neurons the coupling constant was approximately $0.25 \mathrm{~mm}$ (Frohlich et al. , 2010). For humans, assuming sensitivity scales with total neuronal length (Joucla et al. , 2009) somatic depolarization per V/m may be higher, but determining the somatic coupling constant and other membrane compartments in humans to tDCS remains a fundamental research question.

Maximal depolarization of a neuron occurs when the electric field is parallel with the somatodendritic axis which typically corresponds to an electric field radial to the cortical surface, while an electric field orthogonal to the somatodendritic axis does not produce significant somatic polarization (Section 3.4) (Chan et al. , 1988, Bikson et al. , 2004). The somatic coupling strength is roughly related to the size of the 
cell and the dendritic asymmetry around the soma (Svirskis et al., 1997, Radman et al. , 2009), making pyramidal neurons relatively sensitive polarization. For cortical pyramidal neurons, the typical polarity of somatic polarization is consistent with the somatic doctrine (e.g., positive somatic depolarization for positive electric field). Using our field direction convention, the polarity of the coupling constant is inverted for CA1 pyramidal neurons due to their inverted morphology. Experimental and modeling techniques show the coupling constant of dendritic compartments can also be investigated, and the maximal polarization is generally seen at dendritic tufts (Bikson et al. , 2004). However, the polarization should not exceed $\sim 1 \mathrm{mV}$ polarization per V/m electric field in animals (Chan et al. , 1988, Radman et al. , 2007b, Radman et al. , 2009).

If tDCS produces a peak electric field of $0.3 \mathrm{~V} / \mathrm{m}$ at $1 \mathrm{~mA}$ with the majority of cortex at reduced electric fields, then the maximum somatic polarization for the most sensitive cells is $\sim 0.1 \mathrm{mV}$. Similarly, for $2 \mathrm{~mA}$ tDCS stimulation, the most sensitive cells in the brain region with the highest electric field would have somatic polarization of $\sim 0.2 \mathrm{mV}$. Far from clarifying a tDCS mechanism, work by our group and others quantifying the sensitivity of a neuron to weak DC fields has instead raised questions about how such a minimal polarization could result in functional/clinical changes, especially when considering endogenous 'background' synaptic noise can exceed these levels. Motivated by increased evidence in recent years showing tDCS has functional effects, as well as ongoing questions about the role of endogenous electric fields, the mechanisms of amplification have been further explored in animal studies. We organize these efforts by nonlinear single cell properties (Section 2.4) as well as synaptic processing and network processing (Section 2.5).

\subsection{Amplification through both Timing and Rate}

To determine the systemic tDCS effects, our group proposes the relatively small changes to a neurons' potential are collectively amplified at the cellular or network level to result in a meaningful modification. Weak tDCS has subthreshold effects, however the small effects of tDCS may combine with already ongoing, subthreshold neural activity to induce suprathreshold potentials and invoke changes in neural behavior. Evidence for amplification of ongoing activity by tDCS has been shown, notably when there is inherent presynaptic activity that can nonlinearly sum with DC polarizations to induce perceivable effects (Rahman et al., in progress). A human analog to this amplification could be the coupling of anodal tDCS with task specific training (McIntire et al. , 2014, Hendy et al. , 2015, Zhu et al. , 2015). However, to understand these general effects of tDCS amplification, we must first discuss acute amplification at the single neuron level through modulation of spike timing and rate processes.

At the level of a single neuron, the most evident nonlinear response which could serve as a catalyst for acute amplification is an AP, which is a threshold based, all or none response of a neuron. Importantly, as the electric fields generated in the brain during tDCS are too weak to trigger AP's in resting neurons (e.g. $\sim 20 \mathrm{mV}$ membrane depolarization from its resting potential to an AP threshold), we should instead consider how a DC electric field can modulate ongoing AP activity. We have proposed considering acute implication through either: 1) the rate of AP generation (rate effects); and/or 2) amplification through change in the timing of AP (timing effects). As discussed above, classic animal studies on weak DCS showed changes to ongoing AP discharge rate were roughly linear with electric field intensity and membrane polarization by DCS. In this sense, amplification (e.g. gain) would relate to the sensitivity of discharge rate to DCS-induced membrane polarization. Interestingly, Terzuolo and Bullock reported a detectable change in neuronal firing rate at electric fields as small as $0.8 \mathrm{~V} / \mathrm{m}$, and postulated that this detection threshold would likely decrease with longer and more sophisticated experiments (Terzuolo et al. , 1956). Assuming tDCS at $2 \mathrm{~mA}$ generated a peak electric field in the brain of $0.6 \mathrm{~V} / \mathrm{m}(\sim 0.2 \mathrm{mV}$ somatic polarization), and that across animal studies changes in firing rates of $7 \mathrm{~Hz}$ per $\mathrm{mV}$ of membrane 
polarization has been reported (Carandini et al. , 2000), a change in firing rate of $\sim 1.5 \mathrm{~Hz}$ during conventional tDCS is plausible. The above consideration is for isolated neurons, and for neurons that are coupled together in an active network the firing rate response are still further amplified (Section 4).

We proposed in 2007 that changes in AP timing rather than discharge rate could serve to amplify the effects of weak membrane polarization produced by DCS (Radman et al. , 2007b). DCS is not generating AP's by modulating firing rime in response to a depolarizing ramp, as might occur during synaptic input. We demonstrated in acute brain slice recordings and in a simple neuron model that the resulting change in timing could be quantified simply by the induced membrane polarization times the inverse of the ramp slope (Figure 3A1, A2). Thus, the inverse of the ramp-slope is a "gain/amplification" term because the shallower a ramp, the larger the timing change for any given small polarization by DCS (Figure 3B1, B2). For example, based on an approximate $0.2 \mathrm{mV}$ somatic polarization during $2 \mathrm{~mA}$ tDCS, then in response to a $1 \mathrm{mV} / \mathrm{ms}$ ramp slop, timing would change by $0.3 \mathrm{~ms}$. We also validated this novel mechanism using Alternating Current stimulation (Radman et al. , 2007b). This coupling sensitivity and the resulting timing changes were further confirmed by Anastassiou and colleagues using a more complex model (Anastassiou et al. , 2010). Though the basic principle of timing amplification is expected to generalize to other neuron types responding to an increasing synaptic input (Figure 3C1) (Bikson et al. , 2004), the most simple amplification equation (Figure 3A1) makes specific assumptions about membrane properties and dynamics (Radman et al. , 2007a) which may not extend to all neurons types (Radman et al. , 2009).

\section{[FIGURE 3]}

Additional mechanisms of amplification at the single cell level remain an active area of investigation, especially how exposure to long duration fields (e.g. minutes as used in tDCS) may produce cumulative, amplified effects not observed during short term application (e.g. molecular changes) (Gartside, 1968a, b, Fritsch et al. , 2010, Ranieri et al. , 2012). It remains an open and key question how prolonged polarization of both the soma and dendrites can then trigger specific chemical and molecular cascades and lead to the induction of plasticity (Section 3).

\subsection{Seizure Threshold and Modulation}

The coupling constant also provides insight into tDCS safety in regards to triggering of seizures during stimulation. Whereas TMS produces $100 \mathrm{~V} / \mathrm{m}$ pulsed electric fields (suprathreshold), tDCS produces $<1$ $\mathrm{V} / \mathrm{m}$ static electric field, resulting in $<1 \mathrm{mV}$ of polarization (subthreshold). Animal studies indicate that application of DC electric fields $>20 \mathrm{~V} / \mathrm{m}$ (corresponding to $>60 \mathrm{~mA}$ tDCS) can trigger AP's in the most sensitive quiescent cortical cells (Radman et al. , 2009), while electric fields of $\sim 100 \mathrm{~V} / \mathrm{m}$ (corresponding to $>500 \mathrm{~mA} \mathrm{tDCS}$ ) in the somatic depolarizing direction can trigger epileptiform activity in hippocampal slices (Bikson et al. , 2004), although this threshold may decrease for already active neurons. In brain slices, weak DCS on the order of $1 \mathrm{~V} / \mathrm{m}$ can modulate ongoing epileptiform activity, suggesting cathodal tDCS may control ongoing seizures while anodal tDCS may aggravate ongoing seizure activity (Gluckman et al. , 1996, Ghai et al. , 2000, Durand et al. , 2001, Su et al. , 2008, Sunderam et al. , 2010). In a polarity specific fashion (consistent with somatic polarization) DCS can also modulate the propagation of epileptiform activity in slices (Gluckman et al. , 1996), spreading depression in vivo (Liebetanz et al. , 2006a), and perhaps clinical epileptiform activity (Varga et al. , 2011). Though the acute effects of weak DC on ongoing epileptiform activity are well established in animal models, it remains an open question if and how prolonged DCS modulates seizure initiation propensity and epileptogensis. Animal studies (Section 6.4) suggest prolonged cathodal DCS can be anticonvulsant while reports of anodal tDCS effects are mixed (Hayashi et al. , 1988, Liebetanz et al. , 2006b), and pilot human studies suggest an antiepileptic effect. Safety thresholds for seizure generation are discussed further in section 7.2. 


\subsection{Limitations of the Somatic Doctrine}

The limitations of the somatic doctrine are the cell compartments it ignores: the dendrites, axons, and terminals. The dendrites are also electrically excitable, and while the basal dendrite of pyramidal neurons will be polarized similarly as the soma, the apical dendrite will be polarized in the opposite direction (Figure 4) (Andreasen et al. , 1996, Bikson et al. , 2004). Animal studies applying high intensity DC electric fields $(\sim 100 \mathrm{~V} / \mathrm{m})$ have shown active processes (e.g. spikes) can be triggered in the dendrites (Chan et al. , 1988, Wong et al. , 1992, Andreasen et al. , 1996, Delgado-Lezama et al. , 1999) with sufficiently strong stimulation. Even if the electric fields induced during tDCS are not sufficient in themselves to trigger dendritic spikes, the role of dendritic polarization during tDCS remains an open question, especially considering synaptic input processing (Section 3).

It is well established that axons are sensitive to applied electric fields, specifically the magnitude and direction of polarization is a function of neuronal and axonal morphology (Bullock et al. , 1956, Takeuchi et al. , 1962, Salvador et al. , 2010). While an axon's initial segment would likely be polarized in the same direction as the soma (Chan et al. , 1988), this is not necessarily the case for distal regions of long axons. Thus, it is useful to separately consider the initial segments of an axon (within a membrane space constant of the soma) from more distal axonal processes, which can be further divided into "axons of passage" and afferent axons with terminations (Section 3.3, 3.4). Notably, for long, straight axons of passage (e.g. Peripheral Nervous System, PNS), cathodal stimulation will be more effective at inducing depolarization than anodal stimulation, which opposes the somatic doctrine (Bishop et al., 1926). It has been shown lasting changes can be induced in human PNS axons (so by implication in CNS axons independent of somatic actions) and in brain slices, it has been shown weak DC electric fields can produce acute changes in CNS axon excitability (pre-synaptic/antidromic volley) (Jefferys, 1981, Bikson et al. , 2004, Kabakov et al. , 2012).

As we previously summarized: "A presumption of the somatic doctrine is that under the anode currents are radial and inward through the cortex, while under the cathode current is radial and outward (Figure 4). However, high resolution modeling suggests that in convoluted human cortex, current is neither unidirectional nor dominantly radial (Rahman et al. , 2013). Though the somatic doctrine is based only on radially directed electrical current normal to the cortical surface, during tDCS, significant tangential current flow is also generated along the cortical surface (Rahman et al. , 2013). Indeed, recent work by our group suggests tangential currents may be more prevalent between and even under electrodes (Figure 5). As discussed next, tangential currents cannot be ignored in considering the effects of tDCS. Moreover, due to cortical folding the direction of radial current flow under tDCS electrodes is not consistent, meaning there are clusters of both inward (depolarizing) and outward (hyperpolarizing) cortical current flow under either the anode or the cathode (Rahman et al. , 2013). Due to the cortical convolutions, current is not unidirectional under electrodes, thus, under the cathode there may be isolated regions of inward cortical flow, and in those regions neuronal excitability may increase (Creutzfeldt et al. , 1962). The relative uniformity of direction across a given patch of cortex depends on the electrode montage, with electrode across the head producing the most consistent polarization under each electrode (Turkeltaub et al. , 2012) and closer electrodes, such as the classic M1-SO (anode on motor strip, cathode on contralateral supraorbital area) montage, producing bidirectional current flow with a slight directionality preference on average in some regions under the electrodes (Figure 2). This seems puzzling in light of the dependence on the somatic doctrine in tDCS montage design and study interpretation.” (Bikson et al. , 2012)

[FIGURE 4] [Figure 5] 


\section{Synaptic Processing and Plasticity}

There is a clinical need for lasting changes by tDCS, as it is impractical to improve disease/injury by continuously stimulating with electrodes on the head. The desire for lasting change means tDCS should influence plasticity during or after stimulation in cognitively/therapeutically relevant ways (Yoon et al. , 2012). This section addresses the contribution of animal studies to understanding plasticity generated by weak DC electric fields.

Animal studies, some decades old, have suggested lasting changes in brain excitability by DCS. In the 1960's it was established that weak DC can produce lasting physical change in neural activity, which cannot be explained as a persistent, "reverberating circuit" of activation (Gartside, 1968a, b). These early demonstrations of acute and plastic changes in animal studies also contributed to establishing the somatic doctrine in tDCS (Section 2). Especially notable are animal studies by Bindman and colleagues, who recognized the importance of prolonged DCS for producing polarity specific, lasting, cortical excitability changes ( $>5$ minutes) (Bindman et al. , 1962), which informed their early tDCS work on psychiatric disorders (Costain et al. , 1964, Redfearn et al. , 1964). This work was recognized by Nitsche and Paulus, who adopted multi-minute stimulation in humans to demonstrate polarity specific, lasting changes in cortical excitability through TMS-MEP (Nitsche et al. , 2000). Though these multi-minute protocols are now universally adopted in tDCS research, the mechanisms by which prolonged stimulation are needed to trigger plasticity as well as protocols for optimizing long lasting changes remains a central question in tDCS research. Marquez-Ruiz summarizes, "When tDCS is of sufficient length, synaptically driven aftereffects are induced. The mechanisms underlying these after-effects are largely unknown, and there is a compelling need for animal models to test the immediate effects and after-effects induced by tDCS in different cortical areas and evaluate the implications in complex cerebral processes" (Marquez-Ruiz et al. , 2012). Issues such as how tDCS produces specific changes (e.g. boosting only an adjunct task), are considered linked to the mechanisms of plasticity induction or modulation (Section 3.1).

Synaptic plasticity is considered central in brain plasticity, making synapses a natural focus for lasting tDCS effects. Moreover, both in human and animal studies, changes in synaptically-mediated evoked responses are considered reliable hallmarks of long term plastic changes that could support lasting behavioral or clinical changes. Thus much of modern animal studies on tDCS plasticity has considered synaptic efficacy. Modern animal studies have focused on establishing and characterizing acute change in synaptic efficacy/processing by DCS, and this work is detailed in this section along with its implications for the cellular and subcellular (compartmental) targets of tDCS. Morphological changes are also discussed in in this section.

\subsection{Paradigms for DC Modulation of Synaptic Plasticity}

Electric fields generated by tDCS are subthreshold and too weak to trigger AP's in quiescent neurons. Though their acute role can only be modulatory, effects of DCS on firing rate, timing, and synaptic efficacy have been demonstrated. Lasting changes in synaptic efficacy from DCS could be mediated through different paradigms, which are not necessarily exclusive:

1. Membrane polarization may trigger plastic synaptic changes independent from any past, ongoing, or future, synaptic input or AP generation (e.g. simply holding the membrane at an offset polarization initiates changes). However, in a cortical brain slice model with no background activity, weak polarization was not sufficient to induce plastic changes in synaptic efficacy (Fritsch et al. , 2010).

2. Synaptic plasticity may be affected secondarily to neuronal polarization through amplification of AP rate or timing (Section 2.4). Bindman et al. (1964) has stated "There is some evidence that a 
determining factor in producing long lasting after effects is the change in the firing rate of neurons rather than the current flow that produces the changes." Classic animal studies have indicated weak DCS is sufficient to induce plastic changes (Gartside, 1968a). However, these studies do not directly prove a causal link between altered neuronal activity during stimulation and prolonged effects after stimulation.

3. Incremental membrane polarization in combination with ongoing synaptic activity may induce synaptic plasticity. The specific hypothesis here is the generation of plasticity would require synaptic coactivation during DCS. Fritsch and colleagues has shown synaptic potentiation in vitro under anodal stimulation only occurs during synaptic stimulation of specific frequencies (Fritsch et al. , 2010). In a rabbit study, DCS was combined with repeated somatosensory stimulation in vivo, leading to acute polarity specific changes, and lasting changes only for the cathodal case (Marquez-Ruiz et al. , 2012). If plasticity changes are dependent on a combination of DC polarization and synaptic input, then synapse specific changes are plausible. If one assumes DCS exerts a post-synaptic priming effect (e.g. polarization of soma/dendrite), then coactivation of an afferent synaptic input could be considered Hebbian reinforcement. Clinically this plasticity paradigm is broadly analogous to combining tDCS with a cognitive task or specific behavior which will coactivate a targeted network, or combining tDCS with TMS. Indeed, work showing the importance of coactivation in cortical slices (Rioult-Pedotti et al. , 1998, Hess et al. , 1999) influenced Nitsche and Paulus when developing tDCS. However, unlike in brain slice and anesthetized animal models, the human cortex is constantly active such that tDCS is always applied in conjunction with ongoing synaptic input even if it is not explicitly paired with another intervention.

4. Incremental polarization of the neural membrane may boost ongoing endogenous synaptic plasticity. For example, in the aforementioned rabbit study, DCS modulated ongoing synaptic habituation, a model of associative learning (Marquez-Ruiz et al. , 2012). Clinically this fourth paradigm is analogous to combining tDCS with learning/training (Bolognini et al. , 2010). Using intracellular current injection, Artola showed that depending on the degree of post-synaptic polarization , the same tetanic stimulation can induce either LTD or LTP (Artola et al. , 1990). The direction of endogenous LTP/LTD modulation by concurrent DCS polarity depends on the nature of ongoing potentiation (Kronberg et al. and Rahman et al. , in revision).

5. Meta plasticity is a paradigm where sustained polarization before or possibly after the generation of endogenous LTP "primes" the brain to respond differently to endogenous potentiation. This paradigm still depends on ongoing activity but does not require DCS and brain activity occur at the same time. Evidence from brain slices shows priming with DCS modulates subsequent tetanus induced LTP in a polarity specific manner (Ranieri et al. , 2012), apparently opposite to the somatic doctrine when one considers CA1 neuron morphology results in anodal stimulation producing somatic hyperpolarization.

6. Changes in network dynamics where the generation of LTD/LTP is explained through intervention with ongoing oscillations and may show lasting changes to oscillation dynamics (Reato et al. , 2013, Reato et al. , 2015). Such modulation may reflect interference with the finely tuned excitatory-inhibitory synaptic balance during oscillations (Reato et al. , 2010).

Aside from these possible synaptic plasticity effects, there may be non-synaptic origins of lasting plastic changes following DCS. Though the synapse is typically considered the locus of plastic changes, nonsynaptic changes have been noted after DCS to peripheral axons, which are presumably away from any synapse. In this case, cathodal stimulation inducing potentiation which is consistent with cathodal stimulation induced preferential depolarization in long axons (Ardolino et al. , 2005). Clinically, the question of synaptic vs. non-synaptic origin of tDCS modulation in the CNS has been explored by comparing modulation of TMS and TES evoked potentials induced by tDCS (Ardolino et al. , 2005). In 
clinical neurophysiology, TMS and TES can evoke responses of variable origin, and it is not possible to remove the role of ongoing background synaptic activity. In brain slice models, where background activity is absent, synaptic (orthodromic) and non-synaptic (axon, antidromic) activity can be properly controlled, allowing a more precise isolation of synaptic and non-synaptic mechanisms. As far as functional outcomes, any changes in the CNS from a non-synaptic origin would be expected to affect synaptic processing (Mozzachiodi et al. , 2010).

Considering the complexity of various possible tDCS plasticity mechanism, the need for animal models is evident. Animal models allow for synaptic efficacy to be probed quantitatively with pathway specificity. The mechanisms of plasticity can be analyzed using specific pharmacology and detailed cellular and molecular analysis (Islam et al. , 1995a, Yoon et al. , 2012) not possible in human experiments. Though only viable for a period of hours, brain slices further facilitate imaging, precise drug concentration control, control of the background level and nature of ongoing activity (from quiescent to transient activation at specific frequencies, to oscillations, to epileptiform activity), and the control of electric field orientation relative to slice, which is especially relevant for tDCS (Figure 5). Given the specificity needed to evaluate synaptic plasticity from DCS, a simplistic "sliding scale" explanation of anodal/cathodal tDCS increasing/decreasing "excitability" seems unlikely to capture the nuance of brain function. Animal models should help advance a more thorough understanding of tDCS effects, including consideration for state dependent changes as well as changes in information processing that are not simply explained by "less" or "more" activity.

\subsection{Relation with Tetanic Stimulation induced LTP/LTD}

Animal studies using tetanic stimulation to induce LTP/LTD have suggested multiple forms of plasticity involving distinct pre- and post-synaptic mechanisms on distinct time scales. While thousands of studies on tetanic LTP have been completed, less than 50 of those animal studies involve DC induced plasticity. Despite recent progress, there is much to investigate about plasticity induced by weak DCS. It is remarkable that a decade before the lauded discovery of LTP by trains of suprathreshold pulses by Bliss and Lomo (Bliss et al. , 1973), animal studies had shown lasting changes in excitability following DCS which persisted for multiple hours (Bindman et al. , 1962). Moreover, the field had already begun to address the underlying molecular mechanisms (Gartside, 1968a, b) and translating results to humans!

LTP/LTD induced by either tetanic stimulation or DC may, unsurprisingly, share some common molecular substrates (Gartside, 1968b, Islam et al. , 1995b, Ranieri et al. , 2012, Rohan et al. , 2015). Common forms of LTP/LTD are mediated by the NMDA receptor (Malenka et al. , 2004), which has been implicated in lasting tDCS effects in both humans (Nitsche et al. , 2003a) and rodents in vivo (Rohan et al. , 2015), and in vitro DCS-induced plasticity (Fritsch et al. , 2010). Similarly, the BDNF/TrKB pathway can be a potent modulator of these common forms of LTP/LTD (Lu, 2003), and this pathway has also been implicated in lasting tDCS effects in both humans and in vitro (Fritsch et al. , 2010, Ranieri et al. , 2012).

Earlier work looked at the accumulation of possible molecular targets using stimulated brain tissue, and found DCS affects cyclic adenosine monophosphate (cAMP), the protein kinase C family (PKC), and calcium, each of which play a role in LTP/LTD (Islam et al. , 1994, Islam et al. , 1995a). Building on this, more recent in vivo animal work has shown lasting tDCS effects are diminished by blocking the adenosine A1 receptor (Marquez-Ruiz et al. , 2012). Another recent model using rodents studied anodal tDCS in vivo by evaluating synaptic effects ex vivo, showing enhanced NMDA receptor activation dependent LTP after a single 30 minute anodal tDCS session, remarkably persisting for at least 24 hours. They also showed anodal DCS enhanced the paired pulse facilitation (PPF) ratio independent of NMDAR activation, suggesting effects of tDCS on LTP may have presynaptic origins (Rohan et al., 2015). 
While evidence is accumulating that DCS-induced plasticity shares molecular mechanisms with classic LTP/LTD, the manner in which the primary, polarizing effect of tDCS interacts with this molecular mechanism remains an important area of research. The wealth of techniques and tools developed by tetanic stimulation LTP research have yet to be fully leveraged to dissect the mechanisms of tDCS, and in the context of translational importance, it is interesting that protocols using tetanic stimulation in animals have influenced the design of TMS protocols (LTP/LTD, theta-burst, etc.).

\subsection{Compartments influenced by DCS - Soma and Dendrites}

We assume the influence of DCS begins with membrane polarization, and all other changes are secondary to membrane polarization. DC polarization will influence all neurons in areas of the brain receiving current, with equal regions of neural membrane depolarization and hyperpolarization. Our research is thus focused on the various effects resulting from membrane polarization in each neural region (e.g. soma, dendrite, axon process, axon terminal), as well as whether the somatic doctrine or a different neural region can be used to predict changes in plasticity.

Several animal and clinical studies have speculated that processes linked to the dendrites are responsible for driving the lasting effects of tDCS (e.g. glutamatergic receptors such as the n-methyl-D-aspartic receptor, NMDAR) (Liebetanz et al. , 2002, Nitsche et al. , 2003a, Yoon et al. , 2012). A key question is: as half the dendrite will be polarized in the same direction at the soma and half of the dendrite will be polarized in the opposite direction (Figure 4), how do polarity specific changes arise? Are changes in synaptic processing/plasticity always consistent with the somatic doctrine?

Early animal work probing evoked responses in indicated modulation in excitability, with the direction of evoked response change consistent with the somatic doctrine (Creutzfeldt et al. , 1962, Bindman et al. , 1964), though deviations had already been reported (Bishop et al. , 1950). Recent studies aimed at developing and validating animal models of transcranial electrical stimulation have shown modulation of TMS evoked potentials and visual evoked potentials consistent with the somatic doctrine (Cambiaghi et al. , 2010, Cambiaghi et al. , 2011). In a pioneering work using uniform electric fields in brain slices, Jefferys showed acute modulation of excitability (synaptically driven population spikes) in the dentate gyrus of hippocampal slices when electric fields were parallel to the primary target cell dendritic axis. The detected polarity specific changes were consistent with somatic polarization, and no modulation was seen when the electric field was applied orthogonal to the primary dendritic axis (Jefferys, 1981).

The precise control of the electric field angle is possible in brain slices and was leveraged in subsequent work. For instance, we used the hippocampal slice preparation to confirm the validity of the somatic doctrine in predicting acute changes in excitability, which was initially conceived as a series of straightforward experiments - to our surprise we found several deviations (Bikson et al., 2004). Optical imaging with voltage sensitive dyes provided evidence that DC electric fields always produce bimodal polarization across target neurons such that somatic depolarization is associated with apical dendrite hyperpolarization, and vice-versa, yet over longer timescales, interactions across compartments were observed. In addition, for synaptic inputs to the apical dendritic tuft, we reported modulation inconsistent with the somatic doctrine. Also in hippocampal slices, Kabakov reported modulation of synaptic efficacy in a direction opposite than expected by the somatic doctrine, noting the inversion of dendrite morphology in CA1 pyramids relative to cortex (Kabakov et al. , 2012). In this case, one may speculate apical dendrite depolarization determines the direction of modulation despite somatic hyperpolarization (Bikson et al. , 2004); though Kabakov provides evidence suggesting dendritic polarization affects the magnitude but not direction of modulation (Kabakov et al. , 2012). In cortical slices, modulation of evoked responses is indeed consistent with the somatic doctrine (Fritsch et al. , 2010), which has been confirmed in four distinct 
afferent cortical synaptic pathways (Rahman et al. , 2013). These variations across animal studies could be simply ascribed to differences in region/preparation, timescale (acute, long-term), and different forms of plasticity (BDNF dependent/independent), but this is speculative and provides little insight into tDCS. Rather, in attempt to reconcile these findings in a single framework, we site evidence for and define the "terminal doctrine" to compliment the somatic doctrine.

\subsection{Compartments influenced by DCS - Synaptic Terminals}

We also investigated the effects of tangential fields on synaptic efficacy (Bikson et al. , 2004). Tangential fields are expected to produce little polarization because of their perpendicular orientation to the primary somatodendritic axis, which we have directly confirmed with intracellular recording (Bikson et al. , 2004). Surprisingly, electric fields applied tangentially were as effective at modulating synaptic efficacy as radially directed fields. The afferent axons run tangentially, so we speculated they might be the targets of stimulation. After exploring different pathways, we found axon pathways with synaptic terminals pointed toward the anode were potentiated, while axon pathways with terminals pointed toward the cathode were inhibited. Kabakov (2012) reported similar pathway specific dependence summarizing, "the fEPSP is maximally suppressed when the AP travels toward the cathode, and either facilitated or remains unchanged when the excitatory signal [AP] propagates toward the anode." In addition, they observed changes in paired pulse facilitation (PPF) that was consistent with presynaptic vesicular glutamate release (Kabakov et al. , 2012). We recently confirmed a similar directional sensitivity in cortical slices across four distinct pathways (Figure 5) where an electric field applied tangentially to the surface (producing minimal somatic polarization) modulated synaptic efficacy (Radman et al. , 2009, Rahman et al. , 2013). Interestingly, an in vivo study suggested axonal and dendritic regrowth occurs with tDCS mediated neuroplasticity after cerebral ischemia (Yoon et al. , 2012) (Section 3.5) .

A role for presynaptic modulation during DCS is not surprising and has been historically observed. Purpura and McMurtry (1965) noted "although the [somatic] membrane changes produced by transcortical polarization current satisfactorily explains alterations in spontaneous discharges and evoked synaptic activities in [pyramidal tract] cell, it must be emphasized that the effects of polarizing current on other elements constituting the 'presynaptic,' interneuronal pathway to [pyramidal tract] cells also appear to be determinants of the overt changes observed in [pyramidal tract] cells activities." (Purpura et al. , 1965b) Bishop and O'Leary (1950) quantified presynaptic effects in animals during DCS, also noting presynaptic effects would complicate the interpretation of postsynaptic changes as well as themselves induce long lasting aftereffects (Bishop et al. , 1950).

It is well established that cellular process terminals, including axon terminals, are especially sensitive to electric fields as a result of their morphology, and terminal polarization can modulate synaptic efficacy independent from somatic polarization (del Castillo et al. , 1954, Bullock et al. , 1956, Hubbard et al. , 1962a, b, Takeuchi et al. , 1962, Awatramani et al. , 2005). Moreover, synaptic terminal modulation is cumulative over time, continues after stimulation (Hubbard et al. , 1962b), has a temporal profile noted in classic DC experiments (Bindman et al. , 1964), and suggests the possibility for plasticity. The direction of modulation in brain slice studies consistently suggests terminal hyperpolarization enhances efficacy while depolarization inhibits efficacy. Paired pulse analysis in both a rabbit and rodent model suggests tDCS influences presynaptic sites (Marquez-Ruiz et al. , 2012, Rohan et al. , 2015). Because tDCS induces significant tangential fields (Figure 5), the effect of terminal polarization independent from the somatic doctrine remains a compelling and open question, especially when considered with the need for amplification and the general role of synapses in plasticity.

The proposal of a somatic doctrine versus terminal doctrine can be conceptualized as generically analogous to the pre/postsynaptic debate in tetanic stimulation induced LTP/LTD (Artola et al. , 1990), and as with 
tetanic stimulation induced LTP/LTD, both mechanisms are likely to play a role. Current crossing the grey matter is rarely a pure radial or tangential current, such that simultaneous somatic and terminal polarization is broadly expected (Rahman et al. , 2013). Even in the brain slice, afferent axons and the target neurons are not perfectly orthogonal, which may explain some of the divergent findings in hippocampal brain slices discussed above. Because of the complexity of current flow across the grey matter (Figure 2), quantifying the effects of tDCS becomes more difficult, especially considering the terminal doctrine predicts either excitation or inhibition depending on the direction of incoming axons. Perhaps careful consideration of brain current patterns combined with extending the simple somatic doctrine to include the roles of dendrites, axons, and axons terminals can reconcile clinical findings showing an inversion of classical direction effects (Nitsche et al. , 2000, Ardolino et al. , 2005) or direction neutral effects (Nitsche et al. , 2003b). We emphasize that given the complexity of plasticity paradigms and stimulation targets, possibly leading to multiple forms of tDCS plasticity, translational animal studies are critical alongside clinical neurophysiology to further understand tDCS and ultimately better inform rational electrotherapy. Moreover, meaningful clinical outcomes rely on specific and increasingly long lasting changes; the basis of which can be studied in animals.

\subsection{Morphological Changes - Axonal Growth and Guidance}

Electric fields are known to play a role in controlling developmental and regenerative aspects of the nervous system (McCaig et al. , 2005). Several studies have shown endogenous electric fields within growing and recovering tissue. Here, we will review the effect of DCS on axonal growth in vivo and in vitro, with special attention to dose response as these studies often applied fields at higher current intensities and longer durations than used for clinical tDCS (McCaig et al. , 1991). The study of electric fields and cellular galvanotropism, induction of neuronal growth by an electrical stimulus, has been linked to development, membrane protein redistribution, cell proliferation, and recovery from injury (McCaig et al. , 2005), but we will focus on the role of galvanotropism at tDCS relevant electric field intensities and durations (Ingvar, 1920).

The first quantitative study in vitro was done in 1946 by Marsh and Beams, who exposed medullary explants from chick embryos to an electric field of $\sim 60 \mathrm{~V} / \mathrm{m}$. They showed neural processes grow preferentially towards the cathode, and their development is suppressed towards the anode (Marsh et al. , 1946). Growth direction is not the only factor affected by an electric field, as Jaffe and Poo demonstrated that neurites grow about three times faster towards the cathode at $70 \mathrm{~V} / \mathrm{m}$ (Jaffe et al. , 1979). The lowest reported values to induce galvanotropism in locally induced electric field values are $3 \mathrm{~V} / \mathrm{m}$ applied for 20 minutes (Patel et al. , 1984). For uniform electric fields, values range from $7 \mathrm{~V} / \mathrm{m}$ applied during 16-20 hours (Hinkle et al. , 1981) to 10-50 V/m applied for 24 hours (Patel et al. , 1982). The average neurite growth induced by DC electric fields is $0.4 \mu \mathrm{m}$ per V/m per minute for local fields, and $0.12 \mathrm{~nm}$ per V/m per minute for uniform fields (Patel et al. , 1982).

One possible underlying mechanism is the number of cytoplasmatic projections that guide axonal growth (filopodia). In 1986, McCaig measured that the number of filopodia growing towards the cathode is double the number growing towards the anode (McCaig, 1986). This factor may contribute to an augmentation of the development towards the cathode but is not a necessary mechanism, since without filopodia there is still galvanotropic behavior. Another possible mechanism could rely on electric field-induced receptor migration (McCaig, 1986, Stollberg et al. , 1988, 1990b). Acetylcholine (Ach) receptors present in the axon's terminal can increase the intracellular calcium concentration via second messenger pathways, therefore interacting with the growth of neural processes. In a set of studies, Stollberg and Fraser applied a $400 \mathrm{~V} / \mathrm{m}$ DC electric field to Xenopus muscle cells for 20-40 min, and Ach receptors clustered towards both the anode and the cathode during stimulation. Afterward, Ach receptors continued to accumulate towards the cathodal side (Stollberg et al. , 1988, 1990b). Receptor clustering after application of electric 
fields may be caused by electromigration of the Ach receptors, which is a slow and linear process (Stollberg et al. , 1990a). The last mechanism proposed to contribute to axonal growth is the direct activation of calcium current via an electric field. Applying an electric field has been shown to induce a compartment specific polarization in a neuron (Chan et al. , 1988). Under certain electrode placement configurations, the electric field depolarizes cathodal facing membranes and hyperpolarizes anodal facing membranes. This profile of polarization could differentially activate voltage sensitive calcium channels interacting with the growth cone of the axons (Cooper et al. , 1986).

The effects of extracellular fields on nerve migration have been extensively characterized in vivo. In 1984, Pomeranz et al. applied $1 \mu \mathrm{A}$ of current for 3 weeks to a sprouting rat nerve (Pomeranz et al. , 1984). Hind paw sensitivity was assessed before and after applying the electric field, and they found an increase in responsiveness only when the cathode was placed in the direction of growth of the sprouting nerve (anodal stimulation). Physiological correlates were also measured through histological studies, showing an elevated number of neural fibers for anodal stimulation. In 1987, McDevitt et al. were the first to describe neural regrowth in mammals. They did a cut-suture intervention of the sciatic nerve and applied 30 minute currents that generated fields of approximately $10 \mathrm{~V} / \mathrm{m}$ for 20 days. Electromyographic (EMG) activity was present in $67 \%$ of the animals that received stimulation with growth directed toward the cathode, but only in $17 \%$ with the reversed polarity (McDevitt et al. , 1987). Supporting evidence for an increase in neurofilament growth towards the cathode in damaged sciatic nerves has been shown (Politis et al. , 1988), as well as for morphological regeneration after nerve transection (Roman et al. , 1987). In addition, functional recovery of neurons has been assessed by applying an electric field and measuring various parameters of the rat's gait (Beveridge et al. , 1988). There is still more work to be done assessing functional and physiological correlates simultaneously.

In summary, extracellularly applied electric fields induce an asymmetrical rate of growth towards the cathode in neurites. Historically, the assessment of this differential growth has been studied in the context of development and recovery from injury. Interestingly, endogenous injury potentials, which are presumed to have a functional role, are over an order of magnitude above tDCS electric fields ( $\sim 10 \mathrm{~V} / \mathrm{m}$ compared to $<1 \mathrm{~V} / \mathrm{m}$ ). Given studies on galvanotropism use DCS at higher magnitudes (typically $\sim 100 \mathrm{~V} / \mathrm{m}$ ) and for longer durations (Palmer et al. , 2000), effects at a tDCS relevant dose might initially be dismissed. However, assuming a linear dose response for uniformly applied electric fields (e.g. $0.12 \mathrm{~nm}$ per V/m minute) and considering the scale of individual synaptic/dendritic spines, it is possible that even small morphological modifications have an important role in plastic changes underlying lasting effects induced by tDCS. Indeed, to produce lasting effects from tDCS requires long duration stimulations and may be a reflection of cumulative galvanotropism. For example, $2 \mathrm{~mA}$ tDCS would result in local electric fields of $1 \mathrm{~V} / \mathrm{m}$, which could displace a neuronal process by $2.4 \mathrm{~nm}$ over the course of 20 minutes. Thus, morphological reorientation of axon terminals and dendritic spines at synapses during tDCS may be more significant than the growth of axons over long distances. To distinguish this local synaptic cleft phenomenon from conventional long range axon guidance, we will call the former "nano-galvanotropis". These findings reinforce our overall methodological theme that the relevance of animal studies to tDCS relies on both dose response (e.g. change per $\mathrm{V} / \mathrm{m}$ ) and outcome measures (e.g. plasticity vs. migration).

\section{Network Effects}

The consideration of how weak DC electric fields interact with active neuronal networks (e.g. oscillations) is a compelling area of ongoing research. Just as networks of coupled, active neurons exhibit network activity not seen in isolated neurons, the application of electrical stimulation to active networks often 
produce responses not expected by single neurons. These responses are specific to the network's architecture and level of activity. Neuronal networks also provide a mechanism for amplification beyond the cell/synapse level. While recent clinical work on tDCS has addressed the modulation of EEG oscillations, reports that DCS can alter spontaneous rhythms in an animal spans decades (Dubner et al. , 1939, Antal et al. , 2004, Marshall et al. , 2011). New animal studies on DCS addressing the mechanism of this coupling are reviewed in this section, focusing on acute DCS effects.

\subsection{Further Amplification through Active Networks}

We have considered the concept of amplification through network effects previously: "In principle, the initial action of DCS remains to polarize all neurons subjected to the electric field. Note that tDCS generates electric fields across large areas of cortex. In networks, a key concept is that the entire population of coupled neurons is polarized- this coherent polarization of the population provides a substrate for signal detection and for amplification. Interestingly, the effective coupling constant for a neuron immersed in an active network may be enhanced compared to that neuron in isolation (Reato et al. ,2010) - meaning that by virtue of being in a network, a given compartment (soma) may be polarized directly by the field and indirectly by field actions on a collective of afferent neurons."

"As noted above, the concept that the threshold for electric field sensitivity would be 'lower for modulation of the frequency of an already active neuron than for excitation of a silent one' (Terzuolo et al. , 1956) is well established, but network activity adds another dimension to this. During many network activities, notably oscillations, neurons are near threshold and thus primed for firing. If a neuron is near threshold by virtue of network drive, then a small polarization may be influential in modulating the likelihood of firing. For example, a relatively small depolarization may be sufficient to trigger an action potential. Moreover, because the network is interconnected, activated neurons could synaptically trigger action potentials in other neurons. The whole process can be feed-forward such that a small DC electric field can induce a robust action potential discharge in a population. This has been shown in brain slice (Reato et al. , 2010). This concept is interesting because it blurs the distinction between 'supra-threshold' stimulation, such as TMS, and 'sub-threshold' stimulation, as tDCS is commonly considered." (Bikson et al. , 2012)

\subsection{Oscillations}

A majority of work on weak DC electric fields and network activity in slice has addressed epileptiform activity to investigate seizure control methods. These reports generally observed a change in the likelihood of epileptiform discharge rather than a change to seizure waveforms after the onset of a seizure. This finding is consistent with the concept that weak fields polarize neurons (Bikson et al. , 1999, Bikson et al. , 2004), and weak stimulation is more likely to influence stochastic initial recruitment of neurons in the robust regenerative epileptiform event. DC electric fields may also influence the propagation rate (Francis et al. , 2003, Varga et al. , 2011). Reato et al. (2010) considered the effects of DC electric fields on gamma oscillations in brain slice and reported both transient effects when the electric field was turned on and secondary sustained effects, which are more relevant to tDCS (Reato et al. , 2010) (Figure 6). Sustained effects were characterized by a dramatic compensatory, homeostatic regulation of the network such that the system tried to normalize activity to baseline levels despite the presence of the DC electric field. This network adaptation was apparent when the DC electric field was turned off, as the network was delayed in readjusting to the absence of the field. In this way, excitatory (somatic depolarizing) fields produced post stimulation suppression of oscillations, and vice-versa. Network level mechanisms, as opposed to single neuron behavior, may thus provide a mechanism for activity dependent homeostatic-like observations during tDCS (Cosentino et al. , 2012).

Weak stimulation of 'physiological' activity with AC or pulsed stimulation is more common (Deans et al. , 2007, Frohlich et al. , 2010). Though Reato proposed that the effects of ACS at different frequencies and 
DC could be explained in a single continuous framework (Reato et al. , 2010), it is important to distinguish between studies exploring the limits of network sensitivity to weak AC or pulse fields and prolonged DC (tDCS). It has been well established that when a network is generating spontaneous oscillations of epileptiform activity, an electrical pulse can trigger a regenerative network event. Moreover, repetitive weak pulses or ACS can entrain activity by aligning the phase of these events with that of the repetitive stimulation. By definition, there is no basis for entrainment during prolonged DCS as there is no phase to the DC, suggesting tDCS can affect the average discharge rate or waveform but not the phase of the oscillation. Thus, though entrainment is central in AC/pulsed stimulation studies in animals as well as clinically (Marshall et al. , 2006), its relevance to tDCS is limited.

\section{[FIGURE 6]}

\section{Interneurons and Non-Neuronal Effects}

The role of interneurons and non-neuronal cells, such as glial and endothelial cells, during tDCS remains both an open and critical question. To address their role to tDCS, we distinguish between: 1) primary stimulation effects, reflecting direct membrane polarization and modulation of these cell types by DC electric fields; 2) secondary stimulation effects, reflecting secondary functional changes resulting from direct excitatory neuronal activation that then influence interneurons and other non-neuronal cell types; and 3) modulatory effects, where interneurons and non-neuronal cells alter the sensitivity of neurons to direct effects (e.g. their excitability). The functions of interneurons and non-neuronal cell types are intricately wound together with excitatory neurons that the second and third aspects are presumed (though complex), and we focus mostly on direct stimulation effects.

\subsection{Interneurons}

Because of their relatively symmetric dendritic morphology, interneuron somas are expected to polarize less than pyramidal neurons (Radman et al. , 2009), and based on the somatic doctrine, the importance of an interneuron might then be overlooked. However, we cannot exclude the polarizing effects of electric fields on dendrites and axons. Moreover, interneurons represent a wide range of morphologies and sizes, including more asymmetric morphologies (Freund et al. , 1996). Interneurons exert a powerful regional effect, including playing a role in plasticity and oscillations (Kepecs et al. ,2014). An effect of tDCS on PPF in hippocampal slices may also suggest tDCS can modulate the activity of interneurons (Kabakov et al. , 2012), but the primary role of interneurons during tDCS remains an open question.

\subsection{Glial Cells}

There are three glial cell types, each of which has a different morphology and function in the brain: astrocytes, microglia, and oligodendrocytes. Glial cells represent the majority of cells in the CNS, and the concept of glial cells as merely passive, support cells is outdated as their complex role in neuronal functions are being discovered (Di Castro et al. , 2011).

Relatively recent studies have shown astrocytes can communicate with neurons through calcium oscillations (Pasti et al. , 1997), and they have distributed processes that can influence their sensitivity to applied electric fields (Ruohonen et al. , 2012). An interesting notion is that the glial syncytium, a population of either solely astrocytes or a combination of astrocytes and oligodendrocytes electrically coupled via gap junctions, might act to amplify electric field polarization (He et al. , 2008). Just as a single neuron experiences a biphasic polarization in response to DCS, the glial syncytium may also experience a net biphasic polarization. 
Potassium spatial buffering is another possible mechanism for DC modulation of astrocytes. Astrocytes are thought to regulate excess extracellular potassium and sodium concentrations through a polarization imbalance across their membrane. This imbalance causes both AP propagation and subsequent compensatory release of intracellular potassium into the local environment (Nagy et al. , 2003). The biphasic polarization induced by DC electric fields is expected to drive potassium spatial buffering across the astrocyte or glial syncytium ends. While the best method for exploring possible effects of electric fields on potassium spatial buffering remains unclear, Gardner-Medwin was able to induce extracellular potassium transport with DCS, noting concentration changes near the electrodes that are mechanistically distinct from tissue changes (Gardner-Medwin, 1983). Brain slice studies show no extracellular potassium concentration changes under DC electric fields (Lian et al. , 2003), though the brain slice preparation has been shown to distort extracellular concentration control mechanisms (An et al. , 2008).

Evidence on the effects of tDCS in microglia is beginning to emerge. In general, microglia shift between two morphological/functional states: resting and active. In their resting state, microglia are small, radial cells with processes extending away from their soma, probing the surrounding environment for abnormal and/or nonfunctioning cells. When microglia shift to their activated state, they transform into a larger, rounded cell, and respond to remove debris or unwanted cells, similar to the response of a macrophage (Hanisch et al. , 2007).

Several studies have recorded microglial responses to tDCS on rodents in vivo by staining for ionized calcium binding adaptor molecule 1 (Iba1), which is present in both active and resting microglia. One rodent study showed both anodal and cathodal tDCS increases the density of microglia within the stimulated brain region, which would suggest microglia shift toward their active state during tDCS (Rueger et al. , 2012). However, Iba1 does not distinguish between active and resting microglial states, and the tDCS dosage used ( $0.5 \mathrm{~mA}$ for 15 minutes) has been shown to induce brain lesion in previous studies (Liebetanz et al. , 2009). Whether microglia density changed in this study as a primary response to tDCS or as a secondary response to damaged neuronal tissue is unclear, but this study is nonetheless an important step for understanding the effects of tDCS in microglia at near lesion thresholds (possibly suggesting microglia may be a more sensitive safety measure compared to lesion measurement). Another study on microglial activation also used both anodal and cathodal tDCS on mice at $0.1 \mathrm{~mA}$ and found microglial processes associated with their resting state are shorter when observed immediately after tDCS but normal when observed three hours post tDCS (Monai et al. , 2015). Both of these studies suggest tDCS directly, and possibly indirectly via damaging currents, shift microglia to their more active state, but more work is needed to fully understand tDCS-induced microglial shifts.

Much less information about tDCS and its effect on oligodendrocytes is known. However, one in vivo rodent ACS study found oligodendrocyte-specific progenitor cells increased in the pyramidal tract after multiple days of stimulation ( $\mathrm{Li}$ et al. , 2010), potentially warranting exploration of tDCS effects on oligodendrocyte production.

Neurons and glia can be cultured separately, but morphology and biophysics become altered in culture. In general, there are no drugs for altering glial function, and regardless, any changes in glial function would influence neurons, making direct responses to DC electric fields in vitro difficult to measure. Still, given the growing interest in the role of glial cells on CNS function and the increased sophistication of experimental techniques, the effects of tDCS in glial cells is a worthwhile area of investigation (Ruohonen et al. , 2012). 


\subsection{Endothelial Cells}

Endothelial cells form the blood-brain barrier that tightly regulates transport between the brain extracellular space and blood, and any direct action of DCS on endothelial cells could have profound effects on brain function. Endothelial cells have a spherical shape, indicating their peak polarization will be related to cell diameter (Kotnik et al. , 2000). Membrane polarization is expected to be well below the threshold for electroporation during tDCS, but the direct effect of tDCS to vascular response is an open and compelling question. There is abundant evidence that DC affects vascular function in the skin (Ledger, 1992, Prausnitz, 1996, Berliner, 1997, Malty et al. , 2007), and skin redness is typical under tDCS electrodes (Minhas et al. , 2010). The use of saline (or gel) at the electrode (Minhas et al. , 2010) protects the skin from electrochemical byproducts but these products cannot reach the brain and are not considered a tDCS mechanisms. Vascular and neuronal functions in the brain are closely interrelated, as evidenced by functional Magnetic Resonance Imaging (fMRI). Their relationship is also complex, and it can be difficult to distinguish between direct neuronal and direct vascular effects (Takano et al. , 2011), including during tDCS.

Wachter found a polarity specific change in blood perfusion of a rat during tDCS in a direction consistent with the somatic doctrine, and speculated the direction specificity was consistent with a primary neuronal action (Wachter et al. , 2011). In this sense, the use of brain slices to study DCS is compelling since acute (Bikson et al. , 2004) and lasting synaptic efficacy (Fritsch et al. , 2010) changes can exclude an endothelial and/or vascular contribution. Conversely, endothelial culture models of the blood-brain barrier can be electrically stimulated to access direct effects through changes in neuronal function. We showed that high intensity, electrical stimulation could increase transport across such a model through a phenomenon we termed "electro-permeation" between cells to distinguish it from electroporation of single cells (LopezQuintero et al. ,2010). Investigation of DCS on this model is ongoing.

\section{Applications of DCS to Animal Models of Clinical Pathologies}

\subsection{Pain}

tDCS has shown promising results for treating pain symptoms in humans, and studies using animal models of pain have also provided reason for optimism. Pain symptoms are mainly determined by alterations in excitability and connectivity of pain related neural networks (Knotkova et al. , 2010, Knotkova et al. , 2013) and increased expression of some pro inflammatory cytokines in the brain vascular system (Spezia Adachi et al. , 2012). Recent studies (Laste et al. , 2012, Spezia Adachi et al. , 2012) have shown applying anodal tDCS on rats after they had been under chronic restraint stress could bring their pain threshold back to baseline values. Another study done by Nekhendzy et al (Nekhendzy et al. , 2004) applied DC pulses at different frequencies in a rat model and noted increased pain threshold in rats. In accordance with the findings by Spezia-Adachi et al, they also find an increase in pain threshold (Laste et al. , 2012). However, these results are difficult to interpret due to the stimulation protocol used, making them less translatable to clinical research.

\subsection{Parkinson's Disease}

Few studies have evaluated the effects of tDCS on animal models of Parkinson's Disease (PD). Studies on PD use animal models more commonly because more invasive techniques can be used to monitor the production and extracellular concentrations of the neurotransmitter dopamine. Tanaka et al. (2013) used an in vivo intracranial microdialysis system to show cathodal tDCS can lead to prolonged increases in extracellular dopamine concentrations in the rat striatum (Tanaka et al. , 2013). A behavioral study showed anodal tDCS can improve behavioral symptoms of PD using an in vivo rat model ( $\mathrm{Li}$ et al. , 2011). The discrepancies between these studies, particularly in the effects seen using different polarities, can likely be attributed to the different experimental conditions, as tDCS outcomes depend heavily on dose design 
(electrode position, waveform, see above). However, these opposing results should motivate more detailed animal studies on PD, such as combining neurotransmitter quantification with behavioral analysis, to help provide a stronger connection between behavioral outcomes and associated physiological changes from tDCS. PD and other neurological disorders that depend heavily on abnormalities of extracellular neurotransmitter concentrations would benefit greatly from such studies.

\subsection{Stroke}

The possible benefits of using tDCS for reducing stroke symptoms and improving prognosis using in vivo stroke animal models has gained attention in recent years. Decreases in infarct volume have been shown when administering cathodal tDCS within 45 minutes of inducing ischemia (Notturno et al. , 2014), while improvement in behavioral tests have been shown with administration of anodal tDCS within 1 week after the ischemic event. In the latter study, anodal tDCS was administered for five days starting either one day or one week after the ischemic event, and while both groups consistently outperformed the sham group, the group receiving stimulation one week after ischemia outperformed the group receiving stimulation just one day after the initial onset of stroke on some of the behavioral tests (Yoon et al. , 2012). The potential impact of tDCS as both a preventative and rehabilitative tool is exciting and warrants further study. While the impact of tDCS for improving stroke outcomes is just beginning, these recent studies provide promising evidence for tDCS as a viable clinical treatment.

\subsection{Epilepsy}

This section addresses the use of animal models of epilepsy rather than safety against de novo epilepsy generation (Section 7.2). Attempts to treat epilepsy with tDCS have traditionally assumed cathodal stimulation decreases cortical excitability and therefore epileptic activity, and animal studies seem to further support this notion. Liebetanz et al. (2006) showed in an in vivo rat model that cathodal tDCS led to prolonged elevation of the threshold for localized seizure activity induced by a bipolar stimulating electrode, in both a current and time dependent manner (Liebetanz et al. , 2006b). Kamida et al. (2011) then used the same dose design as Liebetanz in two weeks of daily sessions of cathodal tDCS on a lithiumpilocarpine-induced status epilepticus (SE) rat model. They found that cathodal tDCS had significant behavioral and physiological improvements for two weeks after the stimulation period had ended. Behaviorally, the SE rats receiving cathodal tDCS saw a significant reduction in the number of convulsions and improved performance in the Morris water maze. They were further able to use histology to show cathodal tDCS can reduce SE-induced hippocampal cell loss, and promoted supragranular and CA3 cell sprouting, providing evidence for the physiological changes that underlie the behavioral outcomes (Kamida et al. , 2011). In a later study Kamida used a different epilepsy model with amygdala-kindled rats to show cathodal tDCS can lead to decreased seizure severity and improved Morris water maze performance for days after stimulation with amygdala-kindled rats (Kamida et al. , 2013).

Zobeiri et al. (2013) used a rat model with genetic absence epilepsy that displayed spike and slow wave discharges (SWDs) (Zobeiri et al. , 2013). Using EEG concurrently with tDCS they showed cathodal tDCS led to fewer SWDs during stimulation, and SWDs of shorter duration once the stimulation had ended (both results were intensity dependent). Dhamne and colleagues showed in a rat pentylenetetrazol (PTZ) SE model that $1 \mathrm{~mA}$ cathodal DCS reduced spike bursts, and suppressed clinical seizures, and was more effective in seizure suppression when used in combination with lorazepam (LZP), improving clinical seizure outcomes compared to either DCS or LZP alone (Dhamne et al. , 2015). While these studies use different models of epileptic activity, they converge on finding that cathodal tDCS reduces epileptic activity. Future studies should build on these animal models to examine how cathodal tDCS may be acting in this capacity. 


\subsection{Animal Models of Psychiatric Disorders}

It should be emphasized that there are limitations to some animal models of psychiatric disorders. In some cases, sufficient models either do not exist or traditional models have been criticized (Kekic et al. , 2016), and measuring the presence of a psychiatric disorder analogous to human disorders (e.g. depression, anxiety) through the animals' behavior can be difficult considering similar behaviors can manifest in humans with different psychiatric issues. Psychiatric research in animals is further complicated by issues surrounding interpretation of an animals' behavior as well as an overall inability to determine an animals' feelings, such as suicidal thoughts (Donaldson et al. , 2015). There have been past failures of promising therapeutic interventions which did not translate from animal models to humans, most notably for drug development, which has relied heavily on animal models for intervention development. tDCS has shown positive results for some psychiatric disorders (Loo et al. , 2012, Oliveira et al. , 2013, Pedron et al. , 2014); however, given the inconsistencies related to psychiatric disorders in general, relating results from tDCS animal studies to clinical treatment should be drawn with caution.

\section{Insights on tDCS Safety from Animal Models}

\subsection{Safety Limits for Tissue Injury}

Data for a tDCS lesion threshold in animal models have been used to support the significant safety factor between maximum tDCS and brain damage (Bikson et al. , 2009, Liebetanz et al. , 2009). As the use of tDCS increases, this data warrants updating. Modeling DC predictions across animal and human are specific to the electric field produced in the brain, so data from animal models are solely based on analysis of brain lesion in this section. In addition, our analyses in this section do not consider polarity (anode, cathode) or direction (radial, tangential), instead focusing only on current intensity or electric field magnitude.

Issues that arise from basing human safety standards on histological lesion thresholds from animals have been previously outlined, and include: 1) possible differences in susceptibility between rat and human tissue to damage from tDCS; 2) experimental limits for detecting various modes of damage, including dose response assumptions (Section 1.6); 3) anatomical differences when scaling rodent results from rat to human predictions; and 4) differences in method of stimulation (e.g. transdermal vs. epicranial) (Brunoni et al. , 2012). For all the limitations of basing human safety standards on rat histology, including lack of long term data and associated behavioral changes, this data nonetheless represents an outer safety limit which cannot be approached during clinical tDCS.

Tissue damage resulting from electrodes in direct contact with the brain or using AC waveforms (Agnew et al. , 1987) during animal studies are misleading for tDCS safety (Bikson et al. , 2009) and are not discussed in this review. However, results from three groups who tested safety thresholds for epicranial tDCS are consolidated: 1) Liebetanz and colleagues (Liebetanz et al. , 2009); 2); Fritsch and colleagues (in preparation); and 3) Jankord and colleagues (Jackson et al. , Anodal Limits of transcranial Direct Current Stimulation, 2016, under review). All studies applied tDCS on the surface of the rat skull using a relatively small electrode contact area relative to the return electrode positioned on the body. The lowest tDCS current intensity at which histological damage was recorded for each study was: 1) Liebetanz: $500 \mu \mathrm{A}$ applied through $2.1 \mathrm{~mm}$ diameter circular electrode $\left(3.5 \mathrm{~mm}^{2}\right.$ surface area) for 10 minutes, assessed by hematoxylin and eosin (H\&E) stain; 2) Fritsch: $600 \mu \mathrm{A}$ applied through $4 \mathrm{~mm}$ diameter circular electrode $\left(12.5 \mathrm{~mm}^{2}\right.$ surface area) for 20 minutes, assessed by FluoroJade C stain; and 3) Jankord: $500 \mu$ A applied through $5 \times 5 \mathrm{~mm}$ square electrode $\left(25 \mathrm{~mm}^{2}\right.$ surface area) for 60 minutes, assessed by H\&E stain and immunohistochemistry. 
To scale these results to human applications, we developed a high resolution, computational rat model to predict the current produced in the brain for each study. By comparing the resulting peak electric field in the brain per applied $\mathrm{mA}$ in the rat to the peak electric field produced in the brain per $\mathrm{mA}$ in the human, we propose a scaling factor, which allows us to predict how much current should be applied in the human using a common montage (M1-SO) to approximate the brain electric field produced in a rat for a given current. Applying this scaling factor to the damage threshold observed in each of these rodent studies allows us to predict a current intensity damage threshold in humans. The scaling factor determined was: 1) Liebetanz: 240;2) Fritsch: 288; and 3) Jankord: 134. Combining the reported current intensity thresholds for damage in animal models with the respective human: rat scaling factor results in a predicted human damage threshold of: 1) Liebetanz: $120 \mathrm{~mA}$; 2) Fritsch: $173 \mathrm{~mA}$; and 3) Jankord: $67 \mathrm{~mA}$. While these studies predict highly variable threshold values for inducing human lesions, they are still approximately two orders of magnitude above maximum currents intensities used during tDCS on humans.

While lesion threshold studies have provided valuable safety guidelines for in vivo animal studies, prelesion safety limits from tDCS have not been comprehensively evaluated. The use of biomarkers as signs of brain injury from tDCS could soon become a reliable method for detecting sublesion injuries in both clinical and in vivo animal tDCS. While no comprehensive study on genetic biomarkers has been carried out, the increase in immune and inflammatory biomarkers (e.g. microglia; section 5.2) at higher current intensities near lesion thresholds suggest sublesion predictors of brain injury may be possible (Pelletier et al. , 2015).

Kim et al. (Kim et al. , 2010) assessed whether DCS increases preexisting infarct volume in a rat stroke model. Their results showed no increase at the doses tested $\left(0.785 \mathrm{~cm}^{2}\right.$ epicranial electrode, $0.1 \mathrm{~mA}$ for 20 minutes), and even saw a potential neuroprotective effect.

\subsection{Safety Limits for Seizure Generation}

In repetitive Transcranial Magnetic Stimulation (rTMS), the generation of seizures remains the primary safety concern (Rossi et al. , 2009). Seizure generation is not a concern during tDCS because the electric fields produced by tDCS is static and typically two orders of magnitude below those of TMS (Datta et al. , 2009a, Deng et al. , 2013). As discussed above, in vitro studies have shown the threshold for modulating ongoing epileptiform activity is $\sim 1 \mathrm{~V} / \mathrm{m}$, consistent with a high sensitivity to excitability (Bikson et al. , 1999), which is an order of magnitude lower than intensity thresholds for generation of activity in quiescent brain slice (>80 V/m;). Since the brain is not quiescent, we further tested in vitro if a system in gamma oscillations would have reduced thresholds for electrographic seizure generation. While a moderate reduction in threshold was observed compared to a quiescent slice, the DCS intensity remains above those generated in conventional tDCS. In animal models, anodal DCS was found to reduce seizure thresholds while cathodal DCS did not modulate seizures threshold (Liebetanz et al. , 2006b), but the test paradigm targeted modulation rather than generation of epileptiform activity. Based on existing animal safety data, it may appear that the threshold for injury with DCS may occur before de novo seizure initiation, but more research is needed.

\section{Summary: 3 Tier Approach, beyond the Somatic Doctrine, Experimental Rigor and Dose Response}

Implicitly or explicitly, tDCS protocols in humans, whether directed toward clinical application, neurophysiology, or cognitive function, continue to be interpreted and designed following what we have termed the somatic doctrine of tDCS. Under the somatic doctrine, brain regions under the anode or cathode electrode are assumed to increase or decrease in neuronal excitability as a result of the polarization of 
cortical pyramidal cell somas due to radial current flow. Even though this simple approach is convenient and widely parroted, especially when combined with an equally simplistic explanation of brain function as a sliding scale of excitability that can be "tuned" by tDCS, this not an accurate description of tDCS effects. The adoption of the somatic doctrine with the modern rediscovery of tDCS was based on animal studies, but modern animal studies have illustrated limitations to this approach.

Classic experiments with animal showed that current flow radial to the surface of the cortex can modulate the spontaneous activity of neurons in a stimulation polarity specific manner. Specifically, inward current increases neuronal firing rate, while outward current reduces firing rate (Creutzfeldt et al. , 1962, Bindman et al. , 1964, Purpura et al. , 1965a, b, Gartside, 1968a, b). As this theory collapses to the dependence on the neuronal soma polarization, and polarization mediated excitability changes, we call this the somatic doctrine. The modern rediscovery of tDCS was motivated by animal studies showing that anodal or cathodal tDCS increase or decrease, responses evoked by TMS which in the initial experiments were consistent with the above somatic doctrine (Nitsche et al. , 2000). The use of persistent stimulation (minutes) in classical tDCS studies was informed by animal studies showing that persistent stimulation led to after effects, and now persistent stimulation is ubiquitous in tDCS. However, the very same authors have shown that dose and state dependent features of tDCS hardly maintain consistent polarity specific changes (e.g. $2 \mathrm{~mA}$ cathodal can be excitatory while anodal can be made inhibitory by priming brain activity or by increasing stimulation duration). Despite the publication of this updated clinical neurophysiology information showing complex dose response, clinical and cognitive neuroscience studies continue to be largely rationalized simply following the more / less excited somatic doctrine. Despite positive outcomes from many of these studies, scientific evidence shows that neuromodulation by tDCS is more complex: 1) tDCS does not simply shift "excitability" in a polarity specific; and 2) brain function is evidently not a simple and monolithic "sliding scale of excitability". Just as animal experiments informed the foundations of tDCS almost two decades ago, they can now be applied to inform more rationale, effective optimization of tDCS techniques.

Ongoing experiments in animal models of DCS are beginning to provide insight into how neuromodulation by tDCS cannot be explained as a monolithic sliding scale of excitability (where regions under the anode are "excited" while regions under the cathode are "de-excited"). Brain function and disease are complex and their influence by DCS is complex. Neither polarization of dendrites of synaptic terminals can be ignored, which may result in differential modulation of specific synaptic inputs. This in turn, may lead to distinct forms of tDCS-induced plasticity - depending on the form of endogenous plasticity (e.g. NMDA and dendrite spent vs soma and spiking dependent) the effect of DCS may be distinct. Which neuronal processes are modulated and how, will depend on the tDCS montage used and the state of the underlying network. The rational advancement of tDCS requires departing from the sliding scale approach (applied indiscriminately across cognitive applications and indications) and addressing these mechanistic and targeting issues. With increased recognition of complexity, the need for translational animal studies, that are properly designed, becomes increasingly clear. At the same time, these issues make the investigation daunting. A critical step toward leveraging animal DCS research to increase the sophistication of tDCS is to organize, which was the goal of this review. This includes considering the effects of DCS at three scales: membrane compartment polarization, synaptic efficacy, and network effects. While brain function is evidently understood to span across these levels, this among other structures introduced here, provide a path forward toward framing of new hypotheses.

However, despite over a decade of increasingly sophisticated studies of animal DCS (Table 1), modern tDCS protocols are not informed by prediction from modern animal studies. Rather only classical animal studies showing polarity specific and persistent changes are cited to rationalize sliding scale clinical 
protocols, typically ignoring modern work that in cases complicate simplistic sliding scale theories. We feel increased emphasis on translational animal studies that increase clinical relevance, and recognition in the clinical space that more sophisticated strategies are needed, may correct this trend. Central to enhancing the sophistication of tDCS, including leveraging animal studies, is the notion of "computational neurostimulation" where interventional strategies are informed by quantitative models (Bestmann, 2015, Bikson et al. , 2015, Rahman et al. , 2015).

We emphasized throughout this review the interrelated concepts of methodological rigor and dose response. The relevance of animal DCS studies to tDCS is entirely dependent on: 1) consideration of the applied stimulation design, including intensity; and 2) relevance of outcome measures. For example, poor experimental design leading to electrochemical changes at electrode interfaces will influence neuronal function and produce "real" changes, but they will not be relevant to tDCS. Many animal DCS studies used stimulation intensities producing electric fields across the brain much higher than in tDCS. In these cases, if effect sizes are scaled based on the assumption of linearity, this assumption should be made explicit. Differences between animals and humans are also important in the context of the pivotal role of neuronal morphology and background activity in DCS. Further technical caveats are explained throughout this review with the goal of enhancing the translational relevance of animal DCS work for informing the mechanisms and practices of tDCS.

\section{[TABLE 1]}

\section{Conflict of interest and Acknowledgement}

Support for this review comes from the Department of Defense (Air Force Office of Scientific Research), The Wallace Coulter Foundation, The Epilepsy Foundation, The Andy Grove Fund, and NIH. MB and LP have equity in Soterix Medical Inc. The City University of New York has patents on brain stimulation with MB and LP as inventors. This review is an update of a previously published chapter (Bikson et al. , 2012); portions of that chapter are updated here with permission from CRC Press via the Copyright Clearance Center. 


\section{References}

Agnew WF, McCreery DB. Considerations for Safety in the Use of Extracranial Stimulation for Motor Evoked Potentials. Neurosurgery. 1987;20:143-7.

Alexander JK, Fuss B, Colello R. Electric Field-induced Astrocyte Alignment Directs Neurite Outgrowth. Neuron Glia Biol. 2006;2:93-103.

Ali MM, Sellers KK, Frohlich F. Transcranial alternating current stimulation modulates large-scale cortical network activity by network resonance. J Neurosci. 2013;33:11262-75.

An JH, Su Y, Radman T, Bikson M. Effects of glucose and glutamine concentration in the formulation of the artificial cerebrospinal fluid (ACSF). Brain Res. 2008;1218:77-86.

Anastassiou CA, Montgomery SM, Barahona M, Buzsaki G, Koch C. The effect of spatially inhomogeneous extracellular electric fields on neurons. J Neurosci. 2010;30:1925-36.

Andreasen M, Nedergaard S. Dendritic Electrogenesis in Rat Hippocampal CA1 Pyramidal Neurons: Functional Aspects of $\mathrm{Na}$ and Ca Currents in Apical Dendrites. Hippocampus. 1996;6:79-95.

Antal A, Varga ET, Kincses TZ, Nitsche MA, Paulus W. Oscillatory brain activity and transcranial direct current stimulation in humans. NeuroReport. 2004;15:1307-10.

Ardolino G, Bossi B, Barbieri S, Priori A. Non-synaptic mechanisms underlie the after-effects of cathodal transcutaneous direct current stimulation of the human brain. J Physiol. 2005;568:653-63.

Artola A, Brocher S, Singer W. Different voltage-dependent thresholds for inducing long-term depression and long-term potentiation in slices of rat visual cortex. Nature. 1990;347:69-72.

Awatramani GB, Price GD, Trussell LO. Modulation of transmitter release by presynaptic resting potential and background calcium levels. Neuron. 2005;48:109-21.

Berliner M. Skin microcirculation during tapwater iontophoresis in humans-cathode stimulates more than anode. Microvasc Res. 1997;54:74-80.

Bernabei JM, Lee WH, Peterchev AV. Modeling Transcranial Electric Stimulation in Mouse-A High Resolution Finite Element Study. Conf Proc IEEE Eng Med Biol Soc. 2014:406-9.

Bestmann S. Computational neurostimulation in basic and translational research. Prog Brain Res. 2015;222:xv-xx.

Beveridge JA, Politis MJ. Use of exogenous electric current in the treatment of delayed lesions in peripheral nerves. Plast Reconstr Surg. 1988;82:573-9.

Bikson M, Datta A, Elwassif M. Establishing Safety Limits for transcranial Direct Current Stimulation. Clin Neurophysiol. 2009;120:1033-4.

Bikson M, Datta A, Rahman A, Scaturro J. Electrode montages for tDCS and weak transcranial electrical stimulation: role of "return" electrode's position and size. Clin Neurophysiol. 2010;121:1976-8.

Bikson M, Dmochowski J, Rahman A. The "quasi-uniform" assumption in animal and computational models of non-invasive electrical stimulation. Brain Stimul. 2013;6:704-5.

Bikson M, Ghai RS, Baraban SC, Durand DM. Modulation of Burst Frequency, Duration, and Amplitude in the zero-Ca2+ Model of Epileptiform Activity. J Neurophysiol. 1999;82:2262-70.

Bikson M, Inoue M, Akiyama H, Deans JK, Fox JE, Miyakawa H, et al. Effects of uniform extracellular DC electric fields on excitability in rat hippocampal slices in vitro. J Physiol. 2004;557:175-90.

Bikson M, Peter Bulow P, Stiller J, Datta A, Battaglia F, Karnup S, et al. Transcranial direct current stimulation for major depression-a general system for quantifying transcranial electrotherapy dosage. Curr Treat Options Neurol. 2008:377-85.

Bikson M, Reato D, Rahman A. Cellular and Network Effects of Transcranial Direct Current StimulationInsights from Animal Models and Brain Slice. In: Rossini PM, editor. Transcranial Brain Stimulation: CRC Press; 2012. p. 55-91.

Bikson M, Truong DQ, Mourdoukoutas AP, Aboseria M, Khadka N, Adair D, et al. Modeling sequence and quasi-uniform assumption in computational neurostimulation. Prog Brain Res. 2015;222:1-23.

Bindman LJ, Lippold OC, Redfearn JW. Long Lasting Changes in the Level of the Electrical Activity of Cerebral Cortex Produced by Polarizing Currents. Nature. 1962;196:584-5.

Bindman LJ, Lippold OC, Redfearn JW. The Action of Brief Polarizing Currents on the Cerebral Cortex of the Rat during Current Flow and in the Production of Long-Lasting after-Effects. J Physiol. 1964;172:36982.

Bishop GH, Erlanger J. The Effects of Polarization upon the Activity of Vertebrate Nerve. Am J Physiol. 1926;78:630-57. 
Bishop GH, O'Leary JL. The effects of polarizing currents on cell potentials and their significance in the interpretation of central nervous system activity. Electroencephalogr Clin Neurophysiol. 1950;2:401-16.

Bliss TV, Lomo T. Long-lasting Potentiation of Synaptic Transmission in the Dentate Area of the Anaesthetized Rabbit following Stimulation of the Perforant Path. J Physiol. 1973;232:331-56.

Bolognini N, Fregni F, Casati C, Olgiati E, Vallar G. Brain polarization of parietal cortex augments training-induced improvement of visual exploratory and attentional skills. Brain Res. 2010;1349:76-89.

Bolzoni F, Baczyk M, Jankowska E. Subcortical Effects of transcranial Direct Current Stimulation in the Rat. J Physiol. 2013a;591:4027-42.

Bolzoni F, Pettersson LG, Jankowska E. Evidence for Long-lasting Subcortical Facilitation by transcranial Direct Current Stimulation in the Cat. J Physiol. 2013b;591:3381-99.

Brunoni A, Fregni F, Pagano RL. Translational research in transcranial direct current stimulation (tDCS): a systematic review of studies in animals. Rev Neurosci. 2011;22:471-81.

Brunoni AR, Nitsche MA, Bolognini N, Bikson M, Wagner T, Merabet L, et al. Clinical Research with transcranial Direct Current Stimulation (tDCS): Challenges and Future Directions. Brain Stimul. 2012;5:175-95.

Brzyski RG, Jones GS, Oehninger S, Acosta AA, Kruithoff CH, Muasher SJ. Impact of leuprolide acetate on the response to follicular stimulation for in vitro fertilization in patients with normal basal gonadotropin levels. J In Vitro Fert Embryo Transf. 1989;6:290-3.

Bullock TA, Hagiwara S. Intracellular recording from the giant synapse of the squid. J Gen Physiol. 1956;40:565-77.

Cambiaghi M, Teneud L, Velikova S, Gonzalez-Rosa JJ, Cursi M, Comi G, et al. Flash visual evoked potentials in mice can be modulated by transcranial direct current stimulation. Neuroscience. 2011;185:161-5.

Cambiaghi M, Velikova S, Gonzalez-Rosa JJ, Cursi M, Comi G, Leocani L. Brain transcranial direct current stimulation modulates motor excitability in mice. Eur J Neurosci. 2010;31:704-9.

Carandini M, Ferster D. Membrane potential and firing rate in cat primary visual cortex. J Neurosci. 2000;20:470-84.

Carlson C, Devinsky O. The excitable cerebral cortex Fritsch G, Hitzig E. Uber die elektrische Erregbarkeit des Grosshirns. Arch Anat Physiol Wissen 1870;37:300-32. Epilepsy Behav. 2009;15:131-2.

Chan CY, Hounsgaard J, Nicholson C. Effects of electric fields on transmembrane potential and excitability of turtle cerebellar Purkinje cells in vitro. J Physiol. 1988;402:751-71.

Chan CY, Nicholson C. Modulation by applied electric fields of Purkinje and stellate cell activity in the isolated turtle cerebellum. J Physiol. 1986;371:89-114.

Cooper MS, Schliwa M. Motility of cultured fish epidermal cells in the presence and absence of direct current electric fields. J Cell Biol. 1986;102:1384-99.

Cosentino G, Fierro B, Paladino P, Talamanca S, Vigneri S, Palermo A, et al. Transcranial direct current stimulation preconditioning modulates the effect of high-frequency repetitive transcranial magnetic stimulation in the human motor cortex. Eur J Neurosci. 2012;35:119-24.

Costain R, Redfearn JW, Lippold OC. A Controlled Trial of the Therapeudic Effect of Polarization of the Brain in Depressive Illness. Br J Psychiatry. 1964;110:786-99.

Creutzfeldt OD, Fromm GH, Kapp H. Influence of transcortical d-c currents on cortical neuronal activity. Exp Neurol. 1962;5:436-52.

Datta A, Baker JM, Bikson M, Fridriksson J. Individualized model predicts brain current flow during transcranial direct-current stimulation treatment in responsive stroke patient. Brain Stimul. 2011;4:169-74.

Datta A, Bansal V, Diaz J, Patel J, Reato D, Bikson M. Gyri-precise head model of transcranial direct current stimulation: improved spatial focality using a ring electrode versus conventional rectangular pad. Brain Stimul. 2009a;2:201-7, 207.e1.

Datta A, Bikson M, Fregni F. Transcranial direct current stimulation in patients with skull defects and skull plates: high-resolution computational FEM study of factors altering cortical current flow. Neuroimage. 2010;52:1268-78.

Datta A, Elwassif M, Battaglia F, Bikson M. Transcranial Current Stimulation Focality using Disc and Ring Electrode Configurations: FEM Analysis. J Neural Eng. 2008;5:163-74.

Datta A, Elwassif M, Bikson M. Bio-heat Transfer Model of tDCS-Comparison of Conventional Pad versus Ring Electrode. Conf Proc IEEE Eng Med Biol Soc. 2009b:670-3. 
Datta A, Truong D, Minhas P, Parra LC, Bikson M. Inter-Individual Variation during Transcranial Direct Current Stimulation and Normalization of Dose Using MRI-Derived Computational Models. Front Psychiatry. 2012;3:91.

Deans JK, Powell AD, Jefferys JG. Sensitivity of coherent oscillations in rat hippocampus to AC electric fields. J Physiol. 2007;583:555-65.

del Castillo J, Katz B. Changes in end-plate activity produced by presynaptic polarization. J Physiol. 1954;124:586-604.

Delgado-Lezama R, Perrier JF, Hounsgaard J. Local facilitation of plateau potentials in dendrites of turtle motoneurones by synaptic activation of metabotropic receptors. J Physiol. 1999;515:203-7.

Deng ZD, Lisanby SH, Peterchev AV. Electric field depth-focality tradeoff in transcranial magnetic stimulation: simulation comparison of 50 coil designs. Brain Stimul. 2013;6:1-13.

Dhamne SC, Ekstein D, Zhuo Z, Gersner R, Zurakowski D, Loddenkemper T, et al. Acute seizure suppression by transcranial direct current stimulation in rats. Ann Clin Transl Neurol. 2015;2:843-56.

Di Castro MA, Chuquet J, Liaudet N, Bhaukaurally K, Santello M, Bouvier D, et al. Local Ca2+ detection and modulation of synaptic release by astrocytes. Nat Neurosci. 2011;14:1276-84.

Dmochowski JP, Datta A, Huang Y, Richardson JD, Bikson M, Fridriksson J, et al. Targeted transcranial direct current stimulation for rehabilitation after stroke. Neuroimage. 2013;75:12-9.

Domingo JL, Llobet JM, Corbella J. Toxic effects of vanadium in streptozotocin-treated rats after administration of vanadate to normalize blood glucose levels. Diabetologia. 1990;33:62-3.

Donaldson ZR, Hen R. From psychiatric disorders to animal models: a bidirectional and dimensional approach. Biol Psychiatry. 2015;77:15-21.

Dubner HH, Gerard RW. Factors Controlling Brain Potentials in the Cat. . J Neurophysiol. 1939;2:142-52.

Durand DM, Bikson M. Suppression and Control of Epileptiform Activity by Electrical Stimulation: A Review. Conf Proc IEEE Eng Med Biol Soc. 2001;89:1065-82.

Edwards D, Cortes M, Datta A, Minhas P, Wassermann EM, Bikson M. Physiological and modeling evidence for focal transcranial electrical brain stimulation in humans: a basis for high-definition tDCS. Neuroimage. 2013;74:266-75.

Francis JT, Gluckman BJ, Schiff SJ. Sensitivity of neurons to weak electric fields. J Neurosci. 2003;23:7255-61.

Fregni F, Boggio PS, Nitsche M, Bermpohl F, Antal A, Feredoes E, et al. Anodal transcranial direct current stimulation of prefrontal cortex enhances working memory. Exp Brain Res. 2005;166:23-30.

Fregni F, Liebetanz D, Monte-Silva KK, Oliveira MB, Santos AA, Nitsche MA, et al. Effects of transcranial direct current stimulation coupled with repetitive electrical stimulation on cortical spreading depression. Exp Neurol. 2007;204:462-6.

Freund TF, Buzsaki G. Interneurons of the Hippocampus. Hippocampus. 1996;6:347-470.

Fritsch B, Reis J, Martinowich K, Schambra HM, Ji Y, Cohen LG, et al. Direct current stimulation promotes BDNF-dependent synaptic plasticity: potential implications for motor learning. Neuron. 2010;66:198-204.

Frohlich F, McCormick DA. Endogenous electric fields may guide neocortical network activity. Neuron. 2010;67:129-43.

Gardner-Medwin AR. A study of the mechanisms by which potassium moves through brain tissue in the rat. J Physiol. 1983;335:353-74.

Gartside IB. Mechanisms of Sustained Increases of Firing Rate of Neurones in the Rat Cerebral Cortex after Polarization: Reverberating Circuits or Modification of Synaptic Conductance? Nature. 1968a;220:382-3.

Gartside IB. Mechanisms of Sustained Increases of Firing Rate of Neurones in the Rat Cerebral Cortex after Polarization: Role of Protein Synthesis. Nature. 1968b;220:383-4.

Gasca F, Richter L, Schweikard A. Simulation of a conductive shield plate for the focalization of transcranial magnetic stimulation in the rat. Conf Proc IEEE Eng Med Biol Soc. 2010:1593-6.

Ghai RS, Bikson M, Durand DM. Effects of applied electric fields on low-calcium epileptiform activity in the CA1 region of rat hippocampal slices. J Neurophysiol. 2000;84:274-80.

Gluckman B, Neel E, Netoff T, Ditto W, Spano M, Schiff SJ. Electric field suppression of epileptiform activity in hippocampal slices. J Neurophysiol. 1996;76:4202-5. 
Guleyupoglu B, Schestatsky P, Edwards D, Fregni F, Bikson M. Classification of methods in transcranial electrical stimulation (tES) and evolving strategy from historical approaches to contemporary innovations. $\mathbf{J}$ Neurosci Methods. 2013;219:297-311.

Hamada M, Galea JM, Di Lazzaro V, Mazzone P, Ziemann U, Rothwell JC. Two distinct interneuron circuits in human motor cortex are linked to different subsets of physiological and behavioral plasticity. $\mathbf{J}$ Neurosci. 2014;34:12837-49.

Hanisch UK, Kettenmann H. Microglia: active sensor and versatile effector cells in the normal and pathologic brain. Nat Neurosci. 2007;10:1387-94.

Hayashi Y, Hattori Y, Asaki H, Moriwaki A, Hori Y. Effects of prolonged weak anodal direct current on electrocorticogram in awake rabbit. Acta Medica Okayama. 1988;42:293-6.

He BJ, Snyder AZ, Zempel JM, Smyth MD, Raichle ME. Electrophysiological correlates of the brain's intrinsic large-scale functional architecture. Proc Natl Acad Sci U S A. 2008;105:16039-44.

Hendy AM, Teo W, Kidgell DJ. Anodal transcranial Direct Current Stimulation Prolongs the Crosseducation of Strength and Corticomotor Plasticity. Med Sci Sports Exercise. 2015;47:1788-97.

Hess G, Donoghue JP. Facilitation of long-term potentiation in layer II/III horizontal connections of rat motor cortex following layer I stimulation: route of effect and cholinergic contributions. Exp Brain Res. 1999;127:279-90.

Hinkle L, McCaig CD, Robinson KR. The direction of growth of differentiating neurones and myoblasts from frog embryos in an applied electric field. J Physiol. 1981;314:121-35.

Hubbard JI, Willis WD. Hyperpolarization of mammalian motor nerve terminals. J Physiol. 1962a;163:115-37.

Hubbard JI, Willis WD. Mobilization of Transmitter by Hyperpolarization. Nature. 1962b;193:174-5.

Ingvar S. Reaction of cells to the galvanic current in tissue cultures. Exp Biol Med 1920:198-9.

Islam N, Aftabuddin M, Moriwaki A, Hattori Y, Hori Y. Increase in the Calcium Level following Anodal Polarization in the Rat Brain. Brain Res. 1995a:206-8.

Islam N, Moriwaki A, Hattori Y, Hori Y. Anodal polarization induces protein kinase C gamma (PKC gamma)-like immunoreactivity in the rat cerebral cortex. Neurosci Res. 1994;21:169-72.

Islam N, Moriwaki A, Hori Y. Co-localization of c-fos protein and protein kinase $\mathrm{C}$ gamma in the rat brain following anodal polarization. Indian J Physiol Pharmacol. 1995b;39:209-15.

Jaffe LF, Poo MM. Neurites grow faster towards the cathode than the anode in a steady field. J Exp Zool. 1979;209:115-28.

Jefferys JG. Influence of electric fields on the excitability of granule cells in guinea-pig hippocampal slices. J Physiol. 1981;319:143-52.

Jefferys JG, Deans JK, Bikson M, Fox JE. Effects of weak electric fields on the activity of neurons and neuronal networks. Radiat Prot Dosimetry. 2003;6:321-3.

Joucla S, Yvert B. The "mirror" estimate: an intuitive predictor of membrane polarization during extracellular stimulation. Biophys J. 2009;96:3495-508.

Kabakov AY, Muller PA, Pascual-Leone A, Jensen FE, Rotenberg A. Contribution of axonal orientation to pathway-dependent modulation of excitatory transmission by direct current stimulation in isolated rat hippocampus. J Neurophysiol. 2012;107:1881-9.

Kamida T, Kong S, Eshima N, M. F. Cathodal transcranial direct current stimulation affects seizures and cognition in fully amygdala-kindled rats. Neurol Res. 2013;35:602-7.

Kamida T, Kong S, Eshima N, Abe T, Fujiki M, Kobayashi H. Transcranial direct current stimulation decreases convulsions and spatial memory deficits following pilocarpine-induced status epilepticus in immature rats. Behav Brain Res. 2011;217:99-103.

Kekic M, Boysen E, Campbell IC, Schmidt U. A systematic review of the clinical efficacy of transcranial direct current stimulation (tDCS) in psychiatric disorders. J Psychiatr Res. 2016;74:70-86.

Kepecs A, Fishell G. Interneuron cell types are fit to function. Nature. 2014;505:318-26.

Kim SJ, Kim BK, Ko YJ, Bang MS, Kim MH, Han TR. Functional and histologic changes after repeated transcranial direct current stimulation in rat stroke model. J Korean Med Sci. 2010;25:1499-505.

Knotkova H, Cruciani RA. Non-invasive transcranial direct current stimulation for the study and treatment of neuropathic pain. Methods Mol Biol. 2010;617:505-15.

Knotkova H, Nitsche MA, Cruciani RA. Putative physiological mechanisms underlying tDCS analgesic effects. Front Hum Neurosci. 2013;7:628. 
Kotnik T, Miklavcic D. Analytical description of transmembrane voltage induced by electric fields on spheroidal cells. Biophys J. 2000;79:670-9.

Kronberg G, Bikson M. Electrode assembly design for transcranial Direct Current Stimulation-a FEM modeling study. Conf Proc IEEE Eng Med Biol Soc. 2012:891-5.

Laste G, Caumo W, Adachi LN, Rozisky JR, de Macedo IC, Filho PR, et al. After-effects of consecutive sessions of transcranial direct current stimulation (tDCS) in a rat model of chronic inflammation. Exp Brain Res. 2012;221:75-83.

Ledger PW. Skin biological issues in electrically enhanced transdermal delivery. Adv Drug Deliv Rev. 1992;9:289-307.

Lee WH, Lisanby SH, Laine AF, Peterchev AV. Electric Field Model of Transcranial Electric Stimulation in Nonhuman Primates: Correspondence to Individual Motor Threshold. Conf Proc IEEE Eng Med Biol Soc. 2015;62:2095-105.

Li L, El-Hayek YH, Liu B, Chen Y, Gomez E, Wu X, et al. Direct-current electrical field guides neuronal stem/progenitor cell migration. Stem Cells. 2008;26:2193-200.

Li Q, Brus-Ramer M, Martin JH, McDonald JW. Electrical stimulation of the medullary pyramid promotes proliferation and differentiation of oligodendrocyte progenitor cells in the corticospinal tract of the adult rat. Neurosci Lett. 2010;479:128-33.

Li Y, Tian X, Qian L, Yu X, Jiang W. Anodal transcranial direct current stimulation relieves the unilateral bias of a rat model of Parkinson's disease. Conf Proc IEEE Eng Med Biol Soc. 2011:765-8.

Lian J, Bikson M, Sciortino C, Stacey WC, Durand DM. Local suppression of epileptiform activity by electrical stimulation in rat hippocampus in vitro. J Physiol. 2003;547:427-34.

Liebetanz D, Fregni F, Monte-Silva KK, Oliveira MB, Amancio-dos-Santos A, Nitsche MA, et al. Aftereffects of transcranial direct current stimulation (tDCS) on cortical spreading depression. Neurosci Lett. 2006a;398:85-90.

Liebetanz D, Klinker F, Hering D, Koch R, Nitsche MA, Potschka H, et al. Anticonvulsant Effects of transcranial Direct-current Stimulation (tDCS) in the Rat Cortical Ramp Model of Focal Epilepsy. Epilepsia. 2006b;47:1216-24.

Liebetanz D, Koch R, Mayenfels S, Konig F, Paulus W, Nitsche MA. Safety Limits of Cathodal transcranial Direct Current Stimulation in Rats. Clin Neurophysiol. 2009;120:1161-7.

Liebetanz D, Nitsche MA, Tergau F, Paulus W. Pharmacological approach to the mechanisms of transcranial DC-stimulation-induced after-effects of human motor cortex excitability. Brain. 2002;125:2238-47.

Loo CK, Alonzo A, Martin D, Mitchell PB, Galvez V, Sachdev P. Transcranial direct current stimulation for depression: 3-week, randomised, sham-controlled trial. Br J Psychiatry. 2012;200:52-9.

Lopez-Quintero SV, Datta A, Amaya R, Elwassif M, Bikson M, Tarbell JM. DBS-relevant electric fields increase hydraulic conductivity of in vitro endothelial monolayers. J Neural Eng. 2010;7:16005.

Lu B. BDNF and activity-dependent synaptic modulation. Learn Mem. 2003;10:86-98.

Malenka RC, Bear MF. LTP and LTD: an embarrassment of riches. Neuron. 2004;44:5-21.

Malty AM, Petrofsky J. The Effect of Electrical Stimulation on a Normal Skin Blood Flow in Active Young and Older Adults. Med Sci Monit. 2007;13:147-55.

Marquez-Ruiz J, Leal-Campanario R, Sanchez-Campusano R, Molee-Ardekani B, Wendling F, Miranda PC, et al. Transcranial direct-current stimulation modulates synaptic mechanisms involved in associative learning in behaving rabbits. Proc Natl Acad Sci U S A. 2012;109:6710-5.

Marsh G, Beams HW. In vitro control of growing chick nerve fibers by applied electric currents. J Cell Physiol. 1946:139-57.

Marshall L, Helgadottir H, Molle M, Born J. Boosting slow oscillations during sleep potentiates memory. Nature. 2006;444:610-3.

Marshall L, Kirov R, Brade J, Molle M, Born J. Transcranial electrical currents to probe EEG brain rhythms and memory consolidation during sleep in humans. PLoS One. 2011;6:e16905.

Marshall L, Molle M, Hallschmid M, Born J. Transcranial direct current stimulation during sleep improves declarative memory. J Neurosci. 2004;24:9985-92.

McCaig CD. Dynamic aspects of amphibian neurite growth and the effects of an applied electric field. J Physiol. 1986;375:55-89.

McCaig CD, Rajnicek AM. Electrical fields, nerve growth and nerve regeneration. Exp Physiol. 1991;76:473-94. 
McCaig CD, Rajnicek AM, Song B, Zhao M. Controlling cell behavior electrically: current views and future potential. Physiol Rev. 2005;85:943-78.

McDevitt L, Fortner P, Pomeranz B. Application of weak electric field to the hindpaw enhances sciatic motor nerve regeneration in the adult rat. Brain Res. 1987;416:308-14.

McIntire LK, McKinley RA, Goodyear C, Nelson J. A Comparison of the Effects of transcranial Direct Current Stimulation and Caffeine on Vigilance and Cognitive Performance during Extended Wakefulness. Brain Stimul. 2014;7:499-507.

Merrill DR, Bikson M, Jefferys JG. Electrical stimulation of excitable tissue: design of efficacious and safe protocols. J Neurosci Methods. 2005;141:171-98.

Minhas P, Bansal V, Patel J, Ho JS, Diaz J, Datta A, et al. Electrodes for high-definition transcutaneous DC stimulation for applications in drug delivery and electrotherapy, including tDCS. J Neurosci Methods. 2010;190:188-97.

Minhas P, Datta A, Bikson M. Cutaneous perception during tDCS: role of electrode shape and sponge salinity. Clin Neurophysiol. 2011;122:637-8.

Miranda PC, Correia L, Salvador R, Basser PJ. The role of tissue heterogeneity in neural stimulation by applied electric fields. Conf Proc IEEE Eng Med Biol Soc. 2007:1715-8.

Miranda PC, Faria P, Hallett M. What does the ratio of injected current to electrode area tell us about current density in the brain during tDCS? Clin Neurophysiol. 2009;120:1183-7.

Miranda PC, Lomarev M, Hallett M. Modeling the current distribution during transcranial direct current stimulation. Clin Neurophysiol. 2006;117:1623-9.

Monai H, Ohkura M, Tanaka M, Mikoshiba K, Itohara S, Nakai J, et al. Glial Involvement in transcranial Direct Current Stimulation (tDCS)-induced Plasticity. Society for Neuroscience 2015. Chicago, Illinois 2015.

Mozzachiodi R, Byrne JH. More than synaptic plasticity: role of nonsynaptic plasticity in learning and memory. Trends Neurosci. 2010;33:17-26.

Nagy JI, Rash JE. Astrocyte and Oligodendrocyte Connexins of the Glial Synctium in Relation to Astrocyte Anatomical Domains and Spatial Buffering. Cell Commun Adhes. 2003;10:401-6.

Nekhendzy V, Fender CP, Davies MF, Lemmens HJM, Kim MS, Bouley DM, et al. The Antinociceptive Effect of Transcranial Electrostimulation with Combined Direct and Alternating Current in Freely Moving Rats. Anesth Analg. 2004:730-7.

Nitsche MA, Fricke K, Henschke U, Schlitterlau A, Liebetanz D, Lang N, et al. Pharmacological modulation of cortical excitability shifts induced by transcranial direct current stimulation in humans. $\mathbf{J}$ Physiol. 2003a;553:293-301.

Nitsche MA, Paulus W. Excitability Changes in the Human Motor Cortex by Weak tDCS. J Physiol. 2000:633-9.

Nitsche MA, Schauenberg A, Lang N, Liebetanz D, Exner C, Paulus W, et al. Facilitation of implicit motor learning by weak transcranial direct current stimulation of the primary motor cortex in the human. J Cogn Neurosci. 2003b;15:619-26.

Notturno F, Pace M, Zappasodi F, Cam E, Bassetti CL, Uncini A. Neuroprotective effect of cathodal transcranial direct current stimulation in a rat stroke model. J Neurol Sci. 2014;342:146-51.

Oliveira JF, Zanao TA, Valiengo L, Lotufo PA, Bensenor IM, Fregni F, et al. Acute Working Memory Improvement after tDCS in Antidepressant-free Patients with Major Depressive Disorder. Neurosci Lett. 2013;537:60-4.

Ozen S, Sirota A, Belluscio MA, Anastassiou CA, Stark E, Koch C, et al. Transcranial electric stimulation entrains cortical neuronal populations in rats. J Neurosci. 2010;30:11476-85.

Palmer AM, Messerli MA, Robinson KR. Neuronal galvanotropism is independent of external $\mathrm{Ca}(2+)$ entry or internal $\mathrm{Ca}(2+)$ gradients. J Neurosci. 2000;45:30-8.

Pasti L, Volterra A, Pozzan T, Carmignoto G. Intracellular Calcium Oscillations in Astrocytes: A Highly Plastic, Bidirectional Form of Communication between Neurons and Astrocytes in situ. J Neurosci. 1997; 17:7817-1830.

Patel N, Poo MM. Orientation of neurite growth by extracellular electric fields. J Neurosci. 1982;2:483-96.

Patel NB, Poo MM. Perturbation of the direction of neurite growth by pulsed and focal electric fields. J Neurosci. 1984;4:2939-47. 
Pedron S, Monnin J, Haffen E, Sechter D, Van Waes V. Repeated transcranial Direct Current Stimulation Prevents Abnormal Behaviors Associated with Abstinence from Chronic Nicotine Consumption. Neuropsychopharmacology. 2014;39:981-8.

Pelletier SJ, Cicchetti F. Cellular and molecular mechanisms of action of transcranial direct current stimulation: evidence from in vitro and in vivo models. Int J Neuropsychopharmacol. 2015;18:1-13.

Peterchev AV, Wagner TA, Miranda PC, Nitsche MA, Paulus W, Lisanby SH, et al. Fundamentals of transcranial electric and magnetic stimulation dose: definition, selection, and reporting practices. Brain Stimul. 2012;5:435-53.

Politis MJ, Zanakis MF, Albala BJ. Facilitated regeneration in the rat peripheral nervous system using applied electric fields. J Trauma. 1988;28:1375-81.

Pomeranz B, Mullen M, H. M. Effect of applied electrical fields on sprouting of intact saphenous nerve in adult rat. Brain Res. 1984;303:331-6.

Prausnitz R. The Effects of Electric Current Applied to Skin: A Review for transdermal Drug Delivery. Adv Drug Deliv Rev. 1996;18:395-425.

Purpura DP, McMurtry JG. Intracellular Activities and Evoked Potential Changes during Polarization of Motor Cortex. J Neurophysiol. 1965a;28:166-85.

Purpura DP, McMurtry JG. Intracellular Potentials of Cortical Neurons during Applied transcortical Polarizing Currents. Electroencephalogr Clin Neurophysiol. 1965b;18:203.

Purpura DP, McMurtry JG, Leonard CF. Intracellular spike potentials of dendritic origin during hippocampal seizures induced by subiculum stimulation. Brain Res. 1966;1:109-13.

Radman T, Datta A, Peterchev AV. In vitro modulation of endogenous rhythms by AC electric fields: Syncing with clinical brain stimulation. J Physiol. 2007a;584:369-70.

Radman T, Ramos RL, Brumberg JC, Bikson M. Role of cortical cell type and morphology in subthreshold and suprathreshold uniform electric field stimulation in vitro. Brain Stimul. 2009;2:215-28, 228.e1-3.

Radman T, Su Y, An JH, Parra LC, Bikson M. Spike timing amplifies the effect of electric fields on neurons: implications for endogenous field effects. J Neurosci. 2007b;27:3030-6.

Rahman A, Lafon B, Bikson M. Multilevel computational models for predicting the cellular effects of noninvasive brain stimulation. Prog Brain Res. 2015;222:25-40.

Rahman A, Reato D, Arlotti M, Gasca F, Datta A, Parra LC, et al. Cellular Effects of Acute Direct Current Stimulation: Somatic and Synaptic Terminal Effects. J Physiol. 2013;591:2563-78.

Ranieri F, Podda MV, Riccardi E, Frisullo G, Dileone M, Profice P, et al. Modulation of LTP at rat hippocampal CA3-CA1 synapses by direct current stimulation. J Neurophysiol. 2012;107:1868-80.

Reato D, Bikson M, Parra LC. Lasting modulation of in vitro oscillatory activity with weak direct current stimulation. J Neurophysiol. 2015;113:1334-41.

Reato D, Gasca F, Datta A, Bikson M, Marshall L, Parra LC. Transcranial electrical stimulation accelerates human sleep homeostasis. PLoS Comput Biol. 2013;9:e1002898.

Reato D, Rahman A, Bikson M, Parra LC. Low-intensity electrical stimulation affects network dynamics by modulating population rate and spike timing. J Neurosci. 2010;30:15067-79.

Redfearn JW, Lippold OC, Costain R. A Preliminary Account of the Clinical Effects of Polarizing the Brain in Certain Psychiatric Disorders. Br J Psychiatry. 1964;110:773-85.

Rioult-Pedotti MS, Friedman D, Hess G, Donoghue JP. Strengthening of horizontal cortical connections following skill learning. Nat Neurosci. 1998;1:230-4.

Rohan JG, Carhuatanta KA, McInturf SM, Miklasevich MK, Jankord R. Modulating Hippocampal Plasticity with In Vivo Brain Stimulation. J Neurosci. 2015;35:12824-32.

Roman GC, Strahlendorf HK, Coates PW, Rowley BA. Stimulation of sciatic nerve regeneration in the adult rat by low-intensity electric current. Exp Neurol. 1987;98:222-32.

Rossi S, Hallett M, Rossini PM, Pascual-Leone A, Safety of TMSCG. Safety, ethical considerations, and application guidelines for the use of transcranial magnetic stimulation in clinical practice and research. Clin Neurophysiol. 2009;120:2008-39.

Rueger MA, Keuters MH, Walberer M, Braun R, Klein R, Sparing R, et al. Multi-session transcranial direct current stimulation (tDCS) elicits inflammatory and regenerative processes in the rat brain. PLoS One. 2012;7:e43776.

Ruohonen J, Karhu J. tDCS possibly stimulates glial cells. Clin Neurophysiol. 2012;123:2006-9.

Sadleir RJ, Vannorsdall TD, Schretlen DJ, Gordon B. Transcranial direct current stimulation (tDCS) in a realistic head model. Neuroimage. 2010;51:1310-8. 
Salvador R, Mekonnen A, Ruffini G, Miranda PC. Modeling the electric field induced in a high resolution realistic head model during transcranial current stimulation. Conf Proc IEEE Eng Med Biol Soc. 2010:2073-6.

Spezia Adachi LN, Caumo W, Laste G, Fernandes Medeiros L, Ripoll Rozisky J, de Souza A, et al. Reversal of chronic stress-induced pain by transcranial direct current stimulation (tDCS) in an animal model. Brain Res. 2012;1489:17-26.

Stagg CJ, Nitsche MA. Physiological basis of transcranial direct current stimulation. Neuroscientist. 2011;17:37-53.

Stollberg J, Fraser SE. Acetylcholine receptors and concanavalin A-binding sites on cultured Xenopus muscle cells-electrophoresis, diffusion, and aggregation. J Cell Biol. 1988;107:1397-408.

Stollberg J, Fraser SE. Acetylcholine receptor clustering is triggered by a change in the density of a nonreceptor molecule. J Cell Biol. 1990a;111:2029-39.

Stollberg J, Fraser SE. Local accumulation of acetylcholine receptors is neither necessary nor sufficient to induce cluster formation. J Neurosci. 1990b;10:247-55.

Su Y, Radman T, Vaynshteyn J, Parra LC, Bikson M. Effects of high-frequency stimulation on epileptiform activity in vitro: ON/OFF control paradigm. Epilepsia. 2008;49:1586-93.

Sunderam S, Gluckman B, Reato D, Bikson M. Toward rational design of electrical stimulation strategies for epilepsy control. Epilepsy Behav. 2010;17:6-22.

Svirskis G, Gutman A, Hounsgaard J. Detection of a membrane shunt by DC field polarization during intracellular and whole cell recording. J Neurophysiol. 1997;77:579-86.

Takano Y, Yokawa T, Masuda A, Niimi J, Tanaka S, Hironaka N. A Rat Model for Measuring the Effectiveness of transcranial Direct Current Stimulation using fMRI. Neurosci Lett. 2011;491:40-3.

Takeuchi A, Takeuchi N. Electrical changes in pre- and postsynaptic axons of the giant synapse of Loligo. J Gen Physiol. 1962;45:1181-93.

Tanaka T, Takano Y, Tanaka S, Hironaka N, Kobayashi K, Hanakawa T, et al. Transcranial direct-current stimulation increases extracellular dopamine levels in the rat striatum. Front Syst Neurosci. 2013;7:6.

Terzuolo CA, Bullock TA. Measurement of Imposed Voltage Gradient Adequate to Modulate Neuronal Firing. Proc Natl Acad Sci U S A. 1956;42:687-94.

Toleikis JR, Sances A, Larson SJ. Effects of diffuse transcerebral electrical currents on cortical unit potential activity. Anesth Analg. 1974;53:48-55.

Turkeltaub PE, Benson J, Hamilton RH, Datta A, Bikson M, Coslett HB. Left lateralizing transcranial direct current stimulation improves reading efficiency. Brain Stimul. 2012;5:201-7.

Varga ET, Terney D, Atkins MD, Nikanorova M, Jeppesen DS, Uldall P, et al. Transcranial direct current stimulation in refractory continuous spikes and waves during slow sleep: a controlled study. Epilepsy Res. 2011;97:142-5.

Wachter D, Wrede A, Schulz-Schaeffer W, Taghizadeh-Waghefi A, Nitsche MA, Kutschenko A, et al. Transcranial direct current stimulation induces polarity-specific changes of cortical blood perfusion in the rat. Exp Neurol. 2011;227:322-7.

Wong RK, Stweart M. Different firing patterns generated in dendrites and somata of CA1 pyramidal neurones in guinea-pig hippocampus. J Physiol. 1992;457:675-87.

Yoon KJ, Oh BM, Kim DY. Functional improvement and neuroplastic effects of anodal transcranial direct current stimulation (tDCS) delivered 1 day vs. 1 week after cerebral ischemia in rats. Brain Res. 2012;1452:61-72.

Zhu FF, Yeung AY, Poolton JM, Lee TM, Leung GK, Masters RS. Cathodal Transcranial Direct Current Stimulation over Left Dorsolateral Prefrontal Cortex Area Promotes Implicit Motor Learning in a Golf Putting Task. Brain Stimul. 2015;8:784-6.

Zobeiri M, van Luijtelaar G. Noninvasive transcranial direct current stimulation in a genetic absence model. Epilepsy Behav. 2013;26:42-50. 


\section{TABLE}

Table 1 - In vitro and in vivo animal studies of DCS. A list of animal studies including methodologies and outcomes are provided. The table describes stimulation parameters, outcome measures, and a brief summary of the findings. Note that due to the inhomogeneous nature of experimental methodology and reporting, key parameters like current density and charge density cannot be calculated for some studies. DCS has been widely applied for a variety of disease conditions and studies are grouped accordingly. 


\section{TABLE}

Table 1 - In vitro and in vivo animal studies of DCS. A list of animal studies including methodologies and outcomes are provided. The table describes stimulation parameters, outcome measures, and a brief summary of the findings. Note that due to the inhomogeneous nature of experimental methodology and reporting, key parameters like current density and charge density cannot be calculated for some studies. DCS has been widely applied for a variety of disease conditions and studies are grouped accordingly. 


\section{Figure Legends}

Figure 1 - Animal studies on tDCS mechanism allow rapid screening of stimulation parameters and analysis of neurophysiological and molecular changes in ways not possible clinically. Meaningful translation research in animals required replication of electric fields generated clinically in animal brain/tissue. The electric field generated in the brain during tDCS is dependent on the stimulation dose (current intensity, electrode montage) and head anatomy. It is not trivial to relate externally controlled dose with internally generated electric fields (i.e., the current density in the brain is not the same as at the electrodes), but FEM computational models provide a method to do so. In the experimental design of animal studies, the electric field generated should correspond in intensity to that generated clinically; otherwise results should be applied to the clinical case with caution. For the case of in vitro brain slice studies, the replication of clinical electrical fields is experimentally straightforward with the use of two long parallel wires placed across the bath, generating a uniform electric field. The uniform electric field in the chamber can be calibrated using a field-recording electrode in the current applied to the wires. The relative position of the brain slice in the uniform field is not important to control, but the slice's orientation within the electric field must be carefully controlled; moreover multiple slices can be screened at once.

Figure 2 - The quasi-uniform assumption is implicit in the majority of modeling and animal studies of tDCS. The first aspect of the quasi-uniform assumption is based on the electric field generated in the brain to not significantly change (be uniform) on the scale of a single cortical column or neuronal dendritic tree. Only in this way it is meaningful to represent, for a first approximation, neuromodulation by regional electric field. This assumption underpins the rational basis for replicating an electric field of interest in an animal model as described in the text. Shown is a high-resolution finite element model (FEM) computational model of predicted current distribution using tDCS on humans and rats, as well as DCS on brain slices.

Figure 3 - Incremental membrane polarization produced by tDCS may significantly affect the timing of action potentials in response to a ramp (synaptic, oscillation) input. Moreover, the amplification of effect (change in timing per change in membrane polarization) increased for more gradual input. A.1 Schematic illustrates the principle of timing amplification from Radman et al. (2007b). A.2 The timing amplification was validated in hippocampal CA1 neurons using intracellular injected current ramp of various slopes. B.1/B.2 The timing change increased with 
membrane polarization with a sensitivity (amplification) that is the inverse of the input ramp slope. The amplification would function during processing of incoming synaptic input including oscillations. C.1 Demonstration of timing change in response to an incoming EPSP. An incremental depolarization produced by direct current led to significant change in action potential timing in response to a synaptic input.

Figure 4 - The principle and quantification of the somatic doctrine. (Top) The somatic doctrine simplifies tDCS design by assuming inward current flow under the anode, leading to somatic depolarization, and a generic increase in excitability and function. Under the cathode, an outward current leads to somatic hyperpolarization and a generic decrease in excitability and function. (Bottom) Modern efforts to quantify somatic polarization in animal models have confirmed some aspects of the somatic doctrine, at least under specific controlled and tested conditions, but indicated that the polarization produced by tDCS would be small.

Figure 5 - Further advantages of the brain slice preparation in studying mechanisms of weak $D C$ stimulation. (Top) A discussion in the text, the direction of the applied electric field relative to the somato-dendritic axis can be precisely controlled (adapted from Bikson et al., 2004). The effects of DC current on brain function may vary with orientation. (Bottom) Synaptic function/efficacy is not "one thing", rather there are multiple distinct synaptic afferent to any brain region which can be evaluated in isolation in brain slices. The effects of DC current on synaptic function may be highly pathway specific.

Figure 6 - Modulation of gamma oscillations in brain slice by weak DC fields. Gamma oscillations were induced in the CA3 region by perfusion with carbachol. Negative fields which produce hyperpolarization of CA1 pyramidal neuron soma, attenuated oscillation, but interestingly the attenuation was most pronounced when the fields where turned on, after which oscillation activity partly rebounded even through the field was still on. This suggests homeostatic "adaptation" (arrows) to the DC field by neuronal network system. After the field is turn off, there is an excitatory rebound response consistent with this adaption. An opposite effects is observed for positive fields that would depolarizing the soma of CA3 pyramidal neurons. This adaption at the network level is not expected from single neurons, so reflects an emergent response of an active network to DC fields. 
Meaningful Animal Studies - Matching Electric Fields

Clinical optimization

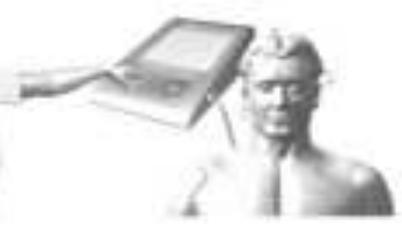

- Incremental Refinement

- Empirical

- Behavioral outcomes

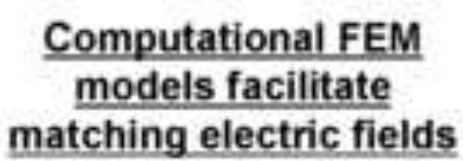

Iranslational Animal Research (animal, brain slice)

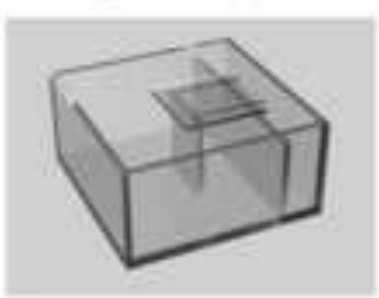

- Rapid Screening

- Mechanistic

- Electrophysiological /molecular I

chemical outcomes

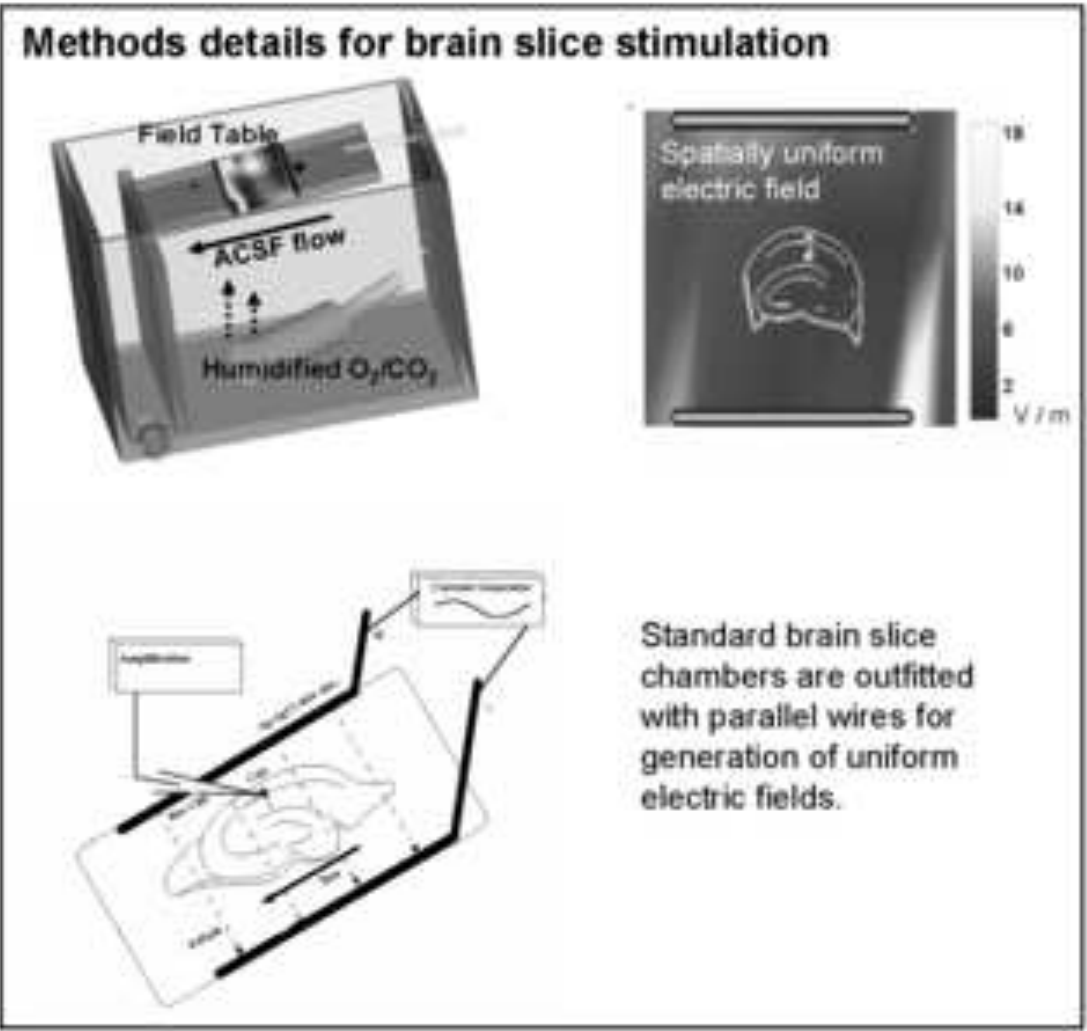




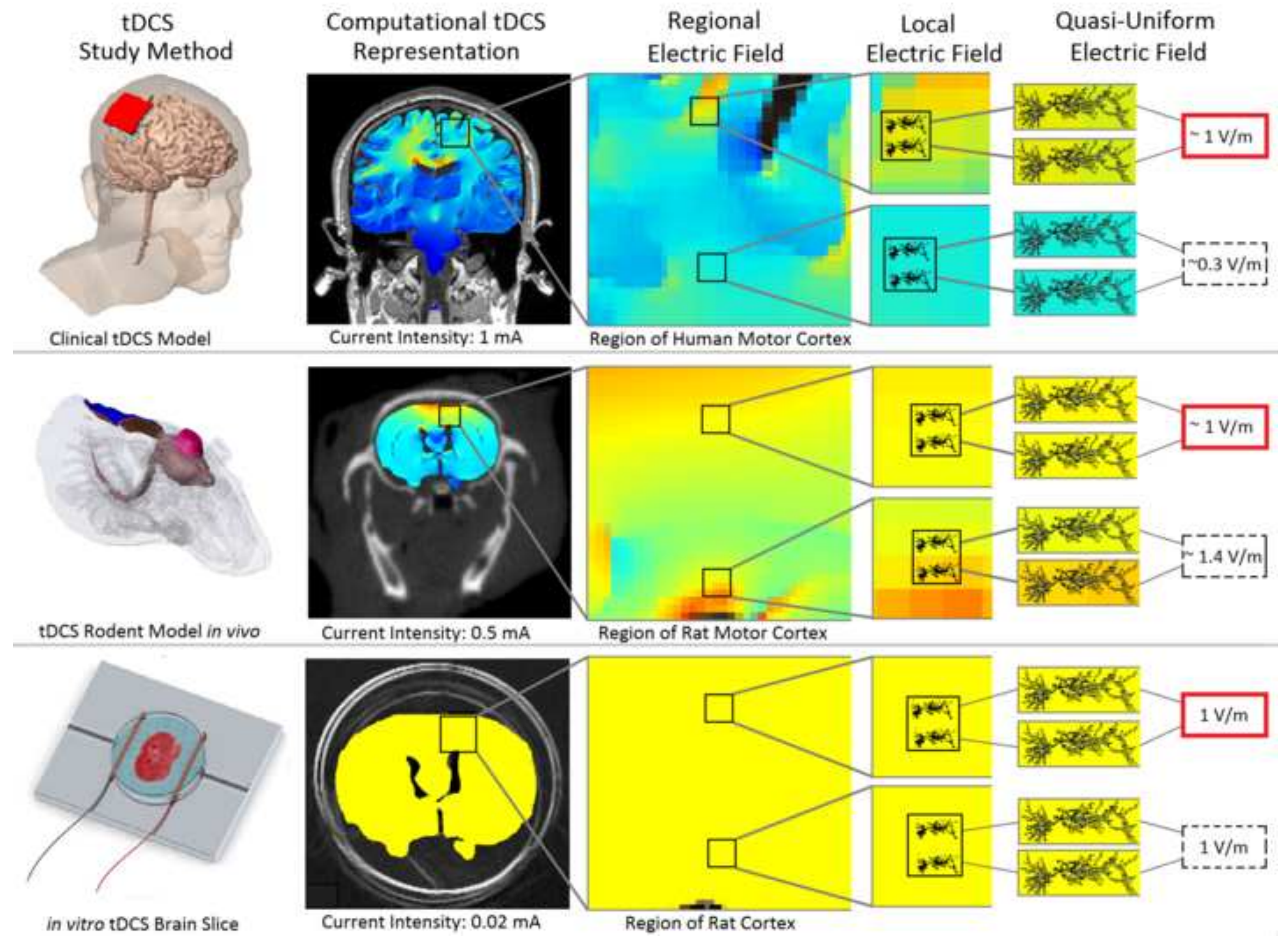


A.1

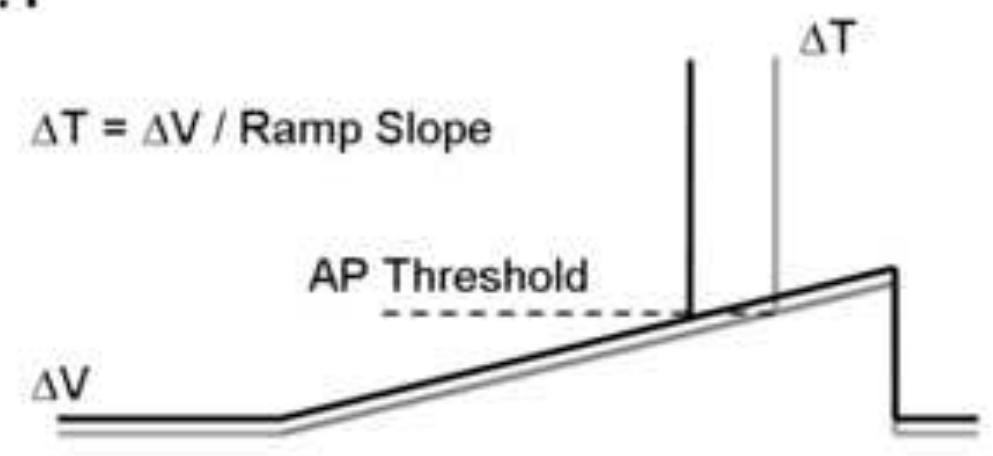

B.1

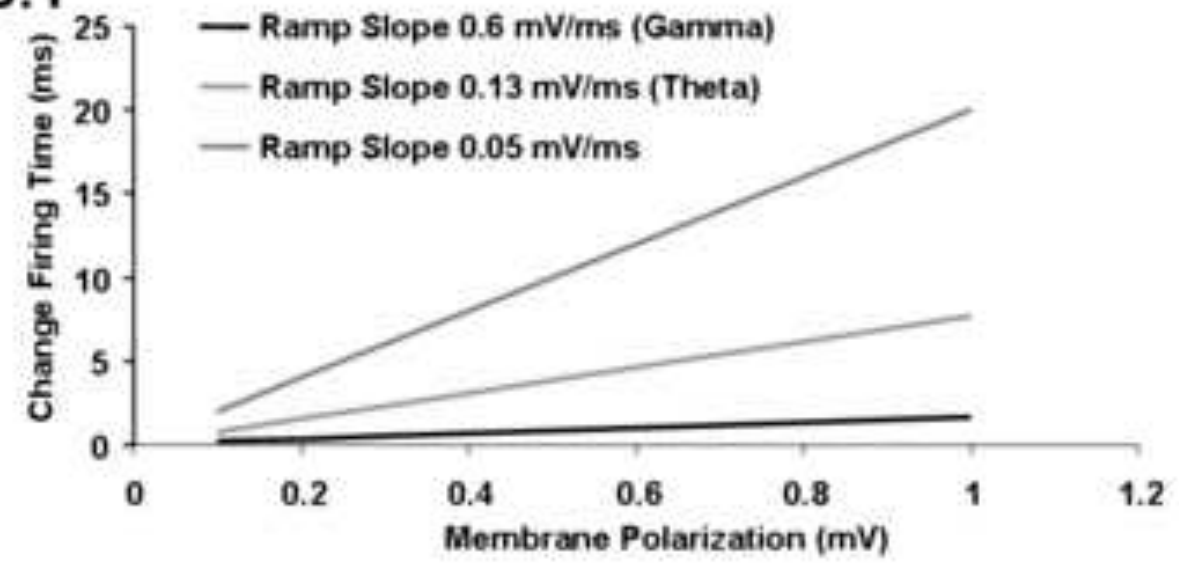

C.1 Depolarizing applied field

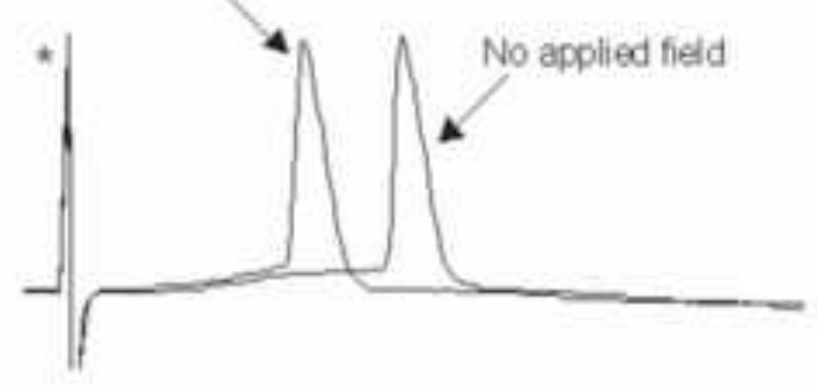

A.2

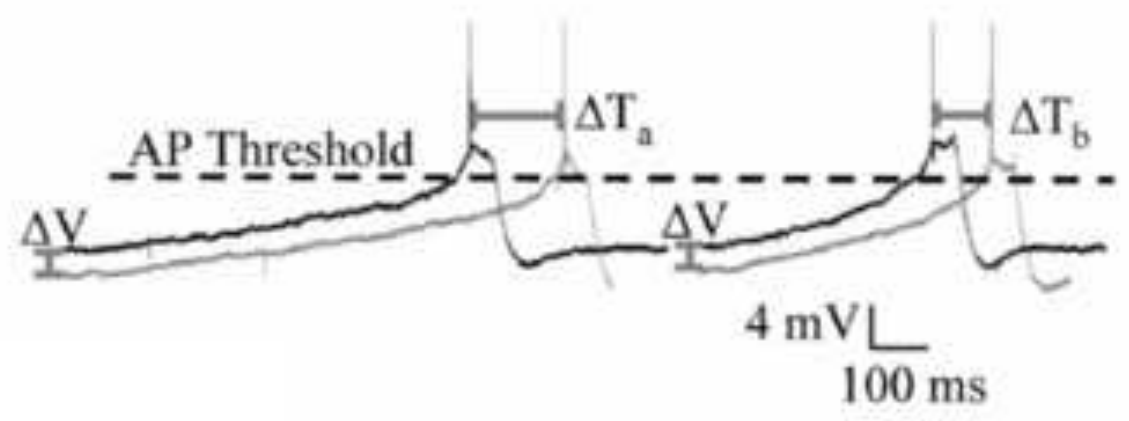

B.2

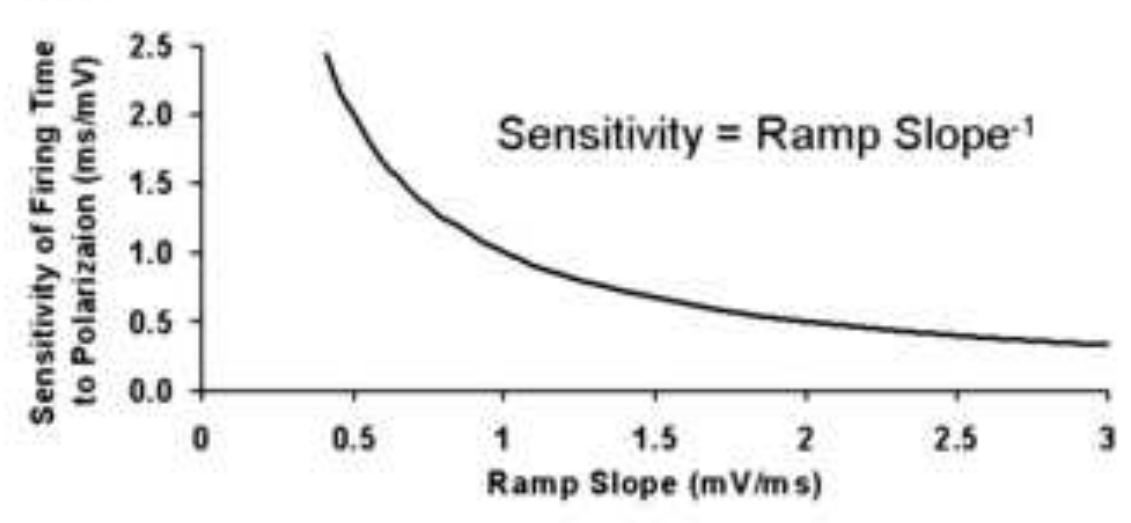

Amplification of weak field induced polarization though timing changes at the single cell level 
A. The principle of "somatic doctrine" in basic tDCS montage design

Current Flow (Electric Field) outward from brain

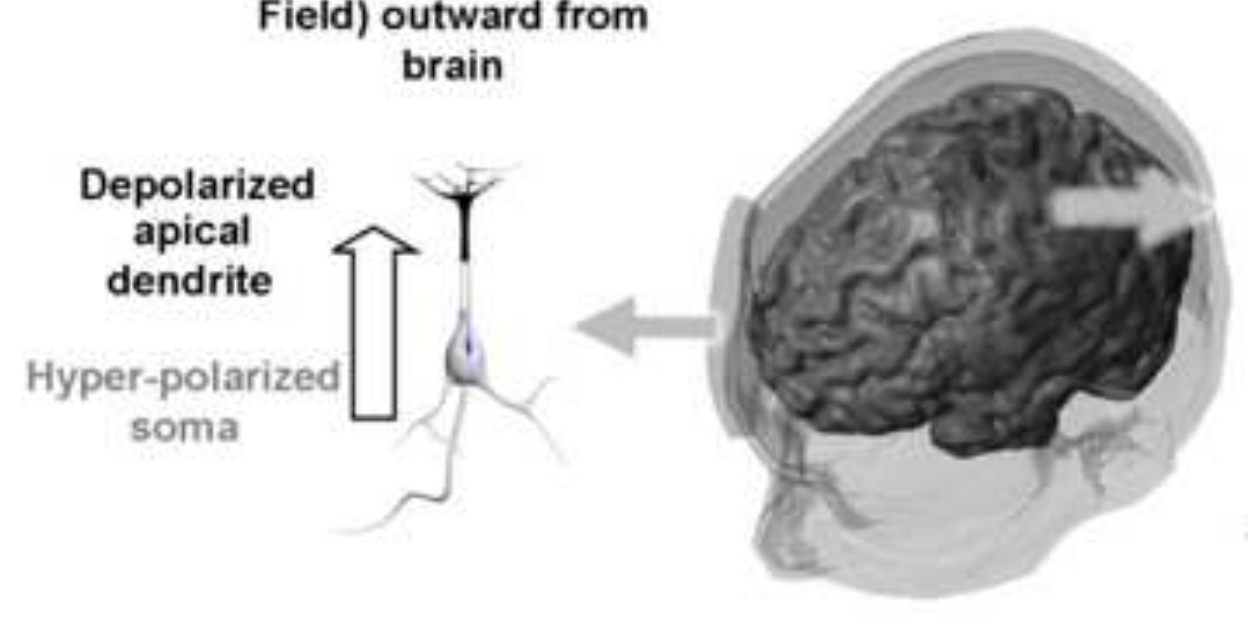

Somatic hyperpolarization $=$ "inhibition" under cathode

Current Flow (Electric Field) inward to brain

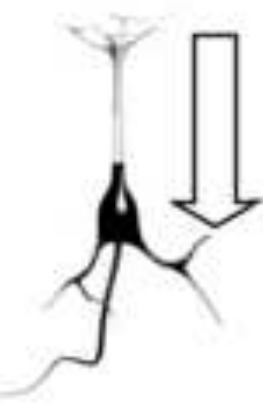

Hyper-polarized apical dendrite

Depolarized soma

\section{B. Quantification of somatic (and dendrite) polarization under DC fields}

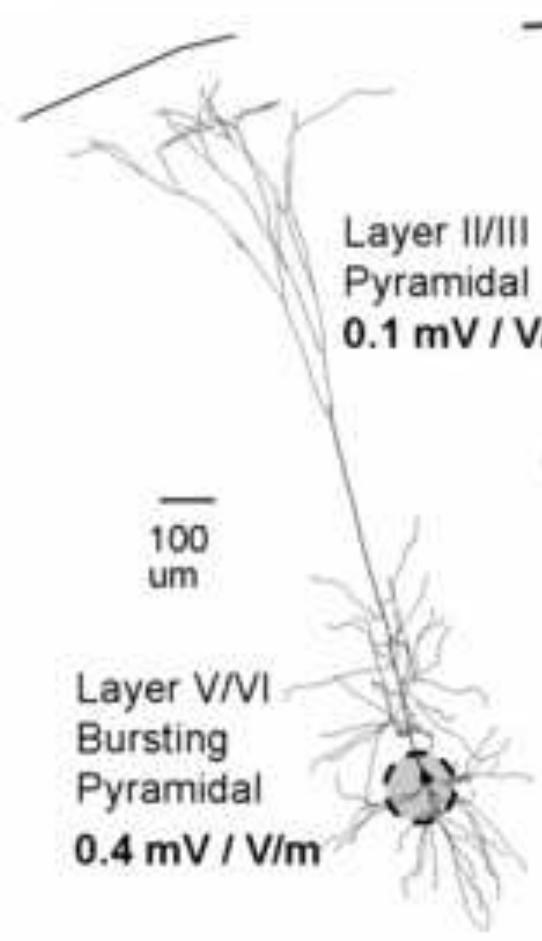

Somatic Sensitivity I Coupling Constant / Polarization Length
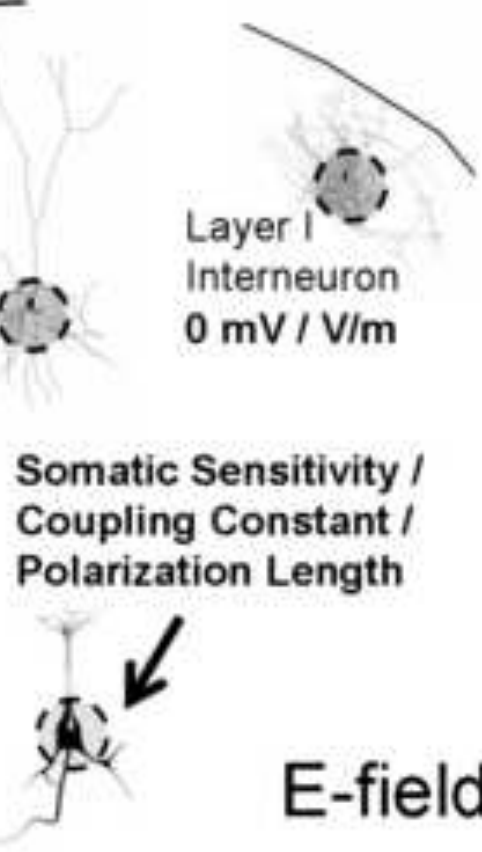

Somatic depolarization $=$ "excitation" under anode 
Interrogation of electric-field direction and pathway specific DC modulation using brain slices
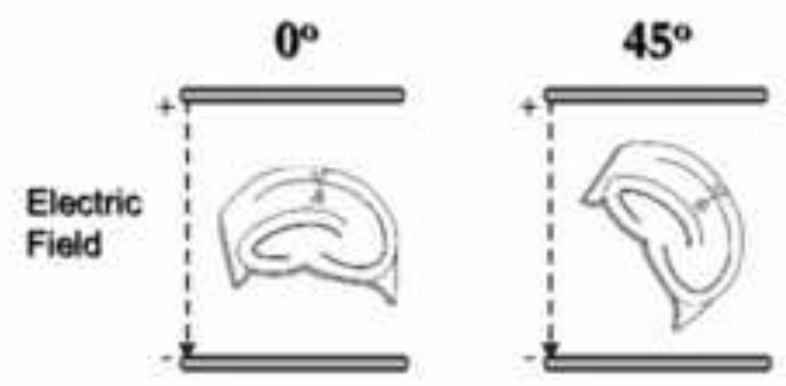

Rat Hippocampal Brain Slice (with field and pathway activation electrodes)

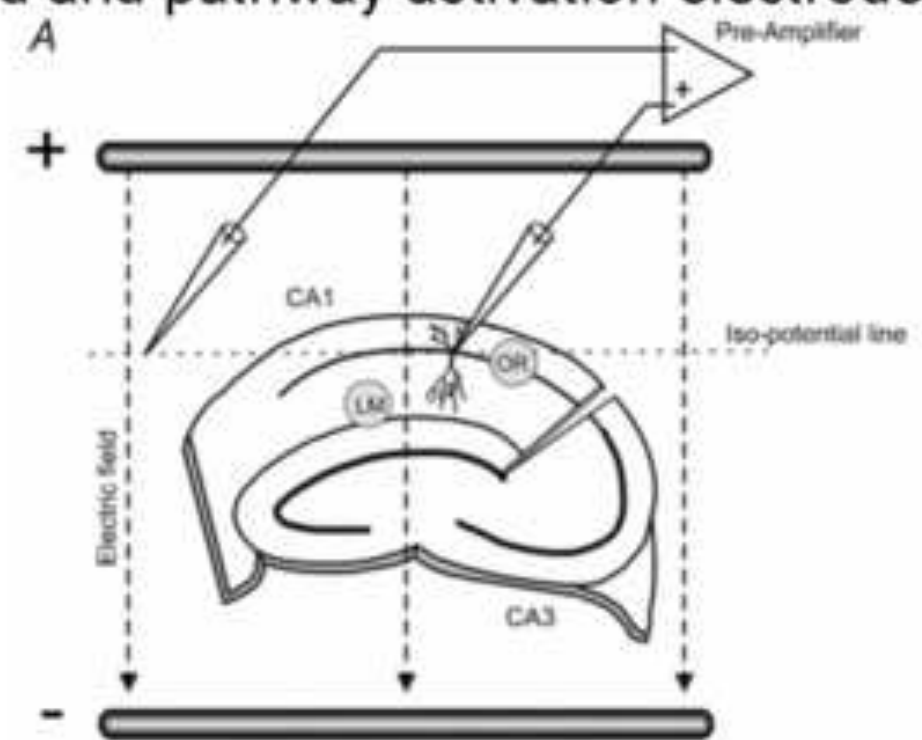

AoligCl uniform field stimalation electrose

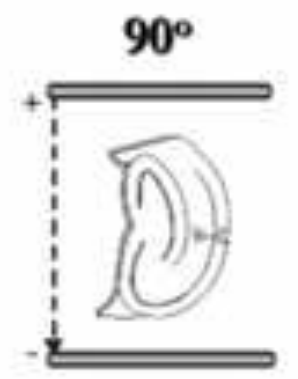

Electric field direction is controlled simply by slice rotation

\section{Rat Cortical Brain Slice} (with field and pathway activation

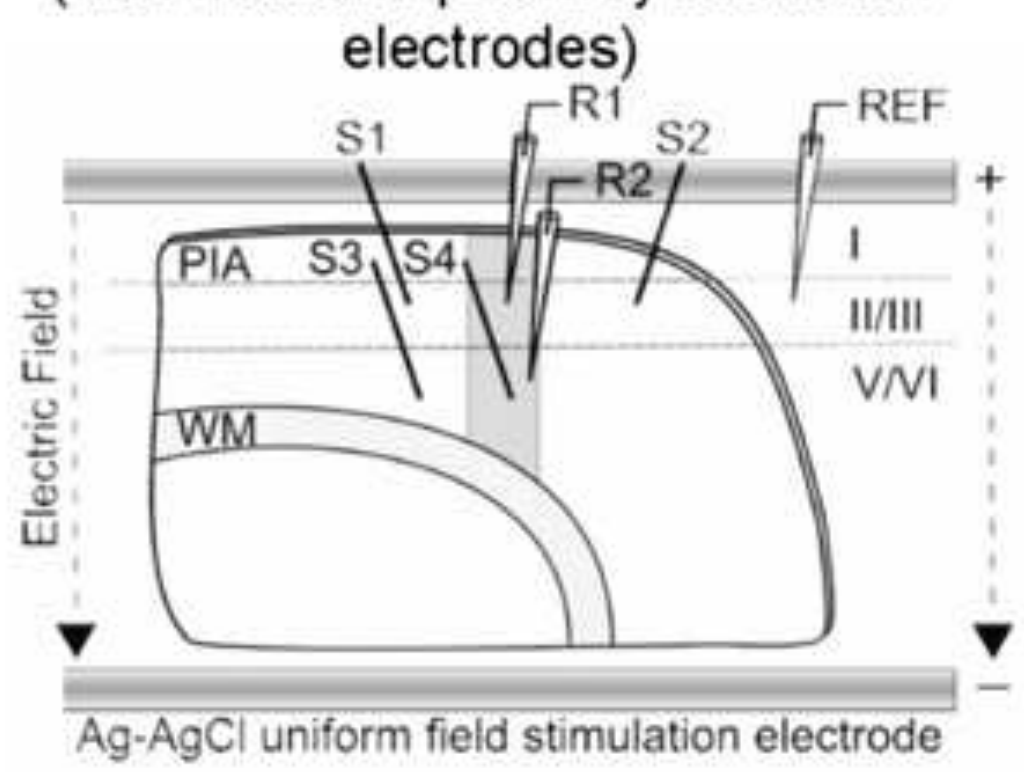



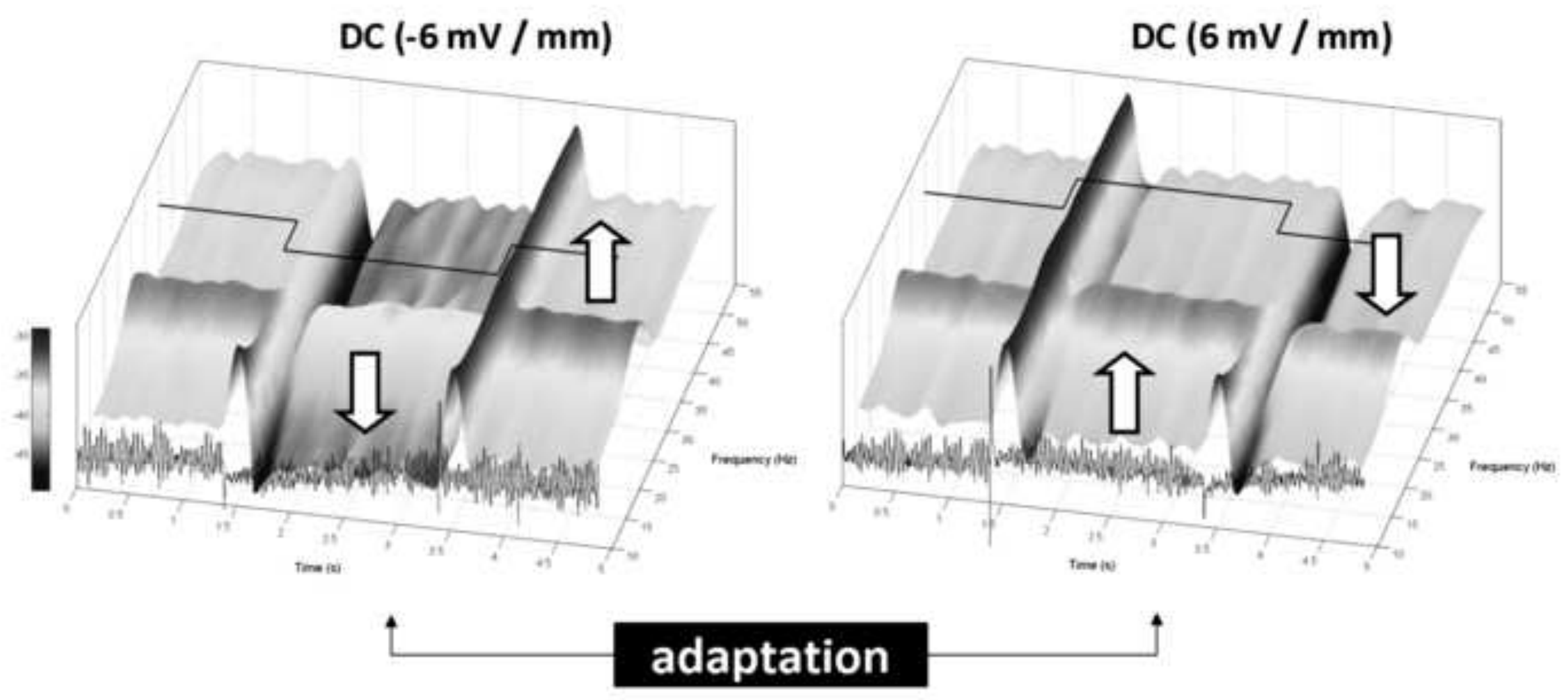


\begin{tabular}{|c|c|c|c|c|c|c|c|c|}
\hline Author & $\begin{array}{l}\text { Number, Age or } \\
\text { Weight, Species }\end{array}$ & $\begin{array}{l}\text { Region of } \\
\text { Interest }\end{array}$ & Electrode Montage & Parameters & $\begin{array}{l}\text { Current } \\
\text { density } \\
(\mathrm{A} / \mathrm{m} 2)\end{array}$ & $\begin{array}{l}\text { Charge } \\
\text { density } \\
(\mathrm{C} / \mathrm{m} 2)\end{array}$ & Outcome Measure & Key Findings \\
\hline \multicolumn{9}{|l|}{ Parkinson } \\
\hline $\begin{array}{l}\text { Tanaka T. et al. } \\
\text { (2013) }\end{array}$ & $\begin{array}{l}\mathrm{N}=27,63 \mathrm{~d} \text {, Sprague } \\
\text { Dawley rats }\end{array}$ & Striatum & $\begin{array}{l}\text { Active: Over the skin } \\
\text { of the cranium, frontal } \\
\text { cortex, } 5 \times 5 \mathrm{~mm} \\
\text { Ref: neck }\end{array}$ & $\begin{array}{l}800 \mu \mathrm{A} \text { anode or } \\
\text { cathode, } 10 \\
\text { minutes, } 32 \\
\mathrm{~A} / \mathrm{m}^{2}\end{array}$ & 32 & 19200 & Micro dialysis & $\begin{array}{l}\text { Cathodal tDCS increases } \\
\text { extracellular dopamine levels } \\
\text { for more than } 400 \text { minutes in } \\
\text { the striatum. }\end{array}$ \\
\hline Li Y. et al. (2011) & $\begin{array}{l}\mathrm{N}=30 \text {, Sprague-Dawley } \\
\text { rats }\end{array}$ & Motor cortex & $\begin{array}{l}\text { Active: Over the } \\
\text { cranium, motor cortex, } \\
\text { saline saturated } \\
\text { sponge, } 3.14 \mathrm{~mm}^{2} \\
\text { Ref: thorax }\end{array}$ & $\begin{array}{l}40 \mu \mathrm{A} \text { or } 80 \mu \mathrm{A}, \\
\text { anode, } 30 \\
\text { minutes }\end{array}$ & 12.7 or 25.4 & $\begin{array}{l}22860 \text { or } \\
45720\end{array}$ & Ipsilateral bias & $\begin{array}{l}\text { Anodal tDCS restored the ability } \\
\text { to orient to the food stimuli } \\
\text { presented on the contralateral } \\
\text { side of the body in a rat model } \\
\text { of Parkinson disease. }\end{array}$ \\
\hline \multicolumn{9}{|l|}{ Epilepsy } \\
\hline $\begin{array}{l}\text { Zobeiri M., van } \\
\text { Luijtelaar G. } \\
\text { (2013) }\end{array}$ & $\begin{array}{l}\mathrm{N}=26,180 \mathrm{~d}, \mathrm{WAG} / \mathrm{Rij} \\
\text { rats, genetic absence }\end{array}$ & $\begin{array}{l}\text { Somatosensory } \\
\text { cortex }\end{array}$ & $\begin{array}{l}\text { Active: over the } \\
\text { cranium, bilateral } \\
\text { perioral region of the } \\
\text { somatosensory cortex, } \\
3 \text { stainless steel } \\
\text { electrodes filled with } \\
\text { saline, } 3.5 \mathrm{~mm}^{2} \\
\text { Ref: over the frontal } \\
\text { cortex }\end{array}$ & $\begin{array}{l}100 \mu \mathrm{AA}, \mathrm{An}-\mathrm{Ca}- \\
\text { Ca-An or Ca-An- } \\
\text { An-Ca, } 4 \text { series } \\
\text { of } 15 \text { minutes } \\
\text { with a gap } \\
\text { interval of } 105 \\
\text { minutes for EEG } \\
\text { recording }\end{array}$ & 28.5 & & EEG and behavior. & $\begin{array}{l}\text { Bilateral cathodal tDCS, } \\
\text { targeting the bilateral foci in a } \\
\text { genetic absence model was } \\
\text { shown to include both short- } \\
\text { term and long-lasting } \\
\text { antiepileptic effects. }\end{array}$ \\
\hline
\end{tabular}




\begin{tabular}{|c|c|c|c|c|c|c|c|c|}
\hline $\begin{array}{l}\text { Kamida T. et al. } \\
\text { (2011) }\end{array}$ & $\begin{array}{l}\mathrm{N}=18,22 \mathrm{~d} \text {, Wistar } \\
\text { rats, lithium- } \\
\text { pilocarpine-induced } \\
\text { status epilepticus at } \\
\text { (P) 20-21 }\end{array}$ & $\begin{array}{l}1.5 \mathrm{~mm} \text { to the } \\
\text { right and } 2 \mathrm{~mm} \\
\text { anterior to the } \\
\text { bregma (fronto- } \\
\text { parietal cortex) }\end{array}$ & $\begin{array}{l}\text { Active: over fronto- } \\
\text { parietal cortex, } 3.5 \\
\mathrm{~mm}^{2} \\
\begin{array}{l}\text { Ref: back of neck, } 1 \mathrm{~cm} \\
\text { needle electrode }\end{array}\end{array}$ & $\begin{array}{l}200 \mu \mathrm{A}, \text { cathode, } \\
30 \text { minutes, } 14 \\
\text { sessions }\end{array}$ & 57.1 & 102780 & $\begin{array}{l}\text { 20-h/day video monitoring, } \\
\text { water maze for spatial } \\
\text { learning at P50-53 \& cell loss } \\
\text { and mossy fiber sprouting in } \\
\text { brain slices. }\end{array}$ & $\begin{array}{l}\text { Reduce subtle status } \\
\text { epilepticus-induced } \\
\text { hippocampal cell loss, } \\
\text { supragranular and CA3 mossy } \\
\text { fiber sprouting, and } \\
\text { convulsions. }\end{array}$ \\
\hline $\begin{array}{l}\text { Liebetanz D. et al. } \\
(2006)\end{array}$ & $\begin{array}{l}\mathrm{N}=65,300 \mathrm{~g} \text {, Wistar } \\
\text { rats, cortical ramp } \\
\text { model of focal epilepsy }\end{array}$ & Frontal cortex & $\begin{array}{l}\text { Active: over the } \\
\text { cranium, frontal } \\
\text { cortex, plastic jacket } \\
\text { filled with saline, } 3.5 \\
\mathrm{~mm} 2 \\
\text { Ref: ventral thorax, } \\
\text { rubber plate, } 10.5 \mathrm{~cm}^{2}\end{array}$ & $\begin{array}{l}\text { Group 1: } 100 \mu \mathrm{A}, \\
\text { cathode for } 30 \\
\text { or } 60 \text { minutes } \\
\text { cathode, } 30 \text { or } \\
60 \text { minutes } \\
\text { anode, } 4 \text { times } \\
\text { weekly } \\
\text { Group 2: } 200 \mu \mathrm{A} \text {, } \\
\text { cathode for } 15 \\
\text { or } 30 \text { minutes, } \\
\text { cathode for } 30 \\
\text { minutes and } \\
\text { anode for } 30 \\
\text { minutes, } 4 \text { times } \\
\text { weekly } \\
\text { Group } 3: 200 \mu \mathrm{A}, \\
\text { cathode for } 30 \\
\text { minutes }\end{array}$ & 28.5 & $\begin{array}{l}51300 \text { or } \\
102600\end{array}$ & $\begin{array}{l}\text { Threshold for localized } \\
\text { seizure activity. }\end{array}$ & $\begin{array}{l}60 \text { minutes of cathodal tDCS at } \\
100 \mu \mathrm{A} \text { or } 30 \text { minutes at } 200 \mu \mathrm{A} \\
\text { increased localized seizure } \\
\text { activity threshold lasting for } \\
\text { less than } 2 \text { hours. }\end{array}$ \\
\hline \multicolumn{9}{|l|}{ Pain } \\
\hline $\begin{array}{l}\text { Spezia Adachi L.N. } \\
\text { et al. (2012) }\end{array}$ & $\begin{array}{l}\mathrm{N}=48,60 \mathrm{~d} \text {, Wistar } \\
\text { rats, model of chronic } \\
\text { restraint stress (CRS) }\end{array}$ & Parietal cortex & $\begin{array}{l}\text { Active: over the skin of } \\
\text { the cranium, mid point } \\
\text { of the lateral angle of } \\
\text { eyes, EEG electrodes } \\
\text { with conductive } \\
\text { adhesive hydrogel, } 1.5 \\
\mathrm{~cm}^{2} \\
\text { Ref: neck and } \\
\text { shoulder, EEG } \\
\text { electrodes with } \\
\text { conductive adhesive } \\
\text { hydrogel, } 1.5 \mathrm{~cm}^{2}\end{array}$ & $\begin{array}{l}0.5 \mathrm{~mA}, \text { anode or } \\
\text { sham, } 20 \\
\text { minutes, } 8 \\
\text { sessions }\end{array}$ & 3.3 & & $\begin{array}{l}\text { Hot plate test, von Frey test, } \\
\text { ELISA for measuring } \\
\text { hippocampal TNF } \alpha \text { levels. }\end{array}$ & $\begin{array}{l}\text { tDCS reverses the detrimental } \\
\text { effects of chronic stress on the } \\
\text { pain system and also decrease } \\
\text { TNF } \alpha \text { levels in the } \\
\text { hippocampus. }\end{array}$ \\
\hline $\begin{array}{l}\text { Laste G. et al. } \\
\text { (2012) }\end{array}$ & $\begin{array}{l}18,250-300 \mathrm{~g} \text {, Wistar } \\
\text { rats, model of chronic } \\
\text { inflammation }\end{array}$ & Parietal cortex & $\begin{array}{l}\text { Active: Over the skin } \\
\text { of the cranium, mid } \\
\text { point of the lateral } \\
\text { angle of eyes, EEG } \\
\text { electrodes with } \\
\text { conductive adhesive } \\
\text { hydrogel, } 1.5 \mathrm{~cm}^{2} \\
\text { Ref: over the neck and } \\
\text { shoulder areas, EEG } \\
\text { electrodes with }\end{array}$ & $\begin{array}{l}500 \mu \mathrm{A}, \text { anode or } \\
\text { sham, 20- } \\
\text { minutes, } 8 \\
\text { sessions, } 33.4 \\
\mathrm{~A} / \mathrm{m}^{2}\end{array}$ & 3.3 & & Hot plate and Von Frey tests. & $\begin{array}{l}\text { Antinociceptive effects } \\
\text { immediately and } 24 \mathrm{~h} \text { after the } \\
\text { last tDCS session. }\end{array}$ \\
\hline
\end{tabular}




\begin{tabular}{|c|c|c|c|c|c|c|c|c|}
\hline & & & $\begin{array}{l}\text { conductive adhesive } \\
\text { hydrogel, } 1.5 \mathrm{~cm}^{2}\end{array}$ & & & & & \\
\hline $\begin{array}{l}\text { Nekhendzy V. et } \\
\text { al. (2004) }\end{array}$ & $\begin{array}{l}\mathrm{N}=31,390-553 \mathrm{~g}, \\
\text { Sprague-Dawley rats, } \\
\text { model for } \\
\text { inflammatory } \\
\text { nociception }\end{array}$ & Parietal cortex & $\begin{array}{l}\text { Active: Over the skin } \\
\text { of the cranium, } \\
\text { anterior pole of the } \\
\text { frontal lobe } \\
\text { Ref: } 2 \text { electrodes } \\
\text { attached to the } \\
\text { mastoid processes }\end{array}$ & $\begin{array}{l}\text { Combined direct } \\
(2.25 \mathrm{~mA}) \text { and } \\
\text { alternating } \\
\text { current }(10-100 \\
\mathrm{Hz})\end{array}$ & $\begin{array}{l}\text { Can not be } \\
\text { calculated } \\
\text { because } \\
\text { electrode } \\
\text { area not } \\
\text { given }\end{array}$ & & Tail-flick and hot-plate tests. & $\begin{array}{l}\text { The combined stimulation } \\
\text { protocol provided immediate, } \\
\text { sustained, frequency-dependent } \\
(40-60 \mathrm{~Hz} \text { ) antinociceptive } \\
\text { effects. }\end{array}$ \\
\hline \multicolumn{9}{|l|}{ Cerebellum } \\
\hline $\begin{array}{l}\text { Ben Taib N.O. et } \\
\text { al. (2009) }\end{array}$ & $\begin{array}{l}\mathrm{N}=9,280-400 \mathrm{~g}, \\
\text { Wistar, model of } \\
\text { hemicerebellectomy }\end{array}$ & Motor cortex & $\begin{array}{l}\text { Active: over the motor } \\
\text { cortex, plastic jacket } \\
\text { filled with saline, } 7.1 \\
\mathrm{~mm}^{2} \\
\text { Ref: supraorbital } \\
\text { region ipsilateral, } 0.8 \\
\text { mm diameter }\end{array}$ & $\begin{array}{l}0.4 \mathrm{~mA}, \text { anode, } \\
20 \mathrm{~min}, 3 \text { times } \\
\text { daily }\end{array}$ & 56.3 & 67560 & $\begin{array}{l}\text { H-Reflexes, F Waves, and M } \\
\text { responses, corticomotor } \\
\text { responses, cutaneomuscular } \\
\text { Reflexes. }\end{array}$ & $\begin{array}{l}\text { tDCS reversed motor cortex } \\
\text { hypo excitability induced by } \\
\text { high-frequency stimulation of } \\
\text { interpositus nucleus following } \\
\text { hemicerebellectomy. }\end{array}$ \\
\hline \multicolumn{9}{|l|}{ Memory } \\
\hline $\begin{array}{l}\text { Dockery C.A. et al. } \\
(2011)\end{array}$ & $\begin{array}{l}\mathrm{N}=41,250-325 \mathrm{~g} \text {, Long } \\
\text { Evans rats, } \mathrm{NL}\end{array}$ & Frontal cortex & $\begin{array}{l}\text { Active: Over the } \\
\text { cranium, frontal } \\
\text { cortex: the anterior } \\
\text { cingulate and } \\
\text { premotor cortices, and } \\
\text { the medial edge of the } \\
\text { primary motor cortex, } \\
\text { plastic jacket filled } \\
\text { with saline, } 3.5 \mathrm{~mm}^{2} \\
\text { Ref: on the back of the } \\
\text { animal, wet sponge } \\
\text { fitted to a rubber-plate } \\
\text { electrode }\end{array}$ & $\begin{array}{l}200 \mu \mathrm{A}, \text { cathode } \\
\text { or anode or } \\
\text { sham, } 30 \\
\text { minutes }\end{array}$ & 57.1 & 102780 & $\begin{array}{l}\text { Allothetic place avoidance } \\
\text { alternation task (APAAT). }\end{array}$ & $\begin{array}{l}\text { The purpose of this study was to } \\
\text { demonstrate the long-term } \\
\text { benefit of diminished } \\
\text { excitability by frontal tDCS } \\
\text { when paired with training on } \\
\text { working memory and skill } \\
\text { learning in a novel task. }\end{array}$ \\
\hline CVS & & & & & & & & \\
\hline
\end{tabular}




\begin{tabular}{|c|c|c|c|c|c|c|c|c|}
\hline $\begin{array}{l}\text { Kamida T. et al. } \\
\text { (2013) }\end{array}$ & $\begin{array}{l}\mathrm{N}=30,220-280 \mathrm{~g}, \\
\text { Sprague-Dawley rats, } \\
\text { model of cerebral } \\
\text { ischemia (Longa } \\
\text { method) }\end{array}$ & $\begin{array}{l}\text { The ischemic } \\
\text { borderline of } \\
\text { the primary } \\
\text { motor cortex }\end{array}$ & $\begin{array}{l}\text { Active: Over the skin } \\
\text { of the cranium, } \\
\text { ischemic borderline } \\
\text { (position determined } \\
\text { by coronal MRI slice } \\
\text { taken bregma line), } \\
\text { plastic cap fitted with } \\
\text { conductive cream, } \\
7 \mathrm{~mm}^{2} \\
\text { Ref: anterior chest, } \\
\text { rubber plate } \\
\text { electrode, } 80 \times 60 \mathrm{~mm} \text {. }\end{array}$ & $\begin{array}{l}0.2 \mathrm{~mA} \text {, anode or } \\
\text { sham, } 20 \\
\text { minutes, } 5 \\
\text { sessions daily, } \\
2.82 \mathrm{~mA} / \mathrm{cm}^{2} .\end{array}$ & 28 & 33600 & $\begin{array}{l}\text { Barnes maze performance } \\
\text { and motor behavioral index } \\
\text { scores, beam balance, } \\
\text { Immunohistochemical } \\
\text { staining for MAP-2 } \\
\text { expression. }\end{array}$ & $\begin{array}{l}\text { This study illustrated the effects } \\
\text { of tDCS applied at different } \\
\text { intervals following the } \\
\text { induction of ischemia. tDCS at } \\
1 \text { week showed better outcomes } \\
\text { than } 1 \text { day after ischemia. MAP- } \\
2 \text { was increased around the } \\
\text { perilesional area in ET group. } \\
\text { GAP- } 43 \text { was increased in the } \\
\text { intact cortex of LT group. }\end{array}$ \\
\hline Li Y. et al. (2011) & $\begin{array}{l}\mathrm{N}=90 \text {, adult, Sprague- } \\
\text { Dawley rats, model of } \\
\text { middle cerebral artery } \\
\text { occlusion }\end{array}$ & $\begin{array}{l}\text { Primary motor } \\
\text { cortex }\end{array}$ & $\begin{array}{l}\text { Active: Over the skin } \\
\text { of cranium, } 5 \mathrm{~mm} \text { to } \\
\text { the left and } 2 \mathrm{~mm} \text { in } \\
\text { front of the interaural } \\
\text { line } \\
\text { Ref: Over the cranium }\end{array}$ & $\begin{array}{l}0.1 \mathrm{~mA}, \text { anode or } \\
\text { cathode, } 30 \\
\text { minutes, } 3,7 \text {, or } \\
14 \text { sessions daily }\end{array}$ & & & $\begin{array}{l}\text { Beam walking test (BWT), } \\
\text { and density of dendritic } \\
\text { spines (DS) and PX1 mRNA } \\
\text { expression. }\end{array}$ & $\begin{array}{l}\text { This study revealed the } \\
\text { therapeutic potential of tDCS as } \\
\text { shown in improvements in } \\
\text { motor function, increased } \\
\text { dendritic spine density, PX1 } \\
\text { mRNA expression. }\end{array}$ \\
\hline $\begin{array}{l}\text { Rueger M.A. et al. } \\
(2012)\end{array}$ & $\begin{array}{l}\mathrm{N}=16 \text {, Adult, Wistar } \\
\text { rats }\end{array}$ & $\begin{array}{l}\text { Primary motor } \\
\text { cortex }\end{array}$ & $\begin{array}{l}\text { Active: Over the } \\
\text { cranium, at bregma, } \\
\text { AP or } 2.0 \mathrm{~mm} \text { ML or } \\
2.0 \mathrm{~mm}, 3.5 \mathrm{~mm}^{2} \\
\text { Ref: on the rat's } \\
\text { ventral thorax }\end{array}$ & $\begin{array}{l}500 \mu \mathrm{A}, \text { anode or } \\
\text { cathode, } 15 \\
\text { minutes, } 5 \text { or } 10 \\
\text { sessions daily, } \\
128571 \mathrm{c} / \mathrm{m} 2 .\end{array}$ & 159.2 & 143280 & $\begin{array}{l}\text { Immunohistochemical } \\
\text { analyses for activated } \\
\text { microglia and endogenous } \\
\text { neural stem cells (NSC). }\end{array}$ & $\begin{array}{l}\text { NSCs increased by } \sim 60 \% \text { during } \\
\text { cathodal stimulation, however, } \\
\text { innate immune response with } \\
\text { early increase of Iba1-positive } \\
\text { activated microglia occurred } \\
\text { with both cathodal and anodal } \\
\text { tDCS. }\end{array}$ \\
\hline $\begin{array}{l}\text { Faraji J. et al. } \\
\text { (2013) }\end{array}$ & $\begin{array}{l}\mathrm{N}=24,450-630 \mathrm{~g}, \\
\text { Long-Evans rats }\end{array}$ & $\begin{array}{l}\text { Somatosensory } \\
\text { cortex }\end{array}$ & $\begin{array}{l}\text { Active: Over the dura, } \\
\text { somatosensory cortex, } \\
\text { two stimulation } \\
\text { screws electrodes } \\
\text { Ref: back of the skull, } \\
\text { screw electrode }\end{array}$ & $\begin{array}{l}65 \mu \mathrm{A}, \text { anode, } 10 \\
\text { minutes, } 20 \\
\text { sessions daily }\end{array}$ & & & $\begin{array}{l}\text { Skilled reaching performance, } \\
\text { Neural density and } \\
\text { cytoarchitectonics. }\end{array}$ & $\begin{array}{l}\text { Protocol resulted in an increase } \\
\text { in cortical neural density and } \\
\text { also improved skilled } \\
\text { movement. }\end{array}$ \\
\hline
\end{tabular}




\begin{tabular}{|c|c|c|c|c|c|c|c|c|}
\hline $\begin{array}{l}\text { Kim S.J. Et al. } \\
(2010)\end{array}$ & $\begin{array}{l}\mathrm{N}=61,35 \mathrm{~d} \text {, Sprague- } \\
\text { Dawley rats, model of } \\
\text { cerebral ischemia } \\
\text { (Longa method) }\end{array}$ & $\begin{array}{l}\text { The ischemic } \\
\text { borderline of } \\
\text { the primary } \\
\text { motor cortex }\end{array}$ & $\begin{array}{l}\text { Active: Over the skin } \\
\text { of the cranium, } 3 \mathrm{~mm} \\
\text { to the left and } 2 \mathrm{~mm} \text { in } \\
\text { front of the interaural } \\
\text { line, cup-shaped and } \\
\text { filled with gel, } 0.785 \\
\mathrm{~cm}^{2} \\
\text { Ref: over the trunk, } \\
\text { rubber pad, } 3 \times 3 \mathrm{~cm}^{2} \text {. }\end{array}$ & $\begin{array}{l}0.1 \mathrm{~mA} \text {, for } 30 \\
\text { minutes, anode } \\
\text { or cathode or no } \\
\text { stim, } 14 \text { days' } \\
\text { daily }\end{array}$ & $12.7^{*}$ & 22860 & $\begin{array}{l}\text { Garcia, modified foot fault, } \\
\text { and Rota-Rod, histologic } \\
\text { changes (changes of the white } \\
\text { matter axon and infarct } \\
\text { volume). }\end{array}$ & $\begin{array}{l}\text { The anodal stimulation group in } \\
\text { this study showed preservation } \\
\text { of the axons in the region of the } \\
\text { internal capsule of the infarct } \\
\text { hemisphere, as well as } \\
\text { improvement in motor function. }\end{array}$ \\
\hline $\begin{array}{l}\text { Cambiaghi M. et } \\
\text { al. (2010) }\end{array}$ & $\begin{array}{l}\mathrm{N}=12,25-30 \mathrm{gm}, \\
\mathrm{C} 57 \mathrm{BL} / 6 \text { mice }\end{array}$ & $\begin{array}{l}\text { Primary motor } \\
\text { cortex }\end{array}$ & $\begin{array}{l}\text { Active: Over the } \\
\text { cranium, primary } \\
\text { motor cortex, plastic } \\
\text { jacked filled with } \\
\text { saline, } 4.5 \mathrm{~mm}^{2} \\
\text { Ref: Over the ventral } \\
\text { thorax, saline soaked } \\
\text { sponge, } 5.2 \mathrm{~cm}^{2}\end{array}$ & $\begin{array}{l}250 \mu \mathrm{A}, \text { anode or } \\
\text { cathode or } \\
\text { sham, } 10 \\
\text { minutes, } 1,5.55 \\
\mathrm{~mA} / \mathrm{cm}^{2} \text {. }\end{array}$ & $55.5^{*}$ & 33300 & MEP & $\begin{array}{l}\text { This study illustrated polarity } \\
\text { specific effects of tDCS on motor } \\
\text { evoked potential (MEP). Anodal } \\
\text { tDCS lead to an immediate } \\
\text { increase in MEP, while cathode } \\
\text { did the opposite. Both effects } \\
\text { declined towards basal levels in } \\
\text { the following } 10 \text { minutes. }\end{array}$ \\
\hline $\begin{array}{l}\text { Toleikis J.R. et al. } \\
\text { (1974) }\end{array}$ & $\begin{array}{l}50,0.4 \text { and } 0.6 \mathrm{~kg} \text {, } \\
\text { squirrel monkeys } \\
\text { (Saimiri sciureus), NL }\end{array}$ & $\begin{array}{l}\text { Sensory-motor } \\
\text { cortex }\end{array}$ & 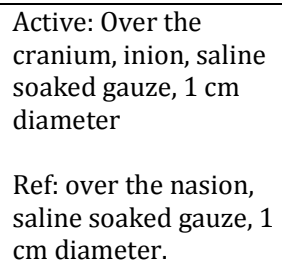 & $\begin{array}{l}\text { Combined direct } \\
(2.5 \mathrm{~mA}) \text { and } \\
\text { alternating } \\
\text { current }(70 \mathrm{~Hz}) .\end{array}$ & 7.9 & combined & $\begin{array}{l}\text { Unit potential activity of } \\
\text { motor cortex. }\end{array}$ & $\begin{array}{l}\text { The protocol used in this study } \\
\text { resulted in changes in cortical } \\
\text { neuronal firing that might help } \\
\text { explain the unresponsive } \\
\text { behavior during the stimulation. }\end{array}$ \\
\hline Cerebral Cortex & & & & & & & & \\
\hline
\end{tabular}




\begin{tabular}{|c|c|c|c|c|c|c|c|c|}
\hline \begin{tabular}{|l|} 
Islam N. et al. \\
(1994)
\end{tabular} & 180-230 g, Wistar rats & $\begin{array}{l}\text { Sensory-motor } \\
\text { cortex }\end{array}$ & $\begin{array}{l}\text { Active: Over the dura, } \\
\text { sensory-motor cortex, } \\
2 \text { silver electrodes, } \\
\text { each of } 1 \mathrm{~mm} \\
\text { diameter } \\
\text { Ref: on the nasal bone, } \\
\text { stainless steel }\end{array}$ & $\begin{array}{l}3.0 \mu \mathrm{A}, \text { anode or } \\
\text { sham, } 30 \text { or } 240 \\
\text { minutes }\end{array}$ & 0.95 & $1710-13680$ & $\begin{array}{l}\text { Immunocytochemistry with } \\
\text { monoclonal antibody } 36 \mathrm{G} 9 \\
\text { raised against purified PKC } \\
\text { gamma. }\end{array}$ & $\begin{array}{l}\text { Results from this study revealed } \\
\text { that Protein Kinase C gamma in } \\
\text { the stimulated hemisphere } \\
\text { increases for } 1 \text { hour following } \\
\text { stimulation and returns to } \\
\text { normal levels after } 72 \text { hrs. }\end{array}$ \\
\hline \begin{tabular}{|l|} 
Gartside I.B. \\
(1968)
\end{tabular} & $250-350 \mathrm{~g}$, rat & $\begin{array}{l}\text { Primary } \\
\text { sensory area }\end{array}$ & $\begin{array}{l}\text { Active: over the } \\
\text { cortical surface, } \\
\text { primary sensory area, } \\
\text { cotton wig soaked in } \\
\text { saline } \\
\text { Ref: on the orbit }\end{array}$ & $\begin{array}{l}0.1-0.5 \mathrm{~mA}, \\
\text { anode, } 10 \\
\text { minutes }\end{array}$ & & & Firing rate of cortical neurons. & $\begin{array}{l}\text { First study to show the } \\
\text { sustained effects of electrical } \\
\text { currents applied to the surface } \\
\text { of the cortex and to provide } \\
\text { evidence that these changes } \\
\text { depend upon protein synthesis. }\end{array}$ \\
\hline $\begin{array}{l}\text { Hattori Y. et al. } \\
(1990)\end{array}$ & $190-240 \mathrm{~g}$, Wistar rats & $\begin{array}{l}\text { Sensory- } \\
\text { motor cortex }\end{array}$ & $\begin{array}{l}\text { Active: over the } \\
\text { surface of the dura, } \\
\text { sensory-motor cortex, } \\
\text { silver electrodes, } 1 \mathrm{~mm} \\
\text { diameter } \\
\text { Ref: midline of the } \\
\text { nasal bone }\end{array}$ & $\begin{array}{l}0.3 \text { or } 3 \text { or } 30 \\
\mu A, \text { anode or } \\
\text { sham, } 30-240 \\
\text { minutes, } 3-5 \\
\text { times per day } \\
\text { for several days }\end{array}$ & $\begin{array}{l}0.095-0.95- \\
9.5\end{array}$ & $171-136800$ & cAMP chromatography. & $\begin{array}{l}\text { Elucidated the polarity specific } \\
\text { effects of tDCS on cAMP, an } \\
\text { important second messenger } \\
\text { involved in many vital neural } \\
\text { mechanisms. Three micro Amps } \\
\text { increased cAMP accumulation in } \\
\text { the polarized cortex, while } 0.3 \\
\text { micro Amps produced the } \\
\text { opposite results. }\end{array}$ \\
\hline
\end{tabular}




\begin{tabular}{|c|c|c|c|c|c|c|c|c|}
\hline $\begin{array}{l}\text { Creutzfelt O.D. et } \\
\text { al. (1962) }\end{array}$ & Adult cat & $\begin{array}{l}\text { Motor and } \\
\text { visual cortices }\end{array}$ & $\begin{array}{l}\text { Active: over the } \\
\text { cortical surface, motor } \\
\text { or visual cortex, Ag- } \\
\text { AgCl electrode, } 1 \mathrm{~mm} \\
\text { tip with CSF as the } \\
\text { conducting medium } \\
\text { Ref: sutured to neck or } \\
\text { temporal muscles, } \\
\text { chloride silver }\end{array}$ & $\begin{array}{l}1-1000 \mu \mathrm{A}, \\
\text { anode or } \\
\text { cathode }\end{array}$ & $0.31-318$ & & $\begin{array}{l}\text { Spontaneous activity, Evoked } \\
\text { activity. }\end{array}$ & $\begin{array}{l}\text { Initial effects on neurons of the } \\
\text { motor cortex were seen } \\
\text { between } 200 \mu \text { a and } \\
500 \mu \text { a. Current strength was } \\
\text { directly proportional to change } \\
\text { in discharge frequency when } \\
\text { the current strength is changed } \\
\text { gradually. The immediate effect } \\
\text { of the anodal stimulation is a } \\
\text { sudden increase in firing rate, } \\
\text { which soon subsides and } \\
\text { substituted by a linear increase } \\
\text { of firing. }\end{array}$ \\
\hline $\begin{array}{l}\text { Fregni F. et al. } \\
(2007)\end{array}$ & $\begin{array}{l}\mathrm{N}=32,365.5 \pm 7.8 \mathrm{~g}, \\
\text { Wistar rats, model of } \\
\text { CSD }\end{array}$ & Parietal cortex & $\begin{array}{l}\text { Active: Over the } \\
\text { cranium, parietal } \\
\text { cortex, plastic jacket } \\
\text { filled with saline, } \\
7 \mathrm{~mm}^{2} \\
\text { Ref: ventral thorax, } \\
\text { rubber plate, } 10.5 \mathrm{~cm}^{2}\end{array}$ & $\begin{array}{l}\text { Combined direct } \\
(0.2 \mathrm{~mA}) \text { and } \\
\text { alternating } \\
\text { current }(1 \mathrm{~Hz}) .\end{array}$ & 28.5 & & $\begin{array}{l}\text { Neurophysiological } \\
\text { parameter of cortical } \\
\text { spreading depression. }\end{array}$ & $\begin{array}{l}\text { The effects of tDCS on cortical } \\
\text { spreading depression were } \\
\text { investigated in this study. } \\
\text { Cortical spreading depression } \\
\text { velocity was increased } \\
\text { significantly after anodal } \\
\text { tDCS/1 Hz ES. }\end{array}$ \\
\hline $\begin{array}{l}\text { Liebetanz D. et al. } \\
(2006)\end{array}$ & $\begin{array}{l}\mathrm{N}=29,377 \pm 45 \mathrm{~g}, \\
\text { Wistar rats, model of } \\
\text { CSD }\end{array}$ & Parietal cortex & $\begin{array}{l}\text { Active: Over the } \\
\text { cranium, parietal } \\
\text { cortex, plastic jacket } \\
\text { filled with saline, } \\
7 \mathrm{~mm} 2 \\
\text { Ref: ventral thorax, } \\
\text { rubber plate, } 10.5 \mathrm{~cm}^{2}\end{array}$ & $\begin{array}{l}200 \mu \mathrm{A}, \text { anode or } \\
\text { cathode or } \\
\text { sham, } 20 \\
\text { minutes }\end{array}$ & 28.5 & 34200 & $\begin{array}{l}\text { Spontaneous cortical } \\
\text { electrical activity } \\
\text { (electrocorticogram) and the } \\
\text { slow (DC) potential change } \\
\text { accompanying CSD. }\end{array}$ & $\begin{array}{l}\text { This study concluded that } \\
\text { anodal tDCS - by increasing } \\
\text { cortical excitability - might } \\
\text { increase the probability of } \\
\text { migraine attack in patients with } \\
\text { history of migraine headache. }\end{array}$ \\
\hline
\end{tabular}




\begin{tabular}{|c|c|c|c|c|c|c|c|c|}
\hline $\begin{array}{l}\text { Bolzoni F. et al. } \\
\text { (2013) }\end{array}$ & $\mathrm{N}=12,2.2-3.4 \mathrm{~kg}$, cat & $\begin{array}{l}\text { Sensory- } \\
\text { motor cortex }\end{array}$ & $\begin{array}{l}\text { Active: Over the } \\
\text { cranium, sensory- } \\
\text { motor cortex, titanium } \\
\text { screws/chamber } \\
\text { containing } 3 \% \text { agar- } \\
\text { agar in saline, } 200 \mathrm{~mm} \\
2 \\
\text { Ref: close to the } \\
\text { temporal muscles, NS, } \\
400 \mathrm{~mm}^{2} \text {. }\end{array}$ & $\begin{array}{l}0.2 \text { or } 0.5 \mathrm{~mA}, \\
\text { anode, } 5 \text { minute } \\
\text { intervals, } 1,1 \text { or } \\
2.5 \mu \mathrm{A} / \mathrm{mm}^{2} .\end{array}$ & $1-2.5$ & $300-750$ & $\begin{array}{l}\text { Descending volleys evoked by } \\
\text { electrical stimuli applied in } \\
\text { the red nucleus (RN), medial } \\
\text { longitudinal fascicle (MLF; to } \\
\text { reticulospinal fibers) and the } \\
\text { pyramidal tract (PT; to } \\
\text { corticospinal or } \\
\text { corticoreticular fibers). }\end{array}$ & $\begin{array}{l}\text { Recordings performed at } \\
\text { various subcortical regions } \\
\text { showed that tDCS successfully } \\
\text { modulated the firing activity of } \\
\text { these regions. The changes were } \\
\text { maintained for } 1-2 \text { hours after } \\
\text { the stimulation. }\end{array}$ \\
\hline $\begin{array}{l}\text { Bindman L.J. et al. } \\
\text { (1964) }\end{array}$ & $\begin{array}{l}\mathrm{N}=200,200-250 \mathrm{~g}, \\
\text { Albino rats }\end{array}$ & $\begin{array}{l}\text { Somatosensory } \\
\text { cortex }\end{array}$ & $\begin{array}{l}\text { Active: Over the dura, } \\
\text { somatosensory cortex, } \\
\text { polyethelene cup filled } \\
\text { with wick or agar gel } \\
\text { Ref: wick or gel }\end{array}$ & $\begin{array}{l}1-10 \mu \mathrm{A}, \text { anode } \\
\text { or cathode, } 1,10 \\
\mu \mathrm{A} / \mathrm{mm}^{2} \text {. }\end{array}$ & & & $\begin{array}{l}\text { Evoked potentials and unitary } \\
\text { spikes. }\end{array}$ & $\begin{array}{l}\text { This is one of the first studies in } \\
\text { the field of tDCS to illustrate } \\
\text { that surface positive currents } \\
\text { increases the size of evoked } \\
\text { potentials acutely and after } \\
\text { cessation of stimulation up to } \\
\text { one hour. Surface negative } \\
\text { currents had opposite effects. }\end{array}$ \\
\hline $\begin{array}{l}\text { Wachter D. et al. } \\
\text { (2011) }\end{array}$ & $\begin{array}{l}\mathrm{N}=80,310 \mathrm{~g}, \text { Sprague- } \\
\text { Dawley rats, NL }\end{array}$ & $\begin{array}{l}\text { Middle cerebral } \\
\text { artery territory }\end{array}$ & $\begin{array}{l}\text { Active: Over the } \\
\text { cranium, middle } \\
\text { cerebral artery } \\
\text { territory, } 3.5 \mathrm{~mm}^{2} \text {. } \\
\text { Ref: ventral thorax. }\end{array}$ & $\begin{array}{l}25,50 \text { or } 100 \\
\mu \mathrm{A}, \text { cathode and } \\
\text { anode for each } \\
\text { animal, } 15 \\
\text { minutes, } 6 \text { every } \\
\text { other day, } 25 \\
714 \mathrm{C} / \mathrm{m}^{2} .\end{array}$ & $\begin{array}{l}7.14-14.2- \\
28.57\end{array}$ & $\begin{array}{l}\text { 6426-12780- } \\
25713\end{array}$ & $\begin{array}{l}\text { Laser Doppler flowmetry, } \\
\text { H\&E staining and } \\
\text { Bielschowsky's silver } \\
\text { impregnation. } \\
\text { Immunohistochemical } \\
\text { staining. }\end{array}$ & $\begin{array}{l}\text { The effects of tDCS on regional } \\
\text { blood flow were elucidated in } \\
\text { this study. At higher intensities } \\
(50 \text { and } 100 \mu \mathrm{A}) \text { anodal tDCS } \\
\text { increased CBF up to } 30 \text { minutes, } \\
\text { cathodal tDCS led to a decrease } \\
\text { of CBF. }\end{array}$ \\
\hline
\end{tabular}




\begin{tabular}{|c|c|c|c|c|c|c|c|c|}
\hline $\begin{array}{l}\text { Mielke D. et al. } \\
(2013)\end{array}$ & $\begin{array}{l}\mathrm{N}=21 \text {, Adult, Sprague } \\
\text { Dawley rats }\end{array}$ & $\begin{array}{l}\text { electrode } \\
\text { contact areas } \\
\text { (ECA) of } 3.5 \\
7.0,10.5, \text { or } \\
14.0 \mathrm{~mm}^{2} \text { over } \\
\text { the skull }\end{array}$ & & $\begin{array}{l}200,400,600, \text { or } \\
700 \mu \mathrm{A} \text { for } 15 \\
\text { minutes } \\
\text { (cathode) }\end{array}$ & & & $\begin{array}{l}\text { laser Doppler blood perfusion } \\
\text { imaging (LDI). }\end{array}$ & $\begin{array}{l}\text { In this study, the application of } \\
\text { cathodal tDCS resulted in a } \\
\text { significant reduction in CBF } \\
\text { even lasted up to } 90 \text { minutes in } \\
\text { distant cortical areas. }\end{array}$ \\
\hline $\begin{array}{l}\text { Bolzoni F. et al. } \\
(2013)\end{array}$ & $\begin{array}{l}\mathrm{N}=15 \text { Sprague-Dawley } \\
\text { and } \mathrm{N}=8 \text { Wistar rats, } \\
200-300 \mathrm{~g}\end{array}$ & $\begin{array}{l}1-2 \text { mm from } \\
\text { the midline at } \\
\text { the level of } \\
\text { bregma }\end{array}$ & $\begin{array}{l}\text { Active: over the } \\
\text { cranium, } 1-2 \mathrm{~mm} \text { from } \\
\text { the midline at the level } \\
\text { of the bregma, sponge } \\
\text { soaked with saline, } \\
6 \mathrm{~mm} \times 8 \mathrm{~mm} \\
\text { Ref: left ear lobe, } \\
\text { sponge. }\end{array}$ & $\begin{array}{l}0.2 \mathrm{~mA} \text {, anode or } \\
\text { cathode, } 1,5 \\
\text { minutes, } 4-5 \\
\mu \mathrm{A} / \mathrm{mm}^{2} \text {. }\end{array}$ & 4.8 & 1440 & $\begin{array}{l}\text { EMG potentials recorded from } \\
\text { neck muscles evoked by weak } \\
(20-60 \mu \mathrm{A}) \text { single, double or } \\
\text { triple stimuli applied in the } \\
\text { medial longitudinal fascicle } \\
\text { (MLF) or in the red nucleus } \\
(\mathrm{RN}) .\end{array}$ & $\begin{array}{l}\text { Described the effects of tDCS on } \\
\text { subcortical structures. } \\
\text { Facilitation and the depression } \\
\text { of subcortical structures } \\
\text { appeared within the first minute } \\
\text { but both were maintained up to } \\
1 \text { h after tDCS. }\end{array}$ \\
\hline $\begin{array}{l}\text { Richter F. et al. } \\
\text { (1996) }\end{array}$ & $\begin{array}{l}\mathrm{N}=8,250 \text { and } 350, \\
\text { Wistar rats, model of } \\
\text { CSD. }\end{array}$ & $\begin{array}{l}\text { Visual cortex, } \\
\text { DC } \\
\text { microelectrode } \\
\text { was inserted in } \\
\text { the gray matter } \\
\text { near the point } \\
\text { of spreading } \\
\text { depression } \\
\text { elicitation at a } \\
\text { depth of about } \\
400 \text { microns. }\end{array}$ & & $10-30 \mu \mathrm{A}$ & & & $\begin{array}{l}\text { Propagation of spreading } \\
\text { depolarization. }\end{array}$ & $\begin{array}{l}\text { Provides evidence that cathodic } \\
\text { polarization of cortical surface } \\
\text { with intensities greater than or } \\
\text { equal to } 30 \mu \mathrm{A} \text { can block the SD } \\
\text { completely. }\end{array}$ \\
\hline
\end{tabular}




\begin{tabular}{|c|c|c|c|c|c|c|c|c|}
\hline $\begin{array}{l}\text { Schweid L. et al. } \\
(2008)\end{array}$ & $\begin{array}{l}\mathrm{N}=3,2.9-3.2 \mathrm{~kg}, \\
\text { domestic adult male } \\
\text { cats }\end{array}$ & $\begin{array}{l}\text { Visuoparietal } \\
\text { (VP) cortex }\end{array}$ & $\begin{array}{l}\text { Active: Over the skin } \\
\text { of the cranium, } \\
\text { visuoparietal cortex, } \\
2 \times 2 \mathrm{~cm} \\
\text { Ref: on forehead, } 2 \times 2 \\
\mathrm{~cm} \text {. }\end{array}$ & $\begin{array}{l}2.0 \mathrm{~mA} \text {, cathode } \\
\text { or sham, } 20 \\
\text { mins, } 8 \text { sessions } \\
\text { every other day, } \\
\text { NS }\end{array}$ & 10 & 12000 & $\begin{array}{l}\text { Capacity to detect, localize } \\
\text { and orient to static targets } \\
\text { appearing at different spatial } \\
\text { eccentricities in the visual } \\
\text { field. }\end{array}$ & $\begin{array}{l}\text { This study suggests that } \\
\text { cathodal tDCS resulted in a } \\
\text { decrease in the behavior during } \\
\text { and immediately after its } \\
\text { application. The effects of tDCS } \\
\text { decay slowly and reaches the } \\
\text { pre-stimulation baseline within } \\
60 \text { minutes. }\end{array}$ \\
\hline $\begin{array}{l}\text { Cambiaghi M. et } \\
\text { al. (2011) }\end{array}$ & $\begin{array}{l}12,56-84 d, C 57 \mathrm{BL} / 6 \\
\text { mice, } \mathrm{NL}\end{array}$ & Visual cortex & $\begin{array}{l}\text { Active: Over the } \\
\text { cranium, primary } \\
\text { visual cortex, plastic } \\
\text { tube fitted with a } \\
\text { conducting medium, } \\
4.5 \mathrm{~mm}^{2} \\
\text { Ref: Right frontal area }\end{array}$ & $\begin{array}{l}250 \mu \mathrm{A}, \text { anode or } \\
\text { cathode or } \\
\text { sham, } 10 \\
\text { minutes, } 1 \\
\text { current density } \\
\text { of } 5.55 \mathrm{~mA} / \mathrm{cm}^{2}\end{array}$ & $55.5^{*}$ & 33300 & $\begin{array}{l}\text { VEP amplitudes of the first } \\
\text { major peak (P1). }\end{array}$ & $\begin{array}{l}\text { In this study, anodal tDCS } \\
\text { resulted in an increase in P1 } \\
\text { amplitude while cathodal } \\
\text { stimulation had opposite effects. } \\
\text { After-effects were reversed } \\
\text { toward baseline within } 10 \\
\text { minutes. }\end{array}$ \\
\hline $\begin{array}{l}\text { Márquez-Ruiz J. et } \\
\text { al. (2012) }\end{array}$ & $\begin{array}{l}13,2.3-2.7 \mathrm{~kg} \text {, White } \\
\text { albino, NL }\end{array}$ & $\begin{array}{l}\text { Somatosensory } \\
\text { cortex }\end{array}$ & $\begin{array}{l}\text { Active: Over the } \\
\text { cranium, } \\
\text { somatosensory cortex, } \\
4 \text { silver ball } \\
\text { stimulating electrode } \\
\text { Ref: on the ear, saline } \\
\text { soaked sponge, } 35 \\
\mathrm{~cm}^{2} \text {. }\end{array}$ & $\begin{array}{l}0.5,1,1.5 \text {, and } 2 \\
\text { mA, anode or } \\
\text { cathode or } \\
\text { sham, } 20 \\
\text { minutes, } 1,3.7 \\
\text { A/m }{ }^{2}\end{array}$ & & & $\begin{array}{l}\text { Local field potential at } \\
\text { vibrissa S1. }\end{array}$ & $\begin{array}{l}\text { This study linked tDCS with } \\
\text { associative learning and LTD. } \\
\text { tDCS could successfully } \\
\text { modulate sensory perception } \\
\text { for associative learning. This } \\
\text { effect was mediated by } \\
\text { adenosine A1 receptors. }\end{array}$ \\
\hline $\begin{array}{l}\text { Liebetanz D. et al. } \\
\text { (2009) }\end{array}$ & $\begin{array}{l}62,310 \pm 24 \mathrm{gm}, \\
\text { Wistar rats, NL }\end{array}$ & Frontal cortex & $\begin{array}{l}\text { Active: Over the } \\
\text { cranium, frontal } \\
\text { cortex, plastic jacket } \\
\text { filled with saline, } 3.5 \\
\mathrm{~mm}^{2} \\
\text { Ref: on the ventral } \\
\text { thorax, rubber plate, } \\
10.5 \mathrm{~cm}^{2}\end{array}$ & $\begin{array}{l}1-1000 \mu \mathrm{A}, \\
\text { cathode, up to } \\
270 \text { minutes, } 1 \text {, } \\
\text { NS. }\end{array}$ & $0.28-285$ & 4617000 & $\begin{array}{l}\text { Histological evaluation (H\&E) } \\
\text { staining } 48 \text { hours after } \\
\text { stimulation. }\end{array}$ & $\begin{array}{l}\text { In an effort to address the safety } \\
\text { limits of cathodal tDCS, this } \\
\text { study revealed that brain } \\
\text { lesions occurred at a current } \\
\text { density equal to or greater than } \\
142.9 \mathrm{~A} / \mathrm{m}^{2} \text { for more than } 10 \\
\text { minutes. Stimulations below } \\
\text { this range did not induce } \\
\text { morphological lesions, even } \\
\text { with } 5 \text { days of application. }\end{array}$ \\
\hline
\end{tabular}




\begin{tabular}{|c|c|c|c|c|c|c|c|c|}
\hline $\begin{array}{l}\text { Hayashi Y. et al. } \\
\text { (1988) }\end{array}$ & $\begin{array}{l}\mathrm{N}=7,2-2.5 \mathrm{~kg} \text {, albino } \\
\text { rabbit }\end{array}$ & Motor cortex & $\begin{array}{l}\text { Active: Implanted in } \\
\text { the cranium, on the } \\
\text { motor cortex, silver } \\
\text { wire } \\
\text { Ref: on the ear, silver } \\
\text { wire, } 3 \times 6 \mathrm{~cm}\end{array}$ & $\begin{array}{l}\text { The anodal } \\
\text { current was } \\
\text { gradually } \\
\text { increased in } \\
\text { steps of } 10 \mu \mathrm{A} \text { to } \\
\text { the intensity } \\
\text { that induced } \\
\text { seizure activity } \\
\text { in the ECoG }\end{array}$ & & & ECoG seizure activity. & $\begin{array}{l}20 \mu \mathrm{A} \text { induced seizure activity } \\
\text { in the frontal cortex, greater } \\
\text { current intensities induced a } \\
\text { more generalized activity that } \\
\text { was eliminated after the current } \\
\text { was turned off. }\end{array}$ \\
\hline $\begin{array}{l}\text { Islam N. et al. } \\
\text { (1995) }\end{array}$ & $180-230 \mathrm{~g}$, Wistar rats & $\begin{array}{l}\text { Sensory-motor } \\
\text { cortex }\end{array}$ & $\begin{array}{l}\text { Active: Over the dura, } \\
\text { sensory-motor cortex, } \\
2 \text { silver electrodes, } \\
\text { each of } 1 \mathrm{~mm} \\
\text { diameter } \\
\text { Ref: on the nasal bone, } \\
\text { stainless steel, NS. }\end{array}$ & $\begin{array}{l}3.0 \mu \mathrm{A}, \text { anode or } \\
\text { sham, } 30 \\
\text { minutes once or } \\
\text { repeated } 5 \\
\text { times/day }\end{array}$ & 2 electrodes & 2 electrodes & $45 \mathrm{Ca}$ autoradiography. & $\begin{array}{l}\mathrm{Ca} 2+\text { accumulation was } \\
\text { detected after } 24 \mathrm{~h} \text { and it } \\
\text { remained virtually constant up } \\
\text { to } 72 \mathrm{~h} \text { after the last anodal } \\
\text { stimulation session. }\end{array}$ \\
\hline $\begin{array}{l}\text { Islam N. et al. } \\
\text { (1995b) }\end{array}$ & $180-230 \mathrm{~g}$, Wistar rats & $\begin{array}{l}\text { Sensory-motor } \\
\text { cortex }\end{array}$ & $\begin{array}{l}\text { Active: Over the dura, } \\
\text { sensory-motor cortex, } \\
2 \text { silver electrodes, } \\
\text { each of } 1 \mathrm{~mm} \\
\text { diameter } \\
\text { Ref: nasal bone, } \\
\text { stainless steel }\end{array}$ & $\begin{array}{l}3.0 \mu \mathrm{A}, \text { anode or } \\
\text { sham, } 30 \\
\text { minutes once or } \\
\text { repeated } 5 \\
\text { times/day }\end{array}$ & 2 electrodes & 2 electrodes & $\begin{array}{l}\text { Double labeling of PKC } \\
\text { gamma and c-fos. }\end{array}$ & $\begin{array}{l}\text { Increase in the intensity of } \\
\text { immunoreactivity for both PKC } \\
\text { gamma and c-fos protein } \\
\text { ipsilateral to the polarization. }\end{array}$ \\
\hline
\end{tabular}

